\title{
Parental Communication and Reflective Practice among Youth Sport Parents
}

\author{
by
}

Sina Azimi

\begin{abstract}
A thesis submitted in conformity with the requirements for the degree of Master of Science

Department of Exercise Sciences University of Toronto
\end{abstract}

(C) Copyright by Sina Azimi 2018 


\title{
Parental Communication and Reflective Practice among Youth Sport Parents
}

\author{
Sina Azimi \\ Master of Science \\ Department of Exercise Sciences \\ University of Toronto \\ 2018
}

\begin{abstract}
Parents can enhance their children's intrinsic motivation, and competence by providing positive feedback and encouraging them to become involved in decision making and problem-solving activities (Babkes \& Weiss, 1999); however, there is limited research available that has demonstrated how parents might learn to engage in these supportive behaviours with their child. Thus, the purpose of this research was to examine whether increasing parents' awareness of communication influences parent-athlete communication behaviours. Ten athletes between 13-15 years of age, and one of their parents were recruited (total $N=20$ ). Parents and athletes completed pre- and post-study interviews and surveys. Parents also participated in a workshop and completed at least one audio diary entry per week over the course of six weeks. The findings indicated that reflective practice and increased awareness of parent-child communication led parents to engage in more autonomy supportive parenting, and to be less critical of their child's performance.
\end{abstract}




\section{Acknowledgments}

I would like to thank my supervisor Dr. Katherine Tamminen for her continuous support and guidance throughout this project. I would have not been able to accomplish what I have accomplished in this research without her. Words can't describe how thankful I am to have worked alongside her on this project. I would also like to thank my committee members Dr. Gretchen Kerr and Dr. Ashley Stirling for their gracious guidance. Their expertise and knowledge guided my research in the right direction. In addition, I would like to thank my external examiner Dr. Jessica Fraser-Thomas for taking the time to review my thesis and provide her appraisal. It was an absolute pleasure to have her as part of my final thesis defence. To all my siblings, Dariush, Davood, Vida, and Sirous, thank you for your unconditional love and support throughout this project. And Lastly, I would like to dedicate this Master's thesis to my mom and dad, Ehteram and Nematollah both of whom I miss dearly. They taught me to never give up, to always do everything to the best of my ability, and to always chase my dreams no matter how crazy they may sound. I love you both endlessly and I hope this thesis can serve as a token of my appreciation for everything that you have done for me. 


\section{Table of Contents}

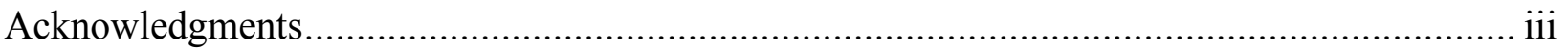

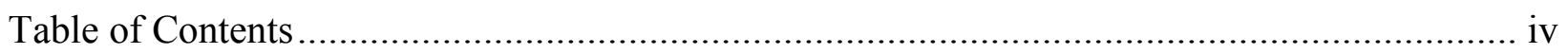

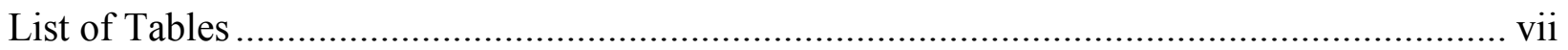

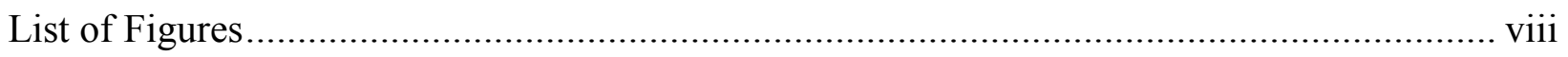

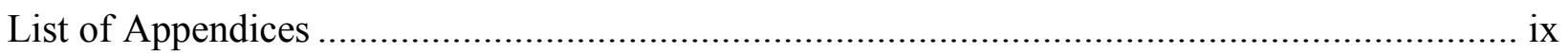

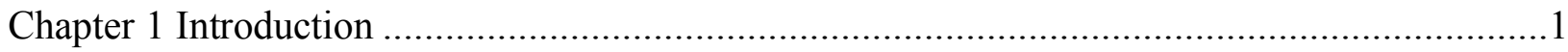

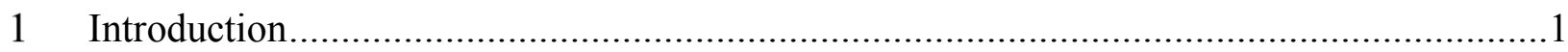

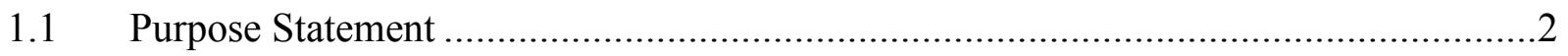

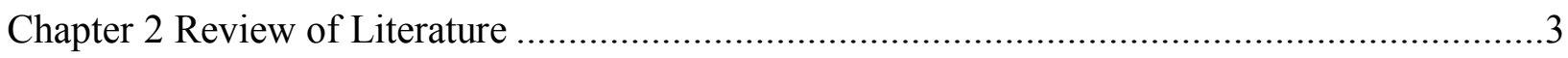

2 Review of Literature.........................................................................................

2.1 Importance of Parents in Sports ......................................................................

2.2 Parenting Styles in Youth Sport ...................................................................

2.3 Interpersonal Communication ..................................................................

2.4 Parents' Behaviour and Communication in Sport ............................................ 10

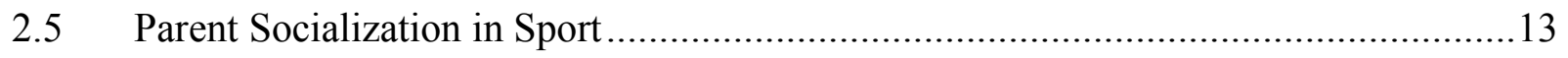

2.6 Reflective Practice ....................................................................................... 14

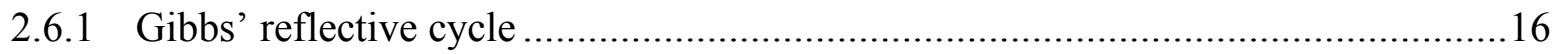

$2.7 \quad$ Research Questions.................................................................................. 19

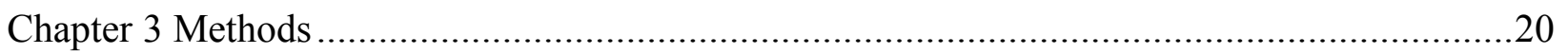

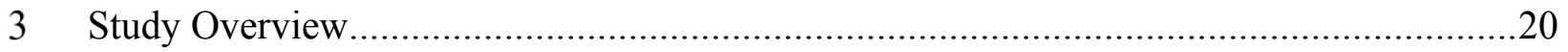

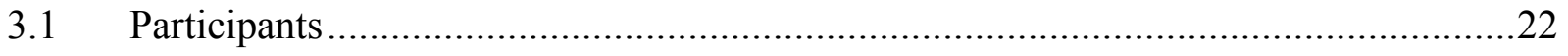

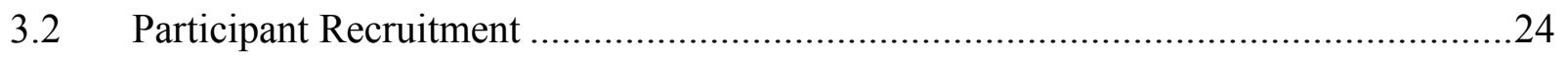

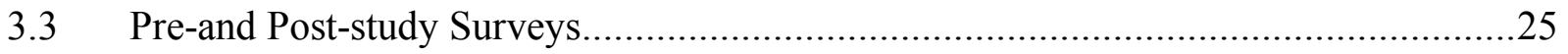




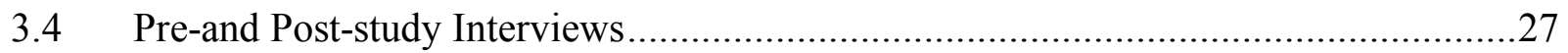

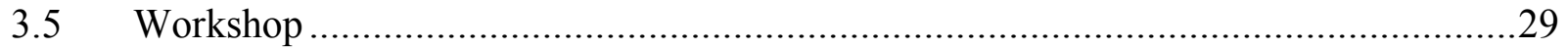

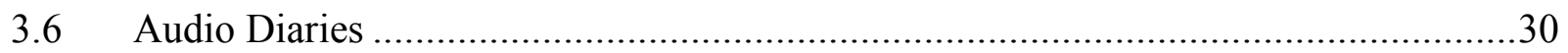

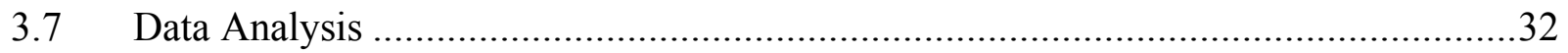

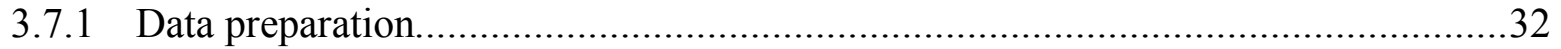

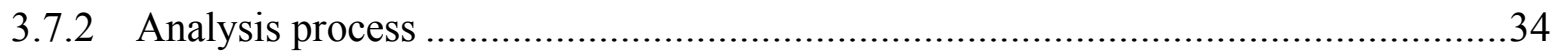

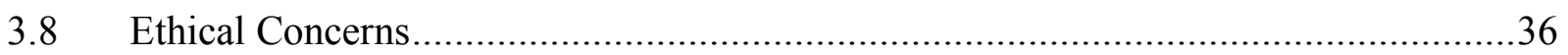

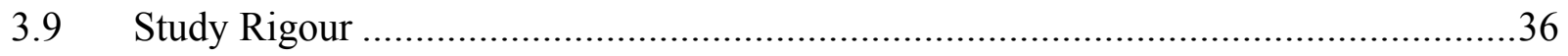

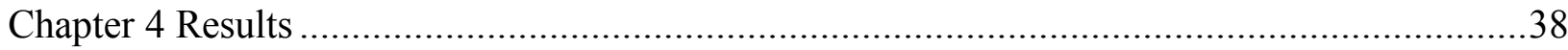

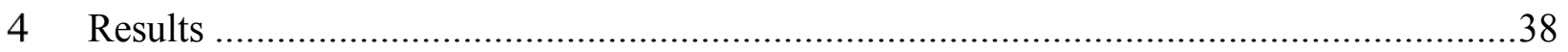

4.1 Influence of Reflective Practice on Parents' Self-Awareness.........................................38

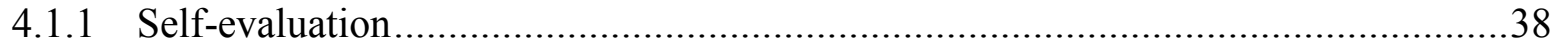

4.2 Parent Awareness of Child's Development …….................................................... 41

4.2.1 Awareness of child's maturity level, capabilities, and personality ..........................41

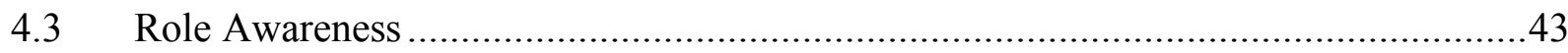

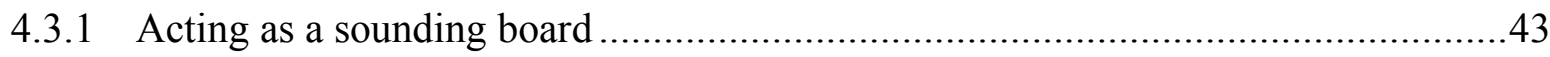

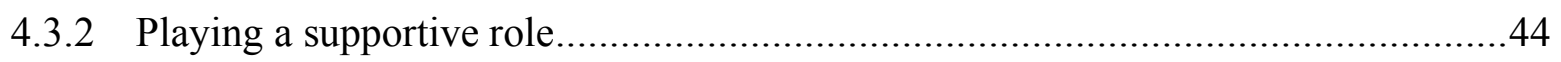

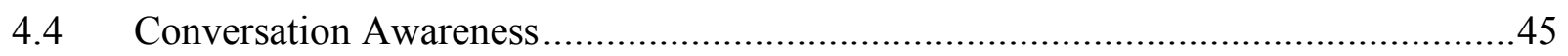

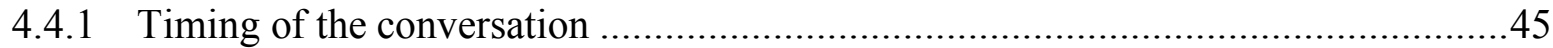

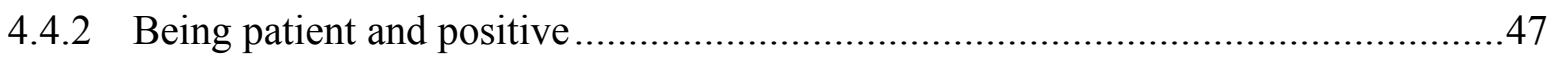

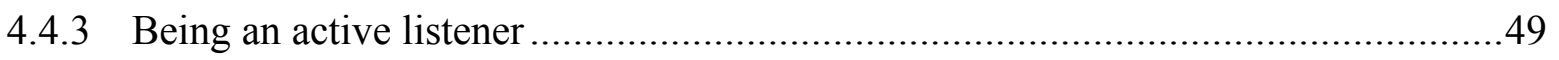

4.4.4 Thinking before speaking.............................................................................49

4.5 Perceived Changes in Parent-Athlete Communication..............................................50

4.5.1 Perceived changes in parents' communication behaviours.....................................50

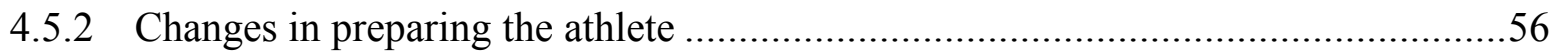

4.5.3 Changes in reaction to mistakes or bad performances...........................................57

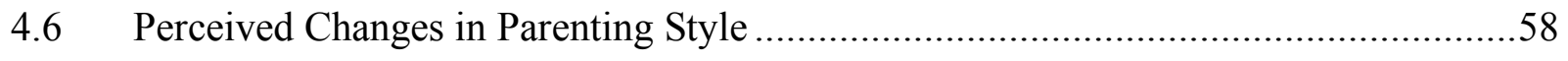

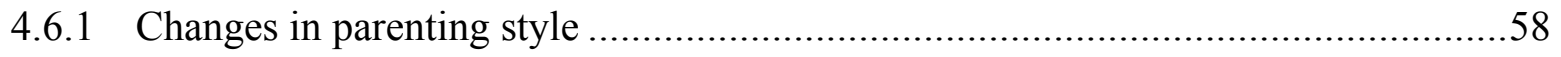




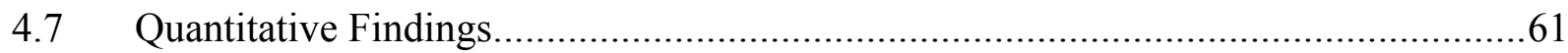

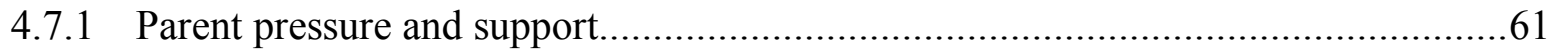

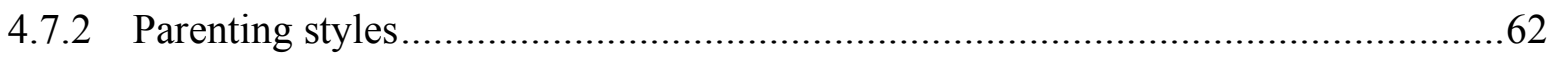

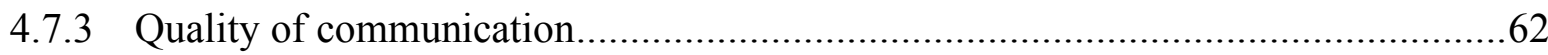

4.7.4 Summary of quantitative findings ...................................................................62

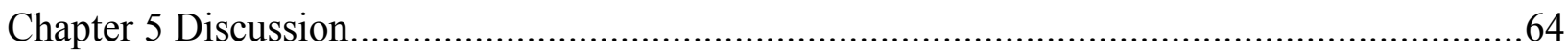

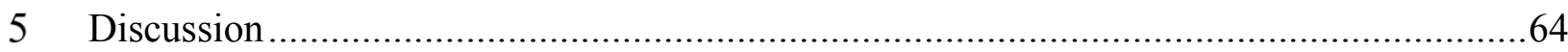

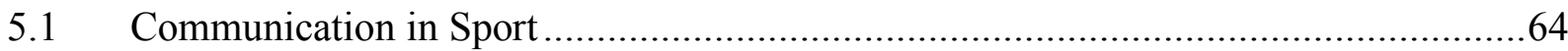

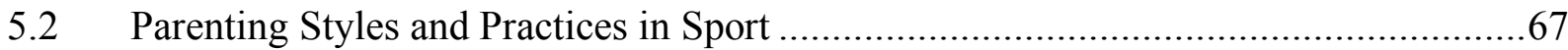

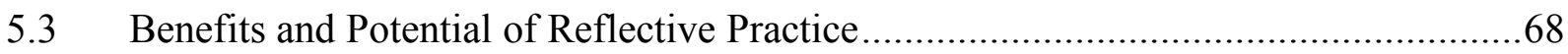

5.4 Parent and Athlete Perceptions of Parental Behaviours …………..............................

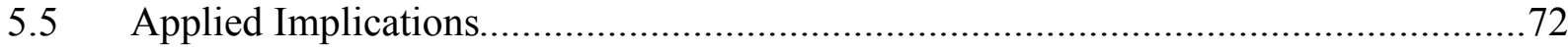

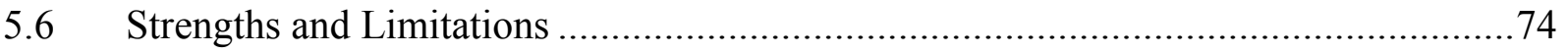

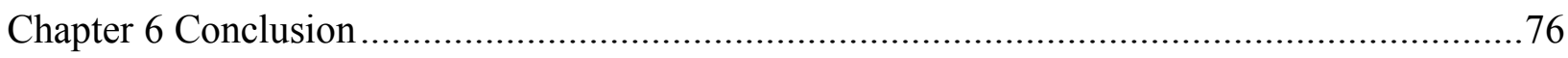

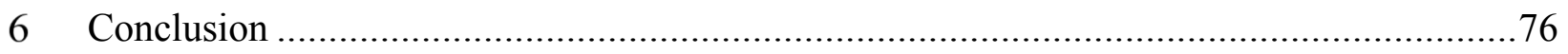

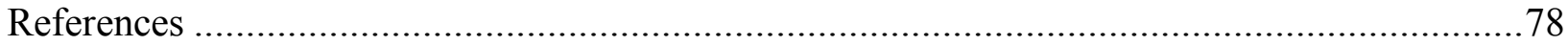

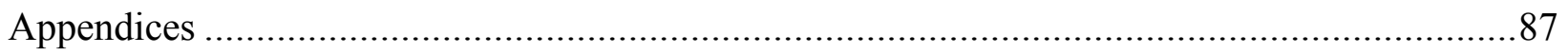




\section{List of Tables}

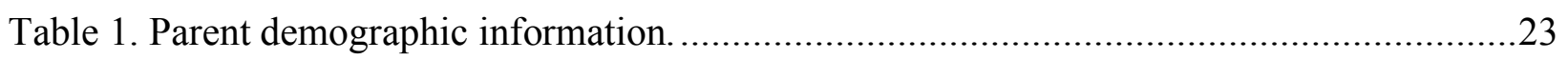

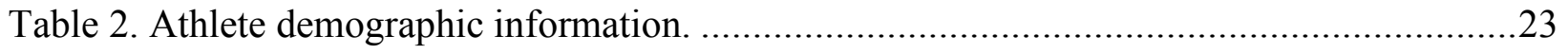

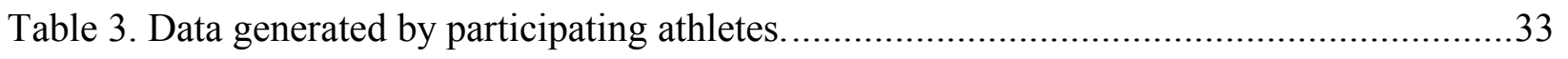

Table 4. Data generated by participating parents............................................................33 


\section{List of Figures}

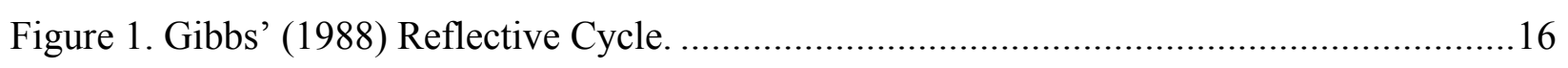

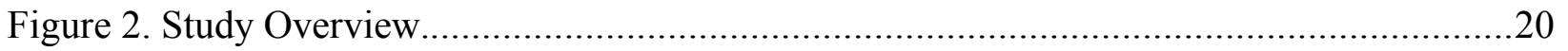




\section{List of Appendices}

Appendix A: Parent/Guardian Information Letter........................................................... 87

Appendix B: Parent/Guardian Consent Form................................................................. 90

Appendix C: Child Information Letter \& Assent Form ................................................. 93

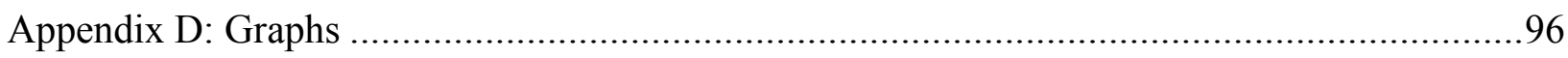

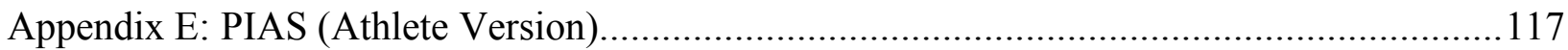

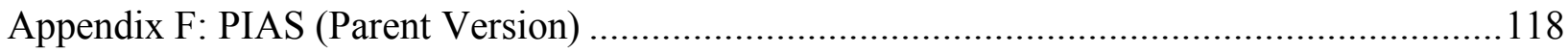

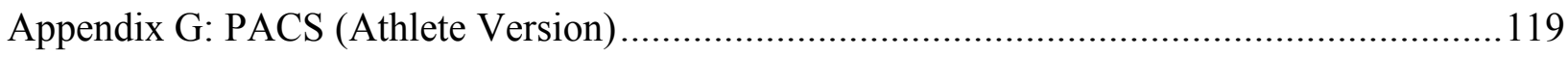

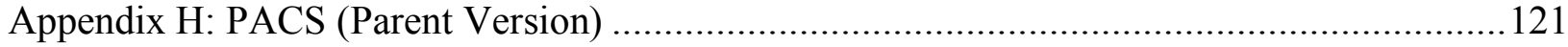

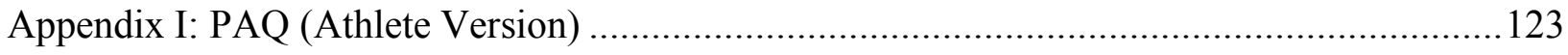

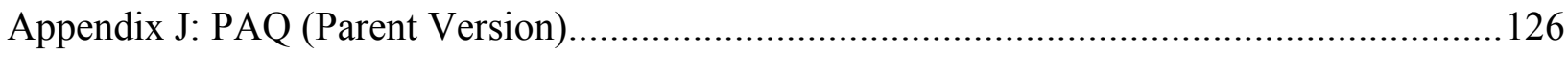

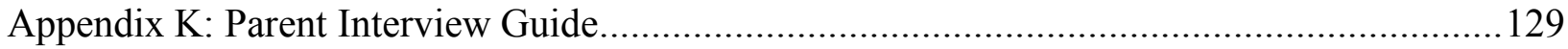

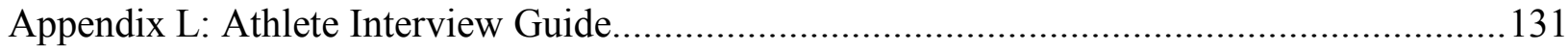

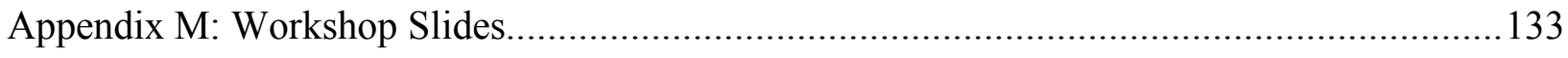

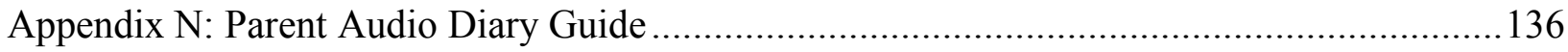

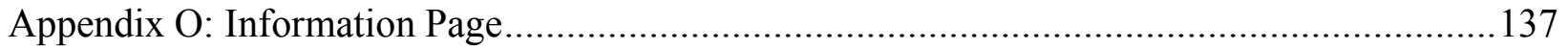

Appendix P: Recruitment Brochure ......................................................................... 138 


\section{Chapter 1 Introduction}

\section{Introduction}

Sport can be defined as a subset of physical activity that is structured, competitive, goal oriented, and contest-based (McPherson et al., 1989, as cited in Crane \& Temple, 2015). Sport participation can lead to a broad range of positive outcomes for young athletes. Sport participation may result in several potential benefits in areas such as personal growth, personal enjoyment, social harmony, and social change (Wankel \& Berger, 1990). Throughout different stages of development, children and youth may have the opportunity to experience success, bounce back from failure, and improve their overall health (Russell \& Limle, 2013). As noted by Bailey (2006), sports may provide opportunities for youth to meet and communicate with others, to take different social roles, and to learn social skills. In addition, sport settings can provide participants with opportunities to experience unique emotions that cannot be experienced in other life situations, which can play a role in the development of one's personality and psychological well-being (Bailey, 2006).

According to the 2018 ParticipACTION report card on physical activity for children and youth, $77 \%$ of children and youth in Canada participate in organized physical activity or sport (ParticipACTION, 2018). Significant figures such as parents contribute to the creation of a motivational climate, which is constructed through parents' behaviours, values, attitudes, and communication. This motivational climate can affect how children come to respond and understand achievement situations (Atkins, Johnson, Force, \& Petrie, 2013), and subsequently influence their enjoyment and motivation to participate in sport (Harwood, Keegan, Smith, \& Raine, 2015). Butcher, Lindner, and Johns (2002) argued that too much pressure and parental discouragement have a negative influence on competitive youth sport participation rate. However, parents often do not realize that their children are feeling pressure, or that they are discouraging their children from participating in sport (Butcher et al., 2002). Hence, it is imperative that researchers examine the roles of significant others (i.e., parents) to ensure positive youth sport experiences. 


\subsection{Purpose Statement}

Researchers have highlighted the potential benefits of youth sport participation and the impact of parents on their children's sporting experience. This thesis reviewed the literature examining the role of parents in sports, their socialization in this environment, and their communication and behaviours within youth sport settings. Furthermore, the present study identified a lack of intervention research studies aimed at improving parent-athlete communication. One approach that was deemed valuable for improving parent-athlete communication in youth sport was to provide parents with information about communication, and to encourage parents to reflect on their communication with their children. Thus, through a six-week intervention study, the purpose of this research was to examine whether increasing parents' awareness of communication would influence parent-athlete communication behaviours. The study addressed the following research questions: (a) How does reflective practice influence parents' selfawareness of their own communication behaviour? (b) Does increased awareness of parent-child communication lead to perceived changes in parents' communication behaviour? (c) Do reflective practice and increased awareness of parent-child communication lead to perceived changes in parents' parenting styles? 


\section{Chapter 2 \\ Review of Literature}

\section{Review of Literature}

\subsection{Importance of Parents in Sports}

Parents comprise an important contributing influence in children's sport, and are recognized for their role in providing the necessary financial and logistical support to enable sporting opportunities (Elliott \& Drummond, 2017). One model that may be used to examine parental involvement in sport is Côté's developmental model of sport participation (DMSP), which divides youth athletes' development into three stages known as sampling (6-12 years of age), specializing (13-15 years of age), and investment (16+ years of age). DMSP also defines and explains the changes that take place in the role of coaches and parents who ultimately shape athletes' primary support group (Côté, 1999). According to the DMSP, during the initial stages of development, parents are highly involved in enrolling their children in organized sports and providing them with necessary equipment and resources. During the specializing and investment stages of development, parents become less involved while still providing financial and emotional support. Hence, parents' leadership role during the sampling stage transforms to more of a following and supporting role in the specializing and investment stages of development (Fraser-Thomas, Côté, \& Deakin, 2008). Therefore, to ensure a healthy transition of athletes from one stage to another, it is important to recognize that parents' behaviours are likely to be different depending on their child's stage of development.

Researchers have examined the role that parents play in shaping adolescent athletes' sport participation patterns, and it has been suggested that parental involvement is associated with athletes' decision to remain versus dropping out of sport. In a retrospective study of athletes who had dropped out or maintained their sport participation, Fraser-Thomas, Côté, and Deakin (2008) reported that during adolescence, parents of dropout athletes had provided instructions and coaching tips while watching practices and meets, and also persisted in providing incentives for good performances. In contrast, parents of engaged athletes demonstrated unconditional support and communicated openly with their child about difficult decisions during adolescence. Hence, to prevent further increase in dropout rates, it is suggested that parents' roles and communication behaviours should correspond with the athletes' needs throughout each and every stage of their 
development. Parents' perception of their children's ability is also a major determinant of children's competence and value beliefs (Fredricks \& Eccles, 2002). More specifically, parents shape their children's beliefs by providing comments on their ability, and by commenting on the value of participating in sport activities. By doing so, parents further help their children in interpreting their experience in achievement contexts (Fredricks \& Eccles, 2002). Moreover, because sports participation is often deemed as voluntary, only a subset of children become involved in sports. Therefore, parents play an important role in supporting and inspiring their children to participate in sports and organized physical activity programs (Fredricks \& Eccles, 2002).

\subsection{Parenting Styles in Youth Sport}

When examining the influence of parents in youth sport, it is important to consider the theories and research on parenting styles, as these parenting styles influence subsequent attitudes, behaviours, and parenting practices. Darling and Steinberg (1993) defined parenting style as "a constellation of attitudes toward the child that are communicated to the child and that, taken together, create an emotional climate in which the parent's behaviors are expressed" (p. 488) There is a clear distinction between one's parenting style and practices. Parenting style is recognized as a general and broad approach whereas parenting practices - a subcategory of parenting style - are specific techniques which reflect parents' goals for their children (Baumrind, 1991; Holt, Tamminen, Black, Mandigo, \& Fox, 2009). The extent of parents' responsiveness and demandingness towards their children determines their parenting style (Baumrind, 1991). Responsiveness refers to the degree to which parents encourage individuality and self-regulation, are compassionate, and display openness and sensitivity towards their children's needs. Demandingness is defined as parents' willingness to confront their children, control, and supervise their behaviours and actions in hopes of integrating them into the family (Baumrind, 1991). Based on these dimensions, the fourfold classification model of parenting styles introduced by Baumrind (1991) categorizes parenting styles as follows: authoritative, authoritarian, permissive, and rejecting-neglecting. Authoritative parents engage in highly demanding and responsive behaviours, offering clear guidelines, and standards for their children's behaviour, and they communicate their standards to their children by being more supportive than punitive. Authoritarian parents expect that their children are socially responsible, cooperative, and self-regulated, and these parents tend to be demanding and display more of a 
dictatorship style of parenting. They are not responsive, and expect orders to be obeyed by their children without the need for explanation. They create an orderly environment, have a clear set of rules, and monitor their children's activity regularly. Permissive parents demonstrate more responsiveness than demandingness in their parenting style, and this parenting style is not considered traditional, as these parents tend to show leniency and avoid confrontation with their children. Finally, rejecting-neglecting parents engage in no disciplinary actions, and are neither demanding nor responsive towards their children. They are disengaging, rejecting, and neglect their parenting responsibilities (Baumrind, 1991). Research on typology of parenting styles suggests that authoritative parenting style takes up the middle ground between authoritarian and permissive parenting styles (Holt \& Knight, 2014). Compared to authoritarian and permissive parenting styles, the authoritative style of parenting has been linked with a range of positive outcomes for children such as increased school engagement and grade average, and greater perception of competence and intrinsic motivation at school (Baumrind, 1989; Steinberg et al., 1992; Pomerantz, Grolnick, \& Price, 2005). Furthermore, Radziszewska, Richardson, Dent, and Flay (1996) research revealed that authoritative parenting style was inversely associated with risk behaviours such as substance abuse and criminal activity. Durkin (1995) provided three reasons as to why authoritative parenting style may be linked with positive outcomes for children. Authoritative parents provide their children with a high level of emotional security that grants them a sense of comfort and autonomy that helps them to be successful. In addition, authoritative parents take the time to explain their actions to their children. Lastly, authoritative parents encourage open bidirectional communication with their children. Open bidirectional communication can result in nurturing various communication skills in interpersonal interactions and raising of well-rounded children.

Parents' adoption of particular parenting styles results in creation of an emotional climate for their children. According to Grolnick (2003), autonomy supportive and control environments are the two emotional climates that affect a child's well-being, and they may enhance or diminish children's intrinsic motivation to engage in certain behaviours. Autonomy supportive parenting refers to an environment which encourages children to initiate their own actions, make decisions, engage in problem-solving activities, and choose from options available to them. In contrast, children perceive their environment as controlling when they feel strong pressure to behave in certain ways. Children in controlling environments are often influenced by evaluation, deadlines, 
and guilt (Grolnick, 2003). Grolnick suggested that children from autonomy supportive families are more intrinsically motivated, and self-determined than children of controlling families (Grolnick, 2003). Therefore, parents can create a healthy environment for their children by communicating with them in an encouraging and supportive manner. Providing frequent positive comments and encouraging athletes to become involved in decision making and problem-solving activities can enhance athletes' intrinsic motivation, and competence (Babkes \& Weiss, 1999), which in turn can affect their motivation to participate in sport (Harwood et al., 2015).

Holt et al. (2009) examined parenting styles and practices in youth sport through fieldwork observation and interviews with parents and their children. The authors reported that some parents demonstrated high level of involvement in their child's sporting experience without being controlling. These parents created an autonomy supportive environment, and formed an appropriate setting for their children' athletic development. In contrast, other parents were also highly involved, however, they were controlling and there was little evidence of behaviours to support their child's autonomy (Holt et al., 2009). Therefore, the authors suggested that parents can still be highly involved in their children's sporting experience by placing minimal pressure on their athletes and by providing a structure that is more autonomy supportive than controlling. Athletes' perceptions of parental involvement and support also play a key role in facilitating an optimal environment for athletes' development. For example, researchers have reported that athletes who perceived more support from their guardians and parents were happier and more motivated than athletes who perceived less support (Babkes \& Weiss, 1999). It has also been suggested that athletes' perceptions of parental behaviour and level of involvement is more important to athletes' well-being than the actual behaviours of the parents (Babkes \& Weiss, 1999). Therefore, this research indicates that it is important to promote supportive environments for young athletes, and that athletes themselves should be included in research on parents in sport.

\subsection{Interpersonal Communication}

To improve parent-athlete communication, it is important to first understand the purpose of communication and various methods of communication that are employed by individuals involved in a conversation. Communication is the underlying practice which makes possible for humans to live as social entities (Matsumoto, 2010). Through communication individuals can 
come together to organize sport and recreational activities, build their social network, and work in tandem towards a common goal (Matsumoto, 2010). It is often through communication that commonness and communities are created (Dahl, 2013). The instant purpose of communication is to convey messages from a sender to a receiver (Dahl, 2013). The classic model of communication process helps to explain how a sender transmits signs or a sequence of signs to a receiver (Dahl, 2013). According to the classic model of communication process, a sender transfers signs or sequence of signs to a receiver. It is the sender's responsibility to encode the intended messages into signs. Then by decoding the signs, the recipient receives the message. The receiver then has the option to provide feedback, which will be interpreted by the sender. This process can be disrupted by noise (Dahl, 2013). Everyday interaction between individuals occur in forms of verbal and nonverbal communication. Verbal communication can be defined as a form of communication that utilizes spoken words and sounds to transfer a message from the sender to the receiver (McCorry \& Mason, 2011). To effectively - verbally - convey a message to a listener the speaker must communicate with clear language, and use words that accurately reflect his/her intended message (McCorry \& Mason, 2011). Moreover, the tone with which the speaker speaks to the listener forms the foundation of their relationship. Speaker's tone indicates his understanding of the listener's needs and increases his ability to meet those needs (McCorry \& Mason, 2011). Within interpersonal communication, there are three types of conversational tone known as expressive, directive, and problem-solving. Expressive tone is spontaneous, and is used to express emotions, tell jokes, or complain. Directive tone is commanding, and is used to give orders, or pass judgement. Lastly, problem-solving tone is rational, unbiased, and fair. Most healthcare practitioners use this tone to indicate to their patients that they are using the analytical portion of their brain to constitute a solution for a certain problem (McCorry \& Mason, 2011). Researchers have also found that using a relaxed and conversational tone by healthcare practitioners can assist them in establishing rapport with their patients (McCorry \& Mason, 2011). Nonverbal communication refers to "all aspects of communication other than words" (Wood, 2010, p. 118). Nonverbal communication is composed of one's body language, personal objects such as jewellery, physical appearance, and facial expressions (Wood, 2010). Verbal and nonverbal communication share similarities in four aspects: (a) verbal and nonverbal communication are both symbolic, which means they both illustrate other things; (b) verbal and nonverbal communication are both rule-guided. That is to say, within a society there is a shared understanding of what verbal and nonverbal behaviours are appropriate in different situations 
and what they mean; (c) verbal and nonverbal communication may be intentional or unintentional; and (d) verbal and nonverbal communication reflect one's cultural ideas, values, customs, and history (Wood, 2010).

Conversations that take place between athletes and their parents can be understood as a form of interpersonal communication. Parenting and family processes are seen as influencing and being influenced by parent-child interaction (Socha \& Stamp, 1995). Researchers have investigated the differences that exist between fathers' and mothers' interaction with their children. Mothers tend to talk more and include a broader range of topics in their discussion, including social and personal issues; whereas fathers tend to talk about more specific topics such as rules, academic achievement, and instrumental tasks (Socha \& Stamp, 1995). Furthermore, research on parentchild interaction suggest that the dynamic of parent-child communication is likely to change given the presence of one or both parents. For instance, in the presence of both parents the child experiences less stimulation directed at him/her from either parent as opposed to when he/she is alone with one parent (Socha \& Stamp, 1995). However, certain behaviours appear to not decline or may even increase in the presence of both parents. Smiling towards the child, for instance, is more frequent and noticeable when both parents are present (Socha \& Stamp, 1995). Therefore, one way to explore the dynamic of parent-child relationship is to examine parental communication in sport settings, and determine how certain verbal and nonverbal communication behaviours are interpreted. As well, the proposed study may enhance our knowledge about the nature of parent-child communication, and how parents and athletes become involved in the process of encoding and decoding of signs.

Scholars in several fields of research have examined outcomes related to communication between parents and their children. Within developmental psychology, researchers have found that infants' face to face communication - facial expressions - with their mothers between birth and three months change from simple attention with no other expressions to active and emotionally positive form of attention (Lavelli \& Fogel, 2005). In addition, Keijsers and Poulin (2013) studied the development of parent-child communication regarding adolescent unsupervised activities over the course of adolescence. They found that between 14 to 19 , the extent of parental control linearly decreases for both genders (Keijsers \& Poulin, 2013). Furthermore, for girls, parent-child communication decreased in early adolescence, and intensified in middle adolescence. Lastly, for boys, disclosure decreased in early adolescence, 
but secrecy and parental solicitation - parents asked their children about unsupervised time maintained their level throughout adolescence (Keijsers \& Poulin, 2013).

Within adolescent health research, parents' communication has been found to have a mediating effect on the relationship between parental support and adolescent women's sexual agency (Klein, Becker, \& Štulhofer, 2018). More specifically, parents’ emotional engagement and support of autonomy positively influenced adolescent women's sexual agency within dyads that had more frequent communication compared to dyads that had less frequent communication (Klein, Becker, \& Štulhofer, 2018). Additionally, researchers have shown that the quality of parent-child communication can be a predictable factor for adolescent sexual health and behaviour. More specifically, receptive, supportive, and open communication is associated with later age of initiating sexual intercourse, and lower chances of sexual risk-taking (Rogers, Ha, Stormshak, \& Dishion, 2015). In contrast, parent-dominated or harsh parent-child communication may negatively affect adolescents' knowledge of sexually transmitted diseases (Rogers et al., 2015).

Furthermore, high levels of parent-adolescent conflict may lead to poor adolescent well-being and increased risk of substance use (Diggs, Neppl, Joen, \& Lohman, 2017). Conversly, positive and healthy parent-child communication can serve as a protective factor for youth to engage in risky behaviours (Diggs et al., 2017). Lastly, positive communication between parents and their children is an important element for achieving healthy behavioural, social, and academic outcomes for children and adolescence (Parletta, Peters, Owen, Tsiros, \& Brennan, 2012). In particular, improving parent-child communication could enhance the likelihood of achieving the desired outcome(s) for interventions targeting child diet quality and obesity (Parletta et al., 2012).

Despite research examining parent-child communication in fields such as developmental psychology and adolescent health, there is relatively less research that has examined the dynamics of parent-child communication in sport settings. Thus, the present study was designed to add to this body of literature and build on the initial sport-related research examining parentchild communication. 


\subsection{Parents' Behaviour and Communication in Sport}

As mentioned above, parents can enhance their children's intrinsic motivation by providing positive and supportive feedback within an autonomy supportive environment. In addition, the ways in which parents behave and communicate in sport settings influence their children's sporting experience (Holt et al., 2009; Babkes \& Weiss, 1999). Researchers have paid a great deal of attention to parents' sideline behaviour and its determinants, using models and theories such as social learning theory and frustration-aggression models to explain spectator behaviour and violence in youth sport settings. Goldstein and Iso-Ahola (2008) used Deci and Ryan's selfdetermination theory (SDT) to study the determinants of parents' sideline behaviour at youth soccer games. SDT proposes that satisfaction of basic psychological needs - competence, autonomy, and relatedness - predicts psychological well-being (Deci \& Ryan, 2008). Using this approach, Goldstein and Iso-Ahola measured items such as parents' ego defensiveness, sport parent aggression, and parents' perception of pressure to establish the determinants of parents' sideline behaviour. Results suggested a strong relationship between parents' feeling of anger and their aggressive actions. Particularly, the angrier the parents were, the more aggressive behaviours they demonstrated (Goldstein \& Iso-Ahola, 2008). The study also examined autonomy- versus control-oriented parents and the behaviours they exhibited in a sport setting. The findings suggested that parents' personality characteristics - autonomy-oriented vs. controloriented - influenced their situational tendencies and motivations. These two main characteristics subsequently affected parents' emotional and behavioural reactions to certain actions on the field (Goldstein \& Iso-Ahola, 2008). Furthermore, control-oriented parents were more likely to become ego defensive and exhibit anger and aggressive behaviours while watching their children's sporting event. In contrast, autonomy-oriented parents were less likely to become ego defensive and as a result, engaged in less aggressive behaviours (Goldstein \& Iso-Ahola, 2008). This research examining the determinants of parents' sideline emotions and behaviour underlines the effect that particular personality orientations could have on parents' behaviours. However, a few limitations exist in their study. For instance, Goldstein and Iso-Ahola adopted quantitative measures of pressure, aggression, and ego-defensiveness using Likert-type scales. However, parents and athletes may interpret pressure and other behaviours differently (Fraser-Thomas, Côté, \& Deakin, 2008). Therefore, research using both quantitative and qualitative measures may be beneficial to allow participants to describe a wider variety of behaviours and communication 
between parents and athletes. Furthermore, implementing a parent education workshop and engaging parents in an intervention over the course of six weeks will address the limited experimental research in this area.

Verbal sideline behaviours of parents are a major form of communication because they signify the primary method of parental involvement during an athlete's sporting event (Dorsch, Smith, Wilson, \& McDonough, 2015). Consequently, there has been recent empirical interest in understanding the factors that underline parents' verbal sideline behaviour. In organized youth sport, the multiple goals perspective suggests that parent verbal sideline behaviour is formed by a combination of instrumental, identity and relational goals (Caughlin, 2010; Dorsch et al., 2015). By definition, instrumental goals are related to overcoming obstacles or completing a specific task; identity goals are related to portraying a desired image of the self and significant others; and relational goals are associated with development and maintenance of relationships (Caughlin, 2010). Within organized youth sport, instrumental goals range from improving an athlete's performance, which could prompt a parent to communicate in a controlling fashion, to improvement of self-worth which in turn could prompt a parent to show warmth and support towards their child (Dorsch et al., 2015). Identity goals, on the other hand, may lead to parents communicating in ways which create an attractive and popular image of themselves and their child. Lastly, parents who are concerned with relational goals communicate in ways that promote feelings of closeness with individuals whom they share an interest, such as athletes, coaches, and peers (Dorsch et al., 2015). Dorsch et al.'s (2015) study of parent goals and verbal sideline behaviour found that parents reported mostly wanting their children to learn about different aspects of the sport and have fun. However, parents also reported changing their rationale behind registering their child in organized sport as their perception of youth sport context evolved. Moreover, some parents' verbal sideline behaviours were aligned with task goals (e.g., improving technical skills and learning to work hard), whereas verbal sideline behaviours of others parents seemed closely linked to ego goals (e.g., preparation for a scholarship).

Additional research by Kidman, McKenzie, and McKenzie (1999) on parents' verbal behaviour examined the nature of parents' verbal behaviour during selected youth sporting events. Based upon their observational analysis of 250 parents, the authors suggested that the incidence of negative comments was too high to construct a sufficiently supportive environment for children participating in sport. More specifically, the ratio of positive to negative to neutral comments 
was approximately $4: 3: 2$. Such a ratio would suggest that parents should decrease the number of negative comments that they make and provide more supportive and positive comments. Another study conducted by Holt, Tamminen, Black, Sehn, and Wall (2008) explored parents' verbal reactions to their children's sport performance. In their study of parents' behaviour in youth sport, interviews and observations revealed that parents provided various types of comments such as praise/encouragement, performance contingent feedback, instruction, striking a balance, negative comments, and derogatory comments. Such categories highlight the spectrum of parents' verbal reactions, ranging from more supportive to more punitive comments (Holt et al., 2008). Based upon their findings, the authors suggested that parents should engage in more supportive, and less controlling behaviours to increase the likelihood of their children achieving more positive outcomes in sport (Holt et al., 2008). Hence, it is apparent that encouraging parents to engage in these supportive behaviours is important for promoting positive sport experiences for young athletes. However, there is limited research available that has demonstrated how parents might learn to engage in these supportive behaviours with their child. The proposed research will address this gap in the literature.

Even though most conceptualizations of negative parental involvement manifest images of swearing and yelling from the sideline, another conduit for negative parental involvement includes the debriefing process after games and practices. One study conducted by Elliott and Drummond (2017) focused on parent-athlete communication in post-game debriefing situations. They concluded that in post-game situations, parents engage in debriefing practices that involve assessing their children's sporting performance, which included verbal comments that are negative, constructive, or critical (Elliott \& Drummond, 2017). In some cases, debriefing upset youth athletes and initiated emotional arguments about their performance. Nevertheless, parents reported that they continued to use negative and criticizing comments when debriefing with youth athletes (Elliott \& Drummond, 2017). A recent study by Tamminen, Poucher, and Povilaitis (2017) also explored conversations between parents and adolescent athletes during the car ride home after sport practices and competitions. Exploring these interactions between athletes and parents provides researchers with information about what parents might consider to be a standard form of communication. Their analysis of semi-structured interviews with athletes and parents revealed that conversations during the car ride home offered parents the opportunity to engage in debriefing with their children. Furthermore, it appeared that the ways in which 
parents communicate with their child defined athletes' experiences during the car ride home. Tamminen et al. (2017) found that in some cases parent feedback contributed to athletes' enjoyment of the car ride home, and in other cases, where parents provided negative feedback, athletes stated that they were tolerating the car ride home or "waiting it out" (Tamminen et al., 2017, p. 10). Lastly, Tamminen et al. (2017) reported that parents could improve the experience of their children during the car ride home by giving athletes time to think, de-emphasizing performance outcomes, asking questions in a supportive manner, and by being supportive and positive. A very limited number of research studies have focused on parent-athlete interaction in different settings (e.g., before, during, and after practices and games). Therefore, the present study asked parents and athletes to describe their interactions before, during and after their sporting practices and competitions. This approach allowed for an examination of parenting behaviours and communication in diverse settings, rather than asking parents and athletes to focus specifically on one situation. In addition, much of the previous research in this area has relied on retrospective interviews; therefore, using audio diaries to collect data prospectively provided parents with the opportunity to describe and reflect on their interaction with their child before, during and after their sporting practices and competitions.

\subsection{Parent Socialization in Sport}

"Human behaviour is a function of the interaction between person and environment" (Goldstein $\&$ Iso-Ahola, 2008, p. 1457). Within organized sports, the ways in which parents behave can be witnessed by and affect athletes and other parents (Knight, Neely, \& Holt, 2011; Omli \& LaVoi, 2009). A research study conducted by Dorsch, Smith, and McDonough (2015) examined parent experiences of parent sport socialization during the initial period of a first child's involvement. The findings of the study suggested that parents with children participating in organized sport for the first time experience a range of socializing events that are shaped by characteristics of other parents and the youth sport context. It was concluded that the organized youth sport context serves as a platform that fosters parent development, and therefore, validates parents' beliefs that their own development is linked to their child's participation in organized sport. The researchers also suggested that socialization with other adults, family members, and participating children most immediately affected and shaped parents' experiences (Dorsch et al., 2015). Hence, in the early stages of athletes' development, parents may use sport as a medium for communication with their children, spending more time with their family, and engaging with other families in the 
community (Dorsch et al., 2015). Furthermore, parents play an important role in shaping each other's experiences and beliefs within organized sport settings; however, these experiences and beliefs may not be informed by information about appropriate behaviours in youth sport settings and may be informally learned from other parents, regardless of whether the behaviours are appropriate for young athletes' development. Therefore, it is important to educate parents on what is considered as desirable behaviours within such settings.

The research findings summarized above provide information on parental involvement in youth sports, and the benefits of autonomy supportive parenting. However, a few points need to be made in regards to the limitations of research in this area. For instance, the study conducted by Holt et al. (2009) examined youth sport parenting styles and practices using a qualitative approach; in their study the authors interpreted and classified participants' parenting styles from descriptions of their general approach to parenting. In order to extend this research, I propose that using mixed methods including interviews as well as an appropriate measure such as the parental authority questionnaire (Buri, 1991) will provide more information about participants' parenting style. In addition, by asking parents to complete a measure of parent-adolescent communication (Barnes \& Olson, 1985), it may be possible to examine the potential associations between parents' parenting style and their communication with their child. Lastly, answers provided to questions in interviews and audio diaries will provide an opportunity to gain insight on parent-child communication in competitive sport settings and the impact that certain parenting styles could have on parent-child communication in sports. Furthermore, previous research has provided information about the ways that parents behave in sport setting and communicate with their children; however, previous research studies (e.g., Fraser-Thomas, Côté, \& Deakin, 2008; Holt et al., 2009) have been largely descriptive in nature and there is a lack of research examining interventions to improve parenting practices or parents' communication. Thus, one aim of the proposed research is to promote better parent-athlete communication in youth sport. One strategy which may be useful to improve parents' communication is to increase parents' awareness of their communication with their child through reflective practice.

\subsection{Reflective Practice}

Reflective practice can be defined as "an active and deliberate cognitive process involving sequences of interconnected ideas that take account of underlying beliefs and knowledge" 
(Hatton \& Smith, 1995, p. 34). Moon (2013) identified characteristics of reflective practice as follows: involves cognitive processes; involves a strong cognitive element; reviews and reconstructs ideas with the aim to improve practice; aims for self-development; and includes emotional involvement. Three key stages underpin the process of reflective practice. Stage one is triggered by an individual's awareness of uncomfortable feelings or thoughts; the second stage involves individual's constructive analysis of the situation and examination of feelings and knowledge; the third stage involves the development of a new outlook on the situation (Morgan, 2009). "Reflective thinking generally addresses practical problems, allowing for doubt and perplexity before possible solutions are reached" (Hatton \& Smith, 1995, p. 34). Individuals can engage in reflective practice both during an action and once an action has concluded. According to Schön (1983), reflection in action can be defined as "an epistemology of practice implicit in the artistic, intuitive process which some practitioners do bring to situations of uncertainly, instability, uniqueness, and value conflict" (Schön, 1983, p. 49). Reflection in action occurs during an action and encompasses thinking about how to reshape and adjust what we are doing while it is underway (Ghaye \& Lillyman, 2000). Conversely, reflection on action is a form of reflection that takes place after an action via verbalized or non-verbalized thought. Reflection on action allows individuals to access and make sense of their knowledge-in-action and subsequently allows individuals to make more informed decisions in practice, based on the knowledge generated from previous experience (Ghaye \& Lillyman, 2000).

Learning through reflection can be defined as "the process of creating and clarifying the meaning of experience (present or past) in terms of self (self in relation to self and self in relation to the world). The outcome of the process is changed perceptual perspective" (Andrews, Gidman, \& Humphreys, 1998, p. 413). Researchers have addressed and examined the relationship between reflective practice and self-awareness among healthcare practitioners. Engagement of professional practitioners in reflection on practice has highlighted reflection to be an important process in assessing the "self" and discovering more effective ways of "being" (Cropley, Hanton, Miles, \& Niven, 2010). For instance, Tod, Marchant, and Andersen (2007) concluded that through self-reflection, practitioners can enhance their understanding of their interactions with clients, and that such knowledge might assist them in becoming more effective consultants. Reflective practice has also been assessed within workforce development and public health roles (Forrest, 2008). It has been suggested that benefits of reflective practice are threefold; first, 
individuals re-define their understanding of professional knowledge; secondly, they develop personal knowledge or self-awareness; and lastly, they evaluate the appropriateness of their actions (Forrest, 2008). Reflective practice has been predominantly applied within public health settings to improve health practitioner-client interaction (Tod et al., 2007; Forrest, 2008); however, there is no research to date that has examined the use of reflective practice among parents and within the context of youth sport. Therefore, reflective practice may be a valuable method to attempt to increase parental awareness of communication, with the aim of influencing parent-athlete communication.

\subsubsection{Gibbs' reflective cycle}

Gibbs' (1988) reflective cycle (Figure 1) represents a form of reflection on action rather than reflection in action, and it is an extension of Kolb's (1984) experiential learning theory in which theory and practice are placed in an iterative circle (Potter, 2015).

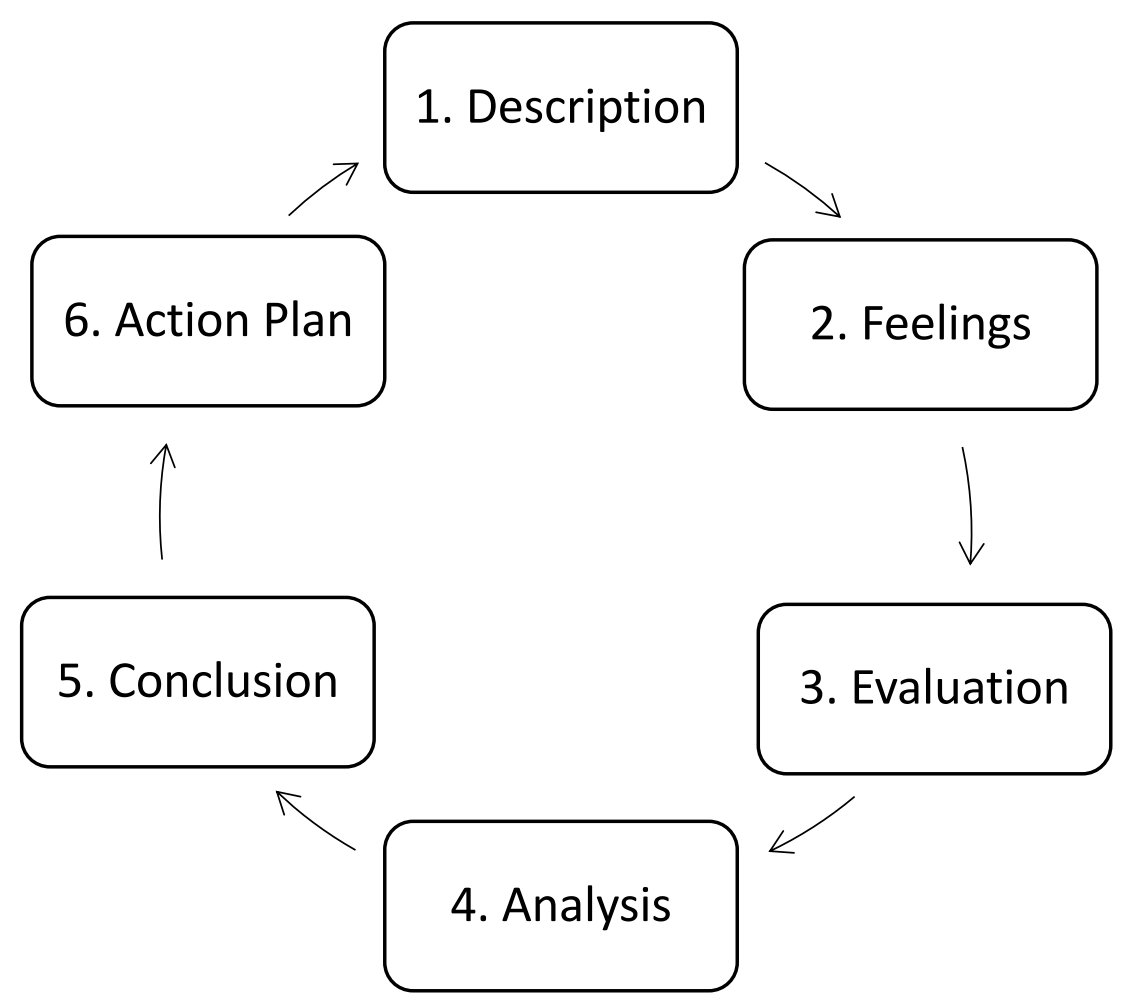

Figure 1. Gibbs' (1988) Reflective Cycle. 
This model proposes that theory and practice enrich each other in this iterative circle. Gibbs' (1988) reflective cycle consists of six stages which asks individuals questions about their experiences:

1. Description: Provide a detailed description of the event you are reflecting on.

2. Feelings (self-awareness): At this stage, try to recall and explore those things that were going on inside your head.

3. Evaluation: What was good or bad about the experience? Make a value judgement.

4. Analysis: What sense can you make of the situation? Bring in ideas from outside the experience to help you. What was really going on? Were other people's experiences similar or different?

5. Conclusion: What can be concluded, in general sense, from these experiences and analysis you have undertaken? More specifically, what can be concluded about your own unique and personal situation or way or thinking/working?

6. Personal Action Plan: What are you going to do differently in this type of situation next time? What steps are you going to take on the basis of what you have learnt?

Gibbs' (1988) reflective cycle is a valuable model for encouraging parental reflective practice about communication with their child by providing useful questions to help structure one's reflective experience. One of the strengths of Gibbs' reflective cycle is its step by step approach to each phases of reflection. This systematic approach to reflection allows for clarity, precision, and flexibility of application within various domains and populations. It provides a starting point for individuals with no experience in reflection, and encourages individuals to convert new knowledge into action and change. An alternative model of reflective practice such as Rolfe, Freshwater, and Jasper's (2001) model of reflection includes three stages that asks individuals 1) What? 2) So what? and 3) Now what? While these are simple and straightforward questions, there is no clarity of what is expected from the participant in each stage of the model. In addition, compared to Gibbs' reflective cycle, Rolfe et al.'s model of reflection fails to incorporate feelings and emotions in the process of reflection. Hence, by adopting Gibbs' reflective cycle as the primary framework in the proposed study, parents can take into consideration their own and their children's feelings and emotions during reflection. Moreover, during the evaluation and analysis stages of Gibbs' reflective cycle, parents are required to look beneath the surface of events and experiences, to achieve deeper levels of reflection and learning. 


\subsubsection{Application of Gibbs' (1988) reflective cycle}

Several studies have applied and assessed the practicality of Gibbs' (1988) reflective practice cycle in various domains. In a single-subject design, Wilding (2008) examined the applicability of Gibbs' reflective cycle in helping a first year student nurse to cope with a practice-related issue during his first clinical placement. It was found that Gibbs' reflective practice allowed the student nurse to reflect on his thoughts and feelings, and permitted him to concentrate on important elements of the story. Moreover, by providing an action plan, he was able to explore the potential situations that could arise again and apply what he learnt to those future situations (Wilding, 2008). Hence, it became evident that reflection could be a tool for discovery and possible learning. Wilding (2008) postulated that Gibbs' reflective cycle can be used in various circumstances, and it can be altered and adapted to varying situations. Another study used Gibbs' reflective cycle to examine nursing students' reflections after meetings with nursing patients and their relatives. The student nurses' responses to the questions produced information such as "becoming aware of what knowledge and skills are needed" and "wanting to do well and to have the right answer" (Söderberg, Sundbaum, \& Engström, 2017). One student nurse expressed his/her outlook on the benefit of Gibbs' reflective practice model as follows: 'I've got to see what difficulties we may encounter as nurses, and this taught me how important it is to have the right attitude and approach" (Södenberg et al., 2017, p. 141). Other nursing students expressed that new knowledge they brought with them from the reflection process included the importance of being able to reach individuals in different life situations, and to convey the knowledge they needed in that moment (Södenberg et al., 2017, p. 141). Lastly, the importance of debriefing to promote reflection is considered the cornerstone of stimulation-based education. Husebø, O'Regan, and Nestel (2015) assessed the applicability of Gibbs' reflective cycle in debriefing during stimulation-based education. The researchers determined that Gibbs' reflective learning cycle was a structured, and easy to follow model. The findings also suggested that individuals who engaged in debriefing used questions from all six stages of Gibbs' (1988) reflective learning cycle. Likewise, Gibbs' reflective cycle adds the dimension of emotion, which is a key component of engagement and subsequent learning. It integrates an emphasis on deeper understanding, and incorporates learning into knowledge and future practice (Husebø et al., 2015). 


\subsection{Research Questions}

Overall, researchers have identified the role of parents in youth sports, provided information on the ways that parents behave and communicate with their children in sport settings, and have highlighted the importance of positive and supportive communication. However, there is limited research available that has demonstrated how parents might learn to engage in these supportive behaviours with their child. Furthermore, there has been no research to date that has applied a model of reflective practice to attempt to improve parents' awareness of their communication with their child. Hence, the purpose of this study is to examine how parental awareness of communication influences parent-athlete communication. The study will address the following three questions: (a) How does reflective practice influence parents' self-awareness of their own communication behaviour? (b) Does increased awareness of parent-child communication lead to perceived changes in parents' communication behaviour? (c) Do reflective practice and increased awareness of parent-child communication lead to perceived changes in parents' parenting styles? 


\section{Chapter 3 \\ Methods}

\section{Study Overview}

This study adopted a mixed method single subject research design consisting of a parent education workshop, as well as audio diaries, surveys, and semi-structured interviews to collect data. Single subject designs include a variety of experimental designs that can be used to determine the effectiveness of an intervention by assessing the relationship between an intervention and outcomes (Kazdin, 2011). As Cannon, Guardino, Antia, and Luckner (2016) stated, "single subject design compares participants with their own performance across time, using pre-intervention measures to establish baseline, repeated measures during the intervention, and post intervention measures to establish maintenance of the skill or behavior” (p. 442). Athletes and parents completed baseline surveys (e.g., perceptions of parental support and pressure) and interviews regarding parent communication in youth sport. Then, parents participated in a workshop during which they were provided with an overview of the current literature on parent-child communication. Following their participation in the workshop, parents completed at least one audio diary entry per week over the course of six weeks, which was structured to encourage reflective practice of their communication behaviour in youth sport. At the end of the six-week period athletes and parents completed follow up surveys and interviews to examine perceived changes in parents' communication behaviour and to determine whether such changes were also perceived by athletes.

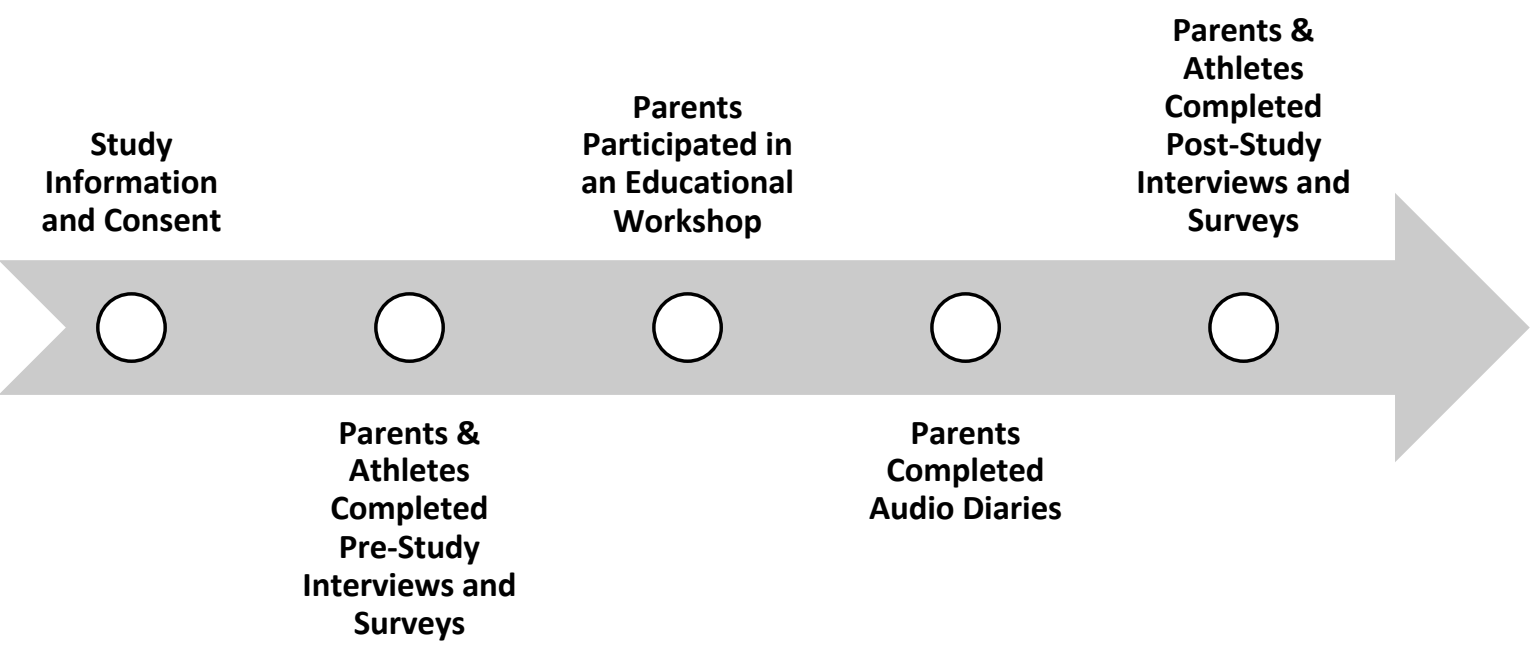

Figure 2. Study Overview. 
The study adopted a critical realist paradigm which entails of a transcendental realist ontology and an eclectic realist epistemology (Easton, 2010). Critical realists attempt to understand the nature of a phenomenon through analysis of complex relationships and interactions within that environment (Easton, 2010). Within a transcendental realist ontology it is assumed that events occur independent of people's perception and cognition; however, such events and the reality of them can never be known with full certainty (Tsang, 2014). Within the present research, adopting a transcendental realist ontology means that parents and athletes may experience a shared interaction with one another, but they may have difference experiences or interpretations of that event. Epistemologically, critical realists understand that knowledge is produced within social settings and the relationships that exist between social and natural objects with in those settings (Easton, 2010). Within the present study, this eclectic realist epistemology means that the interactions that take place between a parent and a child construct the foundation of both the parent's and the child's reality. Therefore, single subject case study research design provides an appropriate setting to generate qualitative data, which then can be analyzed through an overarching critical realist paradigm to identify common experiences of parent-child communication across participants.

Within the present study, I acted as the instrument for collecting semi-structured interviews; therefore it was important that I identify my own position and biases in the present study. Besides being a researcher, I am a former athlete who transformed his passion for sports into coaching young athletes. I started my coaching journey nearly ten years ago with a house league team in my home town. The joy of interacting with youth athletes and being surrounded by their energy day in and day out, encouraged me to obtain my coaching certifications. I currently hold a national B coaching license from the Canadian Soccer Association and a national C coaching license from the United States Soccer Federation. My decision to conduct research on the topic of parental communication in youth sport was made after I came to realize that my childhood experience in sport was quite different than what some of today's young athletes experience in sports. My parents always tried to be positive and supportive before, during, and after my competitions. They encouraged me to engage in discussions with them about what I was struggling with, and they tried their best to help me overcome those struggles. In contrast, throughout my coaching journey I have observed some parents' behaviours that were not as positive or supportive as I had expected them to be. Therefore, it was my goal to create an 
intervention which could potentially improve parent-child communication in sporting contexts. My personal experience in sport as a child, and the positive interactions I had with my parents about sport related topics formed my biases in the present study. Hence, to minimize these biases I engaged in weekly discussions with my supervisor who acted as a critical friend throughout my research.

\subsection{Participants}

To select information-rich cases for our study, participants were recruited through a purposeful sampling technique (Palinkas et al., 2015). Seven male and three female competitive athletes between the ages of 13-15 years and one of their parents were recruited to participate in this study (total $N=20$ ). Recruited parents consisted of six male (Father) and four female (Mother) ranging from 41 to 53 years of age. Eight parents and children self-identified as white/Caucasian, one parent and child self-identified as south Asian, and one parent and child self-identified as Mexicans. Tables 1 and 2 provide a summary of the participants' descriptive characteristics. To maintain anonymity, participants' names were replaced with pseudonyms. Parent and child pseudonyms were matched by first letter. For instance Chris and Chloe demonstrate a fatherdaughter relationship, whereas Bob and Brandon demonstrate a father-son relationship. 
Table 1. Parent demographic information.

\begin{tabular}{cccc}
\hline & \multicolumn{2}{c}{ Parents } & \\
\hline Name & Gender & Age & Education Level \\
\hline Bob & Male & 45 & Completed college/university \\
\hline Chris & Male & 41 & Post-graduate \\
\hline David & Male & 48 & Post-graduate \\
\hline Lisa & Female & 53 & Completed college/university \\
\hline Mark & Male & 46 & Completed college/university \\
\hline Nick & Male & 43 & Completed college/university \\
\hline Ron & Male & 52 & Post-graduate \\
\hline Sarah & Female & 43 & Completed college/university \\
\hline Tammy & Female & 48 & Completed college/university \\
\hline Vicki & Female & 47 & Completed college/university \\
\hline
\end{tabular}

Table 2. Athlete demographic information.

\begin{tabular}{ccccc}
\hline & \multicolumn{5}{c}{ Athletes } & \\
\hline Name & Gender & Age & Primary Sport & Years Involved in Sport \\
\hline Brandon & Male & 15 & Hockey & 8 or More \\
\hline Chloe & Female & 13 & Soccer & 8 or More \\
\hline Dean & Male & 14 & Soccer & 8 or More \\
\hline Luca & Male & 15 & Soccer & 8 or More \\
\hline Melissa & Female & 13 & Soccer & 8 or More \\
\hline Noah & Male & 13 & Hockey & 8 or More \\
\hline Ryan & Male & 15 & Soccer & 8 or More \\
\hline Sophie & Female & 13 & Soccer & 8 or More \\
\hline Tyler & Male & 15 & Soccer & $4-5$ Years \\
\hline Victor & Male & 13 & Hockey & 8 or More \\
\hline
\end{tabular}

Athletes were presently involved in their respective sports at a high performance or provincial level (i.e. AAA Hockey \& Ontario Player Development League soccer). Ontario Player Development League (OPDL) is one of Ontario's first standards-based youth high performance leagues that combines top level competition with strict high performance training standards. 
Players involved in AAA hockey are competing at the highest level of hockey offered in Ontario. Players participating in OPDL soccer or AAA hockey are often recruited to represent team Ontario at provincial level competitions and/or team Canada at international tournaments. Additionally, high performance athletes (OPDL soccer and AAA hockey) between the ages of 13-15 years are likely to join Canadian/ American post-secondary institutions on athletic scholarships. As a result, parents of high performance athletes are assumed to be dealing with various organizational, competitive, and developmental stressors (Harwood \& Knight, 2009). It has been suggested that parents of athletes in the specialized stage experience greater time and family-related stressors due to the increase in training and competition load (Harwood \& Knight, 2009). In addition, factors such as athletes' injury, finance, and time commitment also play a role in increasing the level of parental stress in high performance youth sports. Likewise, it is particularly important to examine parent-athlete communication in this age group (13-15 years of age) because during this period athletes are frequently engaged in training and competition, and at this stage parents take an active interest in their children's sport participation (Côté, 1999). While athletes at this stage are developing more mature relationships with their peers and becoming independent from their parents, parents still play a key role in providing practical and emotional support to their children (Wylleman \& Lavallee, 2004). Therefore, recruitment of athletes between the ages of 13-15 years who were involved in OPDL soccer and/or AAA hockey and their parent provided information-rich cases for the purpose of this study.

\subsection{Participant Recruitment}

Typical case purposeful sampling was used (Palinkas et al., 2015) to recruit participants for the study. Male and female athletes were recruited if: (a) they were between 13-15 years of age and were part of an OPDL soccer or AAA hockey team; (b) if athletes typically traveled to and from games and practices with their participating parent; and (c) if athletes typically had their participating parent attend and watch their games and practices. Upon receiving university research ethics board approval, the researcher arranged meetings with various sport club administrators and provided them with information about the study. Upon receiving their approval, they were asked to send information about the study to parents and athletes within their organization. In addition, the author attended OPDL soccer and AAA hockey games and distributed brochures to the parents in attendance. Brochures contained information about the purpose of the study and its methods (all research-related materials were provided to the 
University of Toronto's research ethics board for approval). In addition, parents and athletes were provided with information letters and consent forms (refer to Appendix A, B, and C) prior to their participation in the pre-study survey and interview. Once parents and athletes had reviewed their information letters and provided written consent, they were eligible to participate in the study.

\subsection{Pre-and Post-study Surveys}

Baseline and post-study surveys were used to assess participants' perceptions of parental support and pressure, parent-athlete communication, and parenting styles. Perception of parental support and pressure was measured through the Parental Involvement in Activities Scale (PIAS) questionnaire (Anderson, Funk, Elliott, \& Smith, 2003). The PIAS is a measure of children's perceptions of their parents' involvement in their extracurricular activity participation (refer to Appendix E and F). All items contain the general wording "my mom or dad" to provide our participants with flexibility in their choice of either their mother or father as the more involved parent in their extracurricular activity participation. The support scale consists of six items (items 1-6) whereas the pressure scale includes ten items (items 7-16). Items on the scale are anchored with "strongly disagree", “disagree", "agree”, and "strongly agree" (Anderson et al., 2003). A modified version of PIAS was administered to the parents to examine their perspective of their own involvement in their children's extracurricular activity. For instance, item (1) in the athlete version of the questionnaire: "When I tell my mom or dad that I want to sign up for an activity or lesson, they think it's a good idea" was changed to "When my child tells me that he/she wants to sign up for an activity or lesson, I think it's a good idea." The PIAS is scored by averaging the individual items to comprise the score for each subscale. Anderson et al. (2003) reported adequate reliability statistics for the PIAS: Cronbach's alpha $=.70$ (support subscale) and .71 (pressure subscale).

Quality of communication between parents and athletes was measured through the ParentAdolescent Communication Scale (PACS) introduced by Barnes and Olson (1985). This measure was chosen because it is widely used by researchers within the field of parent-adolescent communication. The PACS (refer to Appendix $\mathrm{G}$ and $\mathrm{H}$ ) is comprised of two scales: one that measures the degree of openness in parent-athlete communication, measured through items such as "My mother/father is always a good listener" and "It is very easy for me to express all my true 
feelings to my mother/father"; and a scale that assesses the degree of problems in parent-athlete communication, measured through items such as "My mother/father has a tendency to say things to me which would be better left unsaid" and "I don't think I can tell my mother/father how I really feel about some things." Each scale consists of ten items. All items on the scale are anchored with "strongly disagree" coded as 1, "disagree" coded as 2, "neither agree nor disagree" coded as 3, "agree" coded as 4 , and "strongly agree" coded as 5 . The scores for the items on the problem subscale are reversed in value. As a result, a higher overall score on the PACS indicates more positive communication. The PACS is scored by summing the individual items to comprise the score for each subscale. Scores on each subscale range from 10 to 50 . The overall communication score is then calculated by summing the total score from each subscale. The scale is designed such that both the parent and the athlete can complete the questionnaire. For instance, item (14) on the athlete version of the scale "My mother/father tries to understand my point of view" was altered to "I try to understand my child's point of view" on the parent version. Barnes and Olson (1985) reported adequate reliability statistics for the PACS: Cronbach's alpha $=.87$ (openness subscale) and .78 (problems subscale).

Lastly, parenting style was assessed through the Parental Authority Questionnaire (PAQ). This questionnaire was developed by Buri (1991) to measure Baumrind's (1971) permissive, authoritative, and authoritarian parenting styles. It consists of 30 items, all of which are anchored with "strongly disagree" coded as 1 , "disagree" coded as 2 , "neither agree nor disagree" coded as 3, "agree" coded as 4, and "strongly agree" coded as 5. The PAQ has three subscales: permissive (items 1, 6, 10, 13, 14, 17, 19, 21, 24 and 28), authoritarian (items 2, 3, 7, 9, 12, 16, 18, 25, 26 and 29), and authoritative/flexible (items 4, 5, 8, 11, 15, 20, 22, 23, 27, and 30). A modified version of the questionnaire was used for parents to assess their own parenting style. For instance, item (7) on the athlete version of PAQ "As I was growing up, my mother/father did not allow me to question any decision she/he had made" was altered to "As my children were growing up I did not allow them to question any decision I had made" (refer to Appendix I and $\mathrm{J})$. The PAQ is scored by summing the individual items to comprise the score for each subscale. Scores on each subscale range from 10 to 50. Buri (1991) reported adequate reliability statistics for the PAQ: Cronbach's alpha = .75 (mother's permissiveness), .85 (mother's authoritarianism), .82 (mother's authoritativeness), .74 (father's permissiveness), .87 (father's authoritarianism), and .85 (father's authoritativeness). 


\subsection{Pre-and Post-study Interviews}

Parents and athletes also participated in semi-structured interviews consisting of open ended questions to gain further information and understanding of parental communication in youth sport settings. Semi-structured in-depth interviews are the most widely used interviewing format within the field of qualitative research (DiCicco-Bloom \& Crabtree, 2006). Such interviews encourage the interviewee to share rich description of phenomena while leaving the analysis and interpretation to the investigators (DiCicco-Bloom \& Crabtree, 2006). Moreover, individual semi-structured in-depth interviews allow the interviewer to delve deeply into social and personal matters, while developing trust and respect for the interviewee (DiCicco-Bloom \& Crabtree, 2006). Likewise, interviews offer researchers the opportunity to show their interest in understanding the experiences of other people, and the meanings they make of those experiences (Seidman, 1991). An advantage of including interviews in addition to questionnaires and audio diaries is the face to face interaction that takes place between the interviewer and the interviewee. Face to face interviews allow the observation of verbal and nonverbal actions. Having access to facial expressions, gestures, and other paraverbal communications (e.g., tone of speech) may enrich the meaning of the spoken words (Hiller \& DiLuzio, 2004; Carr \& Worth, 2001).

Hence, the author conducted semi-structured interviews with parents and athletes prior to the commencement of the workshop and again one week after the completion of the audio diaries. Once university research ethics board approval was received and participants had provided their consent to participate in the study, they were contacted by the primary investigator to arrange interviews. Interviews were conducted at a place and time that was most convenient for the participants, including at the participants' home or at sports clubs or fields. All interviews were audio recorded and transcribed verbatim. In addition, the author used participant pseudonym to maintain confidentiality and anonymity. Lastly, parents and athletes completed their interviews in a private setting.

Questions included in each interview guide for both athletes and parents (refer to Appendix K and L) covered the following four areas: ice-breakers, transition questions, parent-athlete interactions, and parent-athlete communication. More specifically, questions covered areas such as parental involvement, parenting styles and practices, and parents' communication behaviour at 
various stages of their involvement. Parent interview topics included: (a) ice-breaker questions (e.g., "Please tell me a little bit about yourself and your family." and "How would you describe a day in which you prepare your son/daughter to his/her game and/or practice?"), (b) parents at practices and games (e.g., "Have you ever seen examples of parental behaviour that you feel is inappropriate at sporting events? Can you describe what you saw?" and "How would you describe a good sport parent?"), (c) parent-athlete interactions (e.g., "There are various types of parenting styles. How would you describe your style of parenting?" and "How would you say you prepare your son/daughter for his/her training/competition?"), and (d) parent-athlete communication before, during, and after practices and games (e.g., "How would you describe your interaction with your child before arriving at his/her training or competition?" and "What things do you say to your child after his/her training/games?"). Lastly, to encourage parents to reflect on their communication behaviour, the following question was asked: "If you had a chance to explain to your child the reason behind the way you communicate with him or her before, during and after his/her training/competition, what would you say?"

Athletes' interview questions were modified slightly, however questions covered the same four areas: (a) ice-breaker questions (e.g., "Tell me a little bit about yourself and the sports you play." and "How often do you train and compete for your sport?"), (b) parents at practices and games (e.g., "When you have been competing or training (in said sport) have you ever seen any example of really good parents? Can you describe what you have seen?’), (c) parent-athlete interactions (e.g., "How do you feel about your parents coming to watch you practice or play? And why?", and "How would you say your parents prepare you for your competition and/or training?"), and (d) parent-athlete communication before, during, and after practices and games (e.g., "Think about a time that you made a mistake during practices or games. How would you describe your parent's reaction at that moment?" and "What things do your parents do or say that you don't like after your games/trainings?'). In conclusion, the following question was asked to gain insight into athletes' perspectives on optimal parental communication behaviour, and the way they prefer their parents to communicate: "If you had a chance to tell your parents how you would like them to communicate with you when you are training or competing, what would you say?"

The data from pre-and post-interviews were compared to assess possible changes in parents' communication and in parenting style(s) and practices. Moreover, athletes' interview data 
provided information regarding whether such changes were perceived by athletes. Furthermore, interview data were compared with the data collected from pre-and post-questionnaires. Such comparisons helped shed light on whether the use of audio diaries and workshop were beneficial in increasing parents' awareness of their communication.

\subsection{Workshop}

The purpose of the workshop was to educate parents about research in the area of parental involvement in sport as well as parent-child and parent-athlete communication (see presentation slides, Appendix M). A 45-minute presentation provided parents with research-based information on optimal parental behaviour in sport settings, athletes' perception of preferred parental behaviours at team sport competitions, ideal parent-child communication in and outside of sport, and developmental changes in parent-child communication. Delivering information on these topics provided parents with the opportunity to compare their communication behaviour with research based principles. Upon comparing their communication behaviour with research based information on parent-athlete communication, parents could then reflect on different aspects of their communication behaviour and develop an action plan (through audio diaries) to improve their communication with their child.

At the end of the workshop, a brief portion of the presentation focused on the developmental model of sport participation (DMSP). The DMSP is based on theoretical and empirical data which described the pathways and outcomes associated with development of children and adolescents through sport (Côté \& Vierimaa, 2014). Based on changes in the amount of involvement in sport, deliberate play, and deliberate practice, Côté divided athletes' development into three stages: sampling years (6-12 years of age), specializing years (13-15 years of age), and investment years (16+ years of age) (Côté, Baker, \& Abernethy, 2007). Deliberate play consists of activities that are primarily for intrinsic enjoyment, and offer immediate gratification but also contribute to acquisition of skills (Côté, Baker, \& Abernethy, 2007; Fraser-Thomas, Côté, \& Deakin, 2008). Deliberate practice incorporates activities that are highly structured, generate no immediate enjoyment, and require high degree of effort (Côté, Baker, \& Abernethy, 2007; Fraser-Thomas, Côté, \& Deakin, 2008). According to DMSP, during the sampling years athletes should engage in a variety of sports with high amount of deliberate play, and low amount of deliberate practice (Côté, Baker, \& Abernethy, 2007). During the specializing years, athletes 
should balance the extent to which they engage in deliberate practice and deliberate play, and reduce their involvement in multiple sports. It is during the investment years that athletes are encouraged to engage in high amounts of deliberate practice, reduce their involvement in deliberate play, and focus on one sport only (Côté, Baker, \& Abernethy, 2007). Accordingly, parents' roles alter as their children progress from one stage to another. Parents' leadership role during the sampling years transforms to more of a supporting and following role during the specializing and investment years (Fraser-Thomas, Côté, \& Deakin, 2008). Therefore, by informing parents about various stages of athletes' development and what is expected of the athletes in each stage, parents can manage their communication behaviour to further enhance the likelihood of their children in achieving their goals.

Lastly, a parent handbook specific to the sports from which our participating athletes are recruited was provided to the parents. These sport-specific parent handbooks provided parents with information on how to support their child's participation in sport. For instance, parents were encouraged to focus on learning outcomes and positive points, and avoid bombarding their children with questions after their games.

Overall, parents received research findings on parent-athlete communication, and information on what parents should know and can do in each stage of their children's development, as well as how to best communicate with their children before, during, and after practices and games. To learn about possible changes in parent-athlete communication following the workshop, the data collected from pre-study questionnaires/interviews, and post-study questionnaires/interviews were compared. In addition, transcripts of audio diaries from week (1) to week (6) were read and analyzed to further assess possible changes in parents' communication as a result of the proposed workshop.

\subsection{Audio Diaries}

Audio diaries entail the audio recording of participants' responses and reflections over a period of time (Buchanan, 1991). A central advantage of audio diaries as a method of data collection is its participatory nature. Simply put, the construction of personal experience is directed by the participant, and can be viewed as a performance as well as a creative way to form verbal monologue (Crozier \& Cassell, 2016). A key advantage of collecting data through audio diaries is the minimization of researcher influence over participants' responses (Crozier \& Cassell, 
2016). Hence, audio diaries are useful for capturing private experiences and those that are sensitive and difficult to capture via researcher involvement (Crozier \& Cassell, 2016). Likewise, audio diaries "overcome the traditional limitations of self-report methodology" (Crozier \& Cassell, 2016, p. 399) by enhancing the fluidity in speech, and capturing participants' current psychological mindset (Bakker \& Bal, 2010; Fisher \& Noble, 2004).

Audio diaries provided participants with the opportunity to actively explore their experiences and reflect upon them in a critical way rather than taking such experiences for granted and assuming that experience on its own is sufficient. Therefore, audio diary was used as a method to allow parents to engage in reflective practice and thereby increase awareness of their communication with their child. Parents were asked to complete at least one audio diary per week for six weeks (a Sony audio recorder was provided to each parent). Parents were directed to answer questions provided to them on a prompt sheet, based on stages of Gibbs' (1988) reflective cycle (refer to Appendix N). Questions covered the following six areas: description, feelings, evaluation, analysis, conclusion, and personal action plan. Each question was designed to promote critical thinking and reflection on previous experiences. For instance, in the personal action plan stage parents were asked to answer the following question: "What are you going to do differently in this type of situation next time? What steps are you going to take on the basis of what you have learnt?" More general questions were asked in the start of each entry to allow the participants to elaborate on their experience. To illustrate, in the description stage parents were asked to answer the following question: "What happened? Do not make judgements yet or try to draw conclusions; simply describe the situation." Lastly, parents were asked to draw conclusions that are specific to their own experience. For example, in the conclusion stage parents were asked the following questions: "What can be concluded about your own specific, unique, and personal situation or way of thinking/interacting?" Questions were answered in regards to the interactions that parents had with their child either before, during, or after his/her training or game. Parents were asked to complete an audio diary within 24 hours after their child's practice or game. To accurately determine the effect of the intervention study on parental communication, parents were asked to choose the same context (e.g., after practice) for answering their audio diary questions. For instance, one parent could choose to reflect on his or her communication with his or her child before practices, whereas another parent could choose to reflect on his or her communication with his or her child after games. In the beginning of each week, parents 
received a brief text message from the primary investigator, reminding them to complete their audio diary entry for the week. At the end of the sixth week, arrangements were made with the parents to collect the audio recorders at a time and location that was convenient for them and to complete the post-study surveys and interviews.

\subsection{Data Analysis}

\subsubsection{Data preparation}

Parents and athletes' pre-study and post-study interviews as well as parents' audio diaries were transcribed verbatim by the researcher. Athletes completed pre-study interviews which lasted an average of 25.61 minutes per athlete. They also completed post-study interviews which lasted an average of 10.90 minutes per athlete. Likewise, parents completed pre-study interviews which lasted an average of 40.80 minutes per parent. Parents also completed post-study interviews which lasted an average of 19.99 minutes per parent. Lastly, parents completed a total of 74 audio diary entries at the end of a two-week period with an average of 7.4 entries per parent. Tables 3 and 4 provide a summary of the qualitative data. Parents' and athletes' pre- and poststudy surveys were organized using Microsoft ${ }^{\circledR}$ Excel 2016. 
Table 3. Data generated by participating athletes.

Participants (Athletes) Pre-Study Interview (Minutes) Post-Study Interview (Minutes)

\begin{tabular}{ccc}
\hline Brandon & 22.41 & 13.57 \\
\hline Chloe & 33.01 & 21.57 \\
\hline Dean & 25.17 & 7.14 \\
\hline Luca & 19.31 & 9.16 \\
\hline Melissa & 34.15 & 19.03 \\
\hline Noah & 17.05 & 7.06 \\
\hline Ryan & 28.43 & 7.31 \\
\hline Sophie & 28.06 & 11.42 \\
\hline Tyler & 23.36 & 6.42 \\
\hline Victor & 25.21 & 6.38 \\
\hline$N=10$ & $M=25.61$ & $M=10.90$ \\
\hline
\end{tabular}

Table 4. Data generated by participating parents.

\begin{tabular}{cccc}
\hline $\begin{array}{c}\text { Participants } \\
\text { (Parents) }\end{array}$ & $\begin{array}{c}\text { Pre-Study Interview } \\
\text { (Minutes) }\end{array}$ & $\begin{array}{c}\text { Post-Study Interview } \\
\text { (Minutes) }\end{array}$ & $\begin{array}{c}\text { Audio Diaries } \\
\text { (Number of Entries) }\end{array}$ \\
\hline Bob & 39.12 & 18.13 & 6 \\
\hline Chris & 40.40 & 31.36 & 8 \\
\hline David & 53.49 & 23.53 & 7 \\
\hline Lisa & 22.21 & 17.21 & 7 \\
\hline Mark & 66.01 & 25.41 & 8 \\
\hline Nick & 48.40 & 13.10 & 6 \\
\hline Ron & 41.03 & 26.07 & 6 \\
\hline Sarah & 45.32 & 15.25 & 7 \\
\hline Tammy & 23.53 & 19.47 & $M=7.4$ \\
\hline Vicki & 28.53 & 10.42 & 6 \\
\hline$N=10$ & $M=40.80$ & $M=19.99$ & \\
\hline
\end{tabular}




\subsubsection{Analysis process}

Parents' and athletes' pre- and post-study interviews as well as parents' audio diary entries were subjected to thematic analysis. In order to become immersed in the participants' data, transcripts were read multiple times by the researcher prior to the start of analysis. The inductive content analysis performed in this study followed the steps described by Sparkes and Smith (2014): step 1) immersion, where the researcher tries to become immersed in the data; step 2) generation of initial codes, where the researcher produces a long list of codes across the data set; step 3) searching for and identifying themes, where the researcher refocuses the analysis at a broader level of themes and tries to use a thematic map to help sort out the codes into their respective themes; step 4) reviewing themes, where the researcher tries to have a fairly good idea of what the different themes are, how they fit together, and their overall story. This fourth step consists of two phases. In phase one the researcher checks to see whether the selected themes appear to form a clear pattern. If the identified themes don't fit together, the researcher then tries to rework the theme, create a new theme, or relocate the extracted references to a more appropriate theme. In phase two the researcher tries to ensure that the themes represent the entire data set. At this point the researcher develops clear distinctions between identified themes, and decides whether some themes should be collapsed together. For example, within the present study, themes such as "Role Awareness" and "Conversation Awareness" were identified and developed as separate themes in order to demonstrate the relationship between reflective practice and various types of awareness that parents reported. In addition, a theme such as "Giving space" was removed and its references were integrated within the theme "Being patient and positive" in order to strengthen the overall story that is being told by the theme. The analysis then proceeded to step 5) defining and naming themes, where the researcher aims to identify the essence of each theme; and step 6) writing a report, where the researcher tries to provide a clear interpretation of the data (Sparkes \& Smith, 2014).

In the present study, the analysis began by transcribing parents and athletes' pre-study interviews. Once all pre-study interviews were transcribed, the researcher started the thematic analysis process by first analyzing athletes' pre-study interviews, followed by analysis of parents' pre-study interviews. The researcher then transcribed the parents' audio diary entries. Once all audio diaries were transcribed, the researcher continued with the analysis process by analyzing each parent's audio diary entries. Next, the researcher transcribed parents and athletes' 
post-study interviews. Once all post-study interviews were transcribed, the researcher continued the analysis process by analyzing athletes' post-study interviews followed by analysis of parents' post-study interviews. Thus, the analysis of the interview and audio diary data was an iterative process, moving back and forth between the different sources of data, adding codes and themes as they were identified in the transcripts. Furthermore, the researcher examined the data from post-study interviews and audio diaries of each dyad together. This allowed the researcher to better understand the process that led to changes perceived by each dyad.

Lastly, parents and athletes' surveys were analyzed and subscale scores were calculated to assess participants' perceptions of parental support and pressure, parent-athlete communication, and parenting styles. Parents' and athletes' pre- and post-study surveys were analyzed using Microsoft ${ }^{\circledR}$ Excel 2016. Survey data were first organized by their respective subscale, and were then entered into separate sheets for each dyad, resulting in the production of 30 Excel sheets. In lieu of a participant's missing entry for a subscale, the average of that subscale was calculated to replace the missing entry. In total, two values (openness subscale, parent entry, pre-study; and problem subscale, athlete entry, post-study) from the PACS questionnaire, two values (authoritarian subscale, parent entry, pre-study; and permissive subscale, athlete entry, pre-study) from the PAQ questionnaire, and three values (support subscale, athlete entry, post-study; support subscale, parent entry, pre-study; and pressure subscale, parent entry, post-study) from the PIAS questionnaire were missing. Graphs were used to depict differences between parents and athletes' scores and also changes from start of the study to the end of the study (refer to Appendix D). The researcher then reviewed the data for each subscale multiple times and discussed any developing patterns with the research supervisor who acted as a critical friend throughout this study.

As part of the analysis process, the researcher engaged in weekly discussions with the research supervisor. The research supervisor provided alternative conceptualizations and suggestions about interpretations of both qualitative and quantitative data. Also, diagrams and analytic memos were used to try and conceptualize the connections between themes. Furthermore, theories and findings from previous research were drawn upon in later stages of analysis to inform the development of themes and to guide the presentation of results. 


\subsection{Ethical Concerns}

Precautionary measures were taken in anticipation of any situations that could have posed a risk to the participants. For instance, parents and athletes were informed that if they offered any information throughout their participation that someone was at a risk of harm (themselves or a family member), this information would not be kept confidential and that it would be disclosed to appropriate authorities. Also, uncompensated time lost for completing the study was considered as a risk to the participants; therefore, participants were told about the approximate time required to participate before providing consent and before beginning the study. If participants experienced any stress as a result of their participation in the study, they were asked to contact the primary investigator and/or the research supervisor to discuss their feelings of stress (contact information for both the primary investigator and the research supervisor were included in the information letter). In addition, participants were free to withdraw from the study without any consequences. Lastly, discussing details of parent-child interactions could pose some psychological or emotional discomfort. Therefore, parents and athletes were provided with contact information for the following support services: Children's Aid Society, Center for Addiction and Mental Health, kids help phone, and parent helpline (refer to Appendix O).

\subsection{Study Rigour}

The methodological rigour of the study was strengthened through transparency, maximal credibility, and comparability (Given, 2008). First, participants were provided with a clear and precise description of the study. Secondly, participants were provided with a step by step instruction on how to use the audio recording device. Furthermore, participants were free to question the content of the questionnaires for further clarification. Weekly meetings were scheduled with the research supervisor, Dr. Katherine Tamminen - assistant professor at the University of Toronto - who acted as a critical friend throughout the study. Also, analytical and methodological triangulation was adopted to gain a better understanding of the investigated phenomenon (Sparkes \& Smith, 2014). More specifically, methodological triangulation refers to within-method and between-method triangulation (Wilson, 2014). Within-method and betweenmethod triangulation refer to the use of qualitative and quantitative methods of data collection. In the present study qualitative data were collected through interviews and audio diaries, whereas quantitative data were collected through surveys. Analytical triangulation refers to the use of 
inductive content analysis for data collected from interviews and audio diaries, and descriptive statistics for data collected from surveys. The researcher also kept a reflexive journal throughout participant recruitment, data collection, and data analysis helped to reflect upon the philosophical assumptions of the study and the researcher's attention on the three original research questions (Guba, 1981). In addition, member checking during post-study interviews allowed the participants to elaborate on their experiences from the study, and offer additional interpretation of the data. Member checking has been recommended by other researchers as a tool to enhance the rigour in qualitative research (Birt, Scott, Cavers, Campbell, \& Walter, 2016). Furthermore, member checking enhances the inclusion of participants in the research process, and provides them with the opportunity to offer their interpretation of the data (Birt et al., 2016). In the latter stages of analysis, the findings of the study were compared with the findings of other scholarly articles. Through this method of examination, the proposed research questions were answered by considering all aspects of the findings in relation to the previously published literature on parentathlete communication in sport. 


\section{Chapter 4}

Results

\section{Results}

This section outlines the results of the study informed by both qualitative and quantitative data. Analysis of both parents' and athletes' data resulted in the generation of three major themes which are presented in the following order: influence of reflective practice on parents' selfawareness, perceived changes in parent-athlete communication, and perceived changes in parenting style. The first part of the results will focus on the themes identified in the qualitative data, whereas the latter half of the results will cover the findings from the quantitative data. The first major theme regarding the influence of reflective practice on parents' self-awareness was supported by qualitative data only, whereas the other two major themes regarding perceived changes in parent-athlete communication and parenting style were informed by both qualitative and quantitative data.

\subsection{Influence of Reflective Practice on Parents' Self-Awareness}

Parents reported that reflective practice provided them with an opportunity to engage in a form of self-evaluation which in turn enhanced their awareness of their child, various aspects of their conversations, and their role as a parent. This section aims to provide answers to the first research question of the study which intended to investigate ways through which reflective practice might influence parents' self-awareness of their own communication behaviour.

\subsubsection{Self-evaluation}

\subsubsection{Self-awareness and communication behaviour}

Parents described that as a result of engaging in reflective practice, they started to self-evaluate their communication behaviour. For instance, Chris said:

Because of the study like I said before I got more conscious, my awareness increased, I actually started reflecting back not just in the past few weeks or months, but years, things I have done when she was under seven under eight, so going back eight nine years. I think it has definitely changed my mind [and] my perspective. Sometimes I think I feel sorry that I acted the way I did, .... I think I definitely wanna make a conscious effort to 
improve, I'm sure there is lots to improve on my side, and sometimes I think I can put two and two together to see how my son or daughter reacted, I did not understand at that time why the reaction was that, now that I think back, and now that I understood a bit more because of the study I realized that things could have been done better. So as a better parent, I think I know now to be a bit more conscious and I'm really hoping that down the road, in the coming season and seasons to come it definitely makes me a better parent I hope. (Chris, Post-study interview)

Likewise, in his post-study interview, Bob described how the practice of self-evaluation as a result of the reflective practice process increased his self-awareness. He stated:

I think it creates more awareness on how you communicate, you know how I communicate with my son after games. It's because going through the questions that we had to ask and you're talking about feelings and you're drawing from your own experiences, I think it creates more self-awareness and I think as a parent you always need to be cognizant of what the message is you're trying to get across to your son or daughter. (Bob, Post-study interview)

The statements made by Chris and Bob highlight how the step by step process of Gibbs' reflective cycle helped to increase parents' awareness of their communication behaviour through self-evaluation. For example, Chris's statement reflects the evaluation and analysis steps of Gibbs' reflective cycle, while Bob's statement reflects the feelings step of Gibbs' reflective cycle. Similarly, Tammy stated that reflective practice made her more aware of her communication with her son. She said "I liked that it made me actually reflect on my conversations and made me more conscious of how I interact with Tyler after games for sure" (Tammy, Post-study interview). In her post-study interview, Lisa described reflective practice as a "psychology checker" for parents. She said "I mean it's basically for the parents right, I had to be more reflective on how I behave both in speaking and mannerisms. It was like a psychology checker I guess for me" (Lisa, Post-study interview). Lisa also mentioned that as a result of her continuous reflection, she was more patient with her son as he was attending trials for the provincial team and trying to achieve athletic scholarship to a university. She expressed:

I was then more intense, more like an obsessed parent, right? I guess I realized I shouldn't take things so seriously like, even though he's a high-level athlete and you know we have, 
we have you know provincial trials and we're gearing up for scholarship mode it's like, you know I had to like step aside and say you know 'he's only 15.' (Lisa, Post-study interview)

In addition, reflective practice seemed to help increase parents' emotional awareness. Bob explained how his participation in reflective practice helped increase his awareness of his emotions and realize the impact of prior experience on his communication. He reported:

Sport can be a very emotional, I can be very emotional and sometimes you'll overreact and I think with this study you keep yourself in check. You have to reflect and you have to look at what message you're conveying and look at prior experience and how that has an effect on the message that you're conveying to your son. Whereas before sometimes you might not think of that and the message may not be as positive so I think going through these questions and going through the audio diaries, it makes you more aware of your son, first off, and makes you more aware of how your own experiences affect how you communicate with your son. (Bob, Post-study interview)

Also, through self-evaluation some parents seemed to become more aware of potential consequences of negative communication behaviour. For instance, Lisa said:

You know when Luca talks sometimes if he's feeling bad, he just spins and turns negative like right away as soon as we get in the car and then I just can't get angry right, so I gotta stop myself from getting angry, take a deep breath and say this is about him, don't react because if I get angry then it just escalates everything. (Lisa, Post-study interview)

Similarly, in an audio diary entry, Chris stressed the consequences of negative communication behaviour by stating:

At the end of the day, me getting angry or asking [Chloe] questions in a heated way is not gonna encourage her to give me the right answer or the full answer; she may even hide things from me, or just completely shut down and not talk to me at all. (Chris, Audio diary)

The statements made by Lisa and Chris demonstrate how they actively evaluated and analyzed all aspects of their communication through reflective practice and Gibbs' reflective cycle. They 
not only focused on the importance of positive communication behaviour, but also paid more attention to how detrimental negative communication behaviour can be.

\subsubsection{Creating a habit}

Additionally, parents reported that the use of audio diary as a form of reflection created a habit which in turn led to more awareness of their communication. For instance, Bob said:

I would say it creates a habit, it creates more awareness too. So as a parent I think you have to be more self-aware of how you're communicating with your son because going through the audio diaries - it's the reflection - makes you more aware of your communication style and the message you're trying to get [across]. (Bob, Post-study interview)

Likewise, David commented on how the consecutive format of the audio diaries helped him in creating a habit of reflection. He said:

I don't know if short-term probably long term yeah probably long term because I do have option, like you form a habit of reflection of thinking .... probably the first second time when you do the audio diary you don't realize but by the by the fifth or sixth it's always like become a habit right. (David, Post-study interview)

\subsection{Parent Awareness of Child's Development}

\subsubsection{Awareness of child's maturity level, capabilities, and personality}

As a result of engaging in reflective practice, parents also appeared to become more aware of their child's maturity level, their capabilities, and their personality. For instance, Ron stated that the process of self-reflection helped him understand how strong his son is. He said "It also helped me to understand my kid a little more, how strong he is mentally" (Ron, Post-study interview). Ron also commented on how one's parenting style differs at various stages of development due to the child's maturity level:

I look back and there is a little bit of a difference. There is much more guiding at 13 [years old] like at 13 as supposed to 15 because [Ryan] is more of an adult you know, his 
brain .... is a little more mature you know he understands a little more how things work that kind of thing. (Ron, Post-study interview)

In addition, in her audio diary Tammy explained her observations about her son and how playing with different group of players enhanced his confidence:

Conclusion is that he's getting a lot better at sort of looking after himself and being able to blend in with new groups of players and I think he's developing more confidence. I think the more times he does this, like you know the provincial projects, [and] playing with different groups of players, he just gains more confidence each time .... and I always feel very proud of him I would say. (Tammy, Audio diary)

Thus, parents appeared to have a better understanding of their child's maturity level and personality. As a result, parents may have felt more comfortable in providing their child with more opportunities to make decisions and solve their own problems.

In addition, Mark also realized through the process of engaging in reflective practice that his daughter Melissa liked to engage in debates and discussions after her games:

This is another thing that I noticed - that made me think about it a little bit more - is that I think Melissa is type of kid who .... doesn't mind debating certain components of what happened and talking about some of the things that happened, she likes to stand up for herself and sort of explain it to you. (Mark, Post-study interview)

Mark further elaborated on how having a better understanding of her daughter's ability to discuss certain components of her performance resulted in an open and two way communication between him and Melissa:

I like to hear her talk because I'm thinking of things in a certain way, and she is thinking of things another way, and to me it's a real positive when I hear her talk, like if I'm thinking about something, like why did that go that way, or why did you do that, I find that she is very good at explaining it and in fact her explanation makes me feel better. And secondly I find that she is actually got very positive feeling and confident feeling about herself. (Mark, Post-study interview) 
Thus, it appeared that through engaging in reflective practice, parents gained a better understanding of their child's maturity level, capabilities, and personality. Furthermore, due to having a better understanding of their child's maturity level, parents may have decided that it was the right time in their child's development to provide them with more autonomy and decision making opportunities.

\subsection{Role Awareness}

\subsubsection{Acting as a sounding board}

In addition to increasing parents' awareness of their child, parents reported that through reflective practice they became more aware of the specific roles that they played as a parent. For example, parents described that they often acted as a sounding board for their child, where their primary role was to listen and validate their child's point of view, regardless of whether they agreed or disagreed with them. For instance, in her post-study interview Tammy said:

So listening is probably most important part of the communication, not the talking I guess. That's what I would probably say coming out of this, especially if it's after one of those tough games, it's really just being a sounding board and letting them vent or sometimes validating the way it feels. I think helping them feel confident like encouraging them and just I don't think praise is the right word but letting them know how proud you are of them really I think can bolster the way kids feel. (Tammy, Poststudy interview)

Likewise, Ron said during one of his audio diary entries:

I think I've been doing a really good job of being more than a dad but a friend in these situations to help be a sounding board but also be positive and show him that he's on the right path and on the right track. (Ron, Audio diary)

In addition, Tammy commented on how she was consciously monitoring her communication behaviour and made a conscious effort to speak less and listen more as a result of engaging in reflective practice. She stated:

My instinct was to be probably quite critical but this [study] did make me think 'okay why would you do that, like, you have to chill out' .... I think it made me much more 
aware of the things I say and what I focus on after and why I'm saying it .... I think most the time you really play a big role in just boosting their confidence, being a sounding board and letting them vent. So it made me just sometimes go like, zip it, when my instinct is to talk. (Tammy, Post-study interview)

Tammy's comment was also supported by one of her audio diary entries, which provided an example of a situation where she acted as a sounding board for her son Tyler after his soccer team lost their game. She said:

I don't think there was anything bad about the experience or the chat, I think he needed like I say to vent, so I kinda was just a bit of sounding board and again, as I say, a bit of a validator in terms of how we saw things. (Tammy, Audio diary)

It was also evident that being a sounding board for the athlete also makes the car ride home more enjoyable. For instance, Lisa said "It was a quiet ride home so I didn't drill him with too many questions because I know that's what sets him off. So I played a listening role and the thirty minute ride home was pleasant." (Lisa, Audio diary)

\subsubsection{Playing a supportive role}

Increases in parents' self-awareness through reflective practice also led parents to play a supportive role when and where it was deemed necessary. For instance, Sarah described a situation where she played a supportive role by taking her daughter and her friends out for ice cream. She said "The kids were getting close to the last part of the season and they just wanted to relax and they've been having a lot of stress with the changes and everything so I was happy to take them" (Sarah, Audio diary). She also elaborated on how she felt it was part of her role as a parent to encourage her daughter to stay positive and calm despite going through a challenging time. She stated:

She's a little all over the place and she's worried probably about the next steps for her but it is my job to tell her to keep calm, to give her best and to enjoy every day that she's at soccer because if she enjoys it she will get the best outcome possible. (Sarah, Audio diary) 
Nick also indicated that he provided support to his son Noah by trying to turn Noah's negative outlook into something positive. Nick commented

For him like after the game .... I just try to listen to what his frustrations are and then try to turn it back into a positive or maybe kind of give him some different way of looking at it. (Nick, Post-study interview)

Tammy also said in an audio diary entry that she provided support by letting her son Tyler know that the loss was not all his fault and that there were other players on the field who might have contributed to the loss as well. She said, "I felt that he needed a bit of support and just encourage him to feel better and realize that, you know, there is eleven players on the field not just him" (Tammy, Audio diary). She later added "So, our conversation after, I would say, was letting Tyler vent a little bit and I would say again .... just trying to be supportive and make him feel better about the outcome" (Tammy, Audio diary).

These quotes suggest that there are multiple ways that parents provided support to their child. Parents can provide support by trying to change their child's outlook on a certain situation, listening to their frustration, or presenting them with a small prize (i.e., ice cream) for their continuous hard work. Bob also commented on the way he provides support to his son Brandon after he joined a higher level hockey team: "We just wanna emphasize with him that it's important regardless of what you do, it's always important to work hard and compete hard and understand that we're there to support him through this whole process" (Bob, Audio diary).

\subsection{Conversation Awareness}

\subsubsection{Timing of the conversation}

Reflective practice also increased parents' awareness about various aspects of their communication. Parents reported that they were more conscious about choosing an appropriate time to discuss certain topics with their child. For instance, Ron said:

I thought he could always handle me being a little more aggressive in my conversation but I started to see he needed downtime after games especially. The games were more intense and he needed a little more [time] .... so I had to learn to stay away from that especially when you're driving an hour away. (Ron, Post-study interview) 
Chris also elaborated on how reflective practice helped him in having a conversation at the right time with his daughter Chloe. In his post-study interview Chris said:

One thing I did find is that it actually made me think, I think as parents, we're so used to certain ways, this [study] actually sort of made me take a step back and think [about] what I'm saying and how I'm saying, and sometimes I realize that 'ok you know what, maybe I wasn't even watching what I was saying, and maybe the time was inappropriate.' Definitely at least for me I can tell that if this study didn't come along, I probably would just continue doing what I was doing. (Chris, Post-study interview)

In addition, Chris believed that he still was able to voice his opinion about his daughter's performance but that he was more conscious about choosing an appropriate time to have that discussion with Chloe. He said:

I've always believed in very open and blunt communication no matter who it is in the family, but I think it has made me a bit more cautious may not be the right word, more aware of when to say it. I mean I still will say what I had to but maybe at the right time, maybe at a later time. I mean I've always believed in giving feedback, so if I saw something on the pitch that I want her to improve or I didn't like or I didn't appreciate, I will tell her regardless, but maybe the timing and this is the biggest thing I have learned through the study period that timing is everything. It has to be at the right place, at the right time and I think that's the biggest mistake, I as a sport parent [made], I just blurred it out and not realized that you know she is - after a two hour practice or two hour game and what goes through her mind, the adrenaline rush, may not be the first thing she wants to hear from me. But until she has come down and you know she is more receptive to hear feedback, give it at that time .... I would say that now I'm more conscious and giving the feedback when I think the timing is better. (Chris, Post-study interview)

Chris elaborated on how different components of the study, such as the interviews and audio diaries, increased his awareness of his communication with his daughter:

As we started having conversations, I was talking to you and I started doing the audio diary, I think the awareness was more and as I would do audio diary or even during our interviews before, it actually made me think back and I found that when I was talking to 
[Chloe] on the way back, I was subconsciously being conscious, if that even makes sense? It's like I know that I wanna say a lot of things, but hold on, does she really wanna hear this right now or let's see if she has anything to say. I mean she was on the pitch for two hours, I would be interested to know what she had to say. I mean this was really quite interesting how a single study can have an effect like that. (Chris, Post-study interview)

These statements highlight how reflective practice increased parents' self-awareness about the timing of their conversations with their child. For these parents, it was not necessarily the content of the discussion that needed to be changed but rather considering their child's emotions and feelings was important so that a conversation could take place at an appropriate time.

\subsubsection{Being patient and positive}

Besides being generally supportive, parents also stated that they were more patient and positive in their interaction with their child. For instance, in one of his audio diary entries Bob commented on being patient and positive with his son as he just started to play hockey at a higher level:

We continue to have talks with Brandon and we continue to be to very patient and try to emphasize some of the good things he does in games. We also realize that this is a growing year for him and that it's going to take some time to adjust and play at this level. (Bob, Audio diary)

Bob later on in his post-study interview commented on how the study helped him understand the importance of positive communication:

I thought it was good because it makes you kind of reflect on what you talk about after game and how you phrase certain things and look at how you communicate. I think it's really important to be able to get [your message] across in a positive way and it helps you self-reflect too on how you might deliver that message in a positive way to empower your son. (Bob, Post-study interview)

Similarly, Tammy, who is also a coach herself, talked about how she felt that she needed to be positive with her son and his teammates after they lost a game towards the end of their season: 
So felt like I had to kinda point out the positives, make him feel better, try to encourage them, try to tell them they played well, just to try and make them feel better and just comfort them over the loss. (Tammy, Audio diary)

Moreover, Lisa described one of the lessons that she learned from participating in reflective practice:

What have I learned from all these sessions? I've learned that I shouldn't be the interrogator, I shouldn't give my opinion, only when it's asked; but I think sometimes he has to see a different perspective. I should have patience when he's over critical and try to I guess steer it in a positive direction so that's something I have to learn. (Lisa, Audio diary)

In her post-study interview, Lisa elaborated on the lesson that she had learned:

I think that the parent would be the first line sport psychologist for the kids in a way right, because .... the parents are the people that the kids turn to first to talk to so I guess it should be a positive experience. So [I have to] be more patient and receptive of his ideas even though I think they're silly and the way he reacts to things. (Lisa, Post-study interview)

Besides being patient and positive in their interaction with their child, parents also reported that they were more aware of when their child needed some space after a practice or a game. More specifically, they viewed giving space as a form of being patient in their interaction with their child. Ron illustrates this point in his post-study interview by stating:

I think parents have to understand, sometimes the problem is we have a bad day at work and then we come home angry and they're saying something and we snap at them, but it's similar for them after a bad game or something didn't go well, they don't want to talk about it but we don't put ourselves in their shoe sometimes .... so I think this [study] helps make [parents] more acutely aware a little that you got to give them their space as well. (Ron, Post-study interview) 


\subsubsection{Being an active listener}

Reflective practice also increased parents' self-awareness such that parents became more of an active listener in their daily interactions with their child. Sarah commented on how reflective practice made her pay more attention to her daughter's non-verbal communication behaviours:

It made me more aware of what I was saying .... I always listened to her but I probably wasn't paying that much attention to her non-verbal communication, or maybe not every time. With this exercise every time I drove her to practice or picked her up I was trying to focus on what she had to say about the practice and try to probably ask some questions. (Sarah, Post-study interview)

Furthermore, in the last stage of Gibbs' reflective cycle parents were asked to think about what they would do differently in the future to improve their communication with their child. Mark commented on how he plans to ask more questions from her daughter Melissa. He said:

Basically that will be I think the lesson in terms of personal action plan going into the future, just to think a little bit more about how to approach the conversation and again one of the things for sure is if I want to engage in a conversation about the practice maybe ask questions and have my daughter tell me her thoughts while I get to listen to her speak about it but not necessarily putting my views on top of that. (Mark, Audio diary)

In this quote, Mark can be seen describing elements of the personal action plan stage of Gibbs' reflective cycle, relating to plans for improving communication, and taking new steps on the basis of what he has learned.

\subsubsection{Thinking before speaking}

In multiple accounts from parents it was clear that as a result of engaging in reflective practice, parents were more inclined to think about what they wanted to say before they conversed with their child. For instance, Tammy said:

I feel like it's made me think more, whether or not [Tyler] feels like it's changed our conversations more, I don't know. From my perspective though I think it's improved because I think I'm trying to think more before I speak. (Tammy, post-study interview) 
Similarly, Mark spoke about how he plans on keeping the conversation positive without necessarily hiding the way he feels. He stated:

Basically I think for me .... I don't think I'm ever gonna be able to change in terms of just feeling great or not letting some of the things bother me at all. But I think I can definitely learn to sort of think before I talk and think about what I'm gonna say and how I'm gonna approach that. (Mark, Post-study interview)

As well, Chris elaborated on how reflective practice forced him to take a step back and think about what he wanted to say to his children. He summarized his thoughts as follow:

I think it made me think twice sometimes when I'm talking to [Chloe] .... I think myself included we do it wrong and I think because I personally have never gone through any competitive sport, I don't really know what it means to be on the pitch and to go through what my kids go through. This [study] forced me to take a step back .... because I had to keep thinking you know look back, and focus on the recent conversations I had, I think it's made me and will continue to make me better. (Chris, Post-study interview)

Overall, parents described several ways in which engaging in reflective practice helped them to become aware of and change the content and timing of their conversations with their child, as well as being an active listener, giving their child space, and thinking before speaking.

\subsection{Perceived Changes in Parent-Athlete Communication}

The second research question in this study concerned whether increases in parents' awareness of their communication would lead to perceived changes in their communication behaviours. In this section, three subthemes were identified in the analysis of parents' and athletes' data: perceived changes in parents' communication behaviours, changes in preparing the athlete, and changes in reactions to mistakes or bad performances.

\subsubsection{Perceived changes in parents' communication behaviours}

\subsubsection{General changes and conflict resolution}

The majority of the athletes highlighted some positive changes that they perceived in their parents' communication. For instance, Ryan described how he perceived his dad's 
communication behaviour had changed as a result of his participation in reflective practice. He said "I just enjoy the fact that he's just supportive of me and he doesn't over criticize or analyze any of the situations" (Ryan, Post-study interview). Similarly, Noah, an elite hockey player, talked about how he thought his dad's communication behaviour changed in a positive way: "He's nicer, he doesn't get like mad right at the beginning, he tries, he asks how I think I played or what I did and how I could change it, and stuff like that" (Noah, Post-study interview). Likewise, Brandon mentioned that he perceived positive changes in his dad's communication behaviour following his participation in the study:

I like the directness I guess .... it was more feedback than he had before on like how I can do better than I was on the ice. Yea I think it's more like supportive and direct and the way that he communicates is better now. (Brandon, Post-study interview)

Chloe also described that she perceived her dad to be more interactive with her, despite the fact that she is quite closed off. She said:

I think he was trying to talk to me more, 'cause' I don't really like to talk about my feelings and stuff, I'm very closed off .... but he was trying to talk to me more, ask me more questions, how I was feeling, and like took my feelings into account more I guess. He actually understands why and he tries to put, I guess, himself in my shoes. (Chloe, Post-study interview)

Moreover, Melissa perceived that her dad was more conscious of what he was saying. She expressed: "Maybe like, now he be more like, conscious of like, what he was saying and how it affected my playing" (Melissa, Post-study interview). However, as she provided a more detailed description, it was clear that she didn't perceive many changes in her dad's communication behaviour outside of sport. She said:

Not including soccer, it's probably the same, and then including soccer it's probably changed like a little bit because he's been more like I said before, conscious and he kind of is probably thinking about it more. (Melissa, Post-study interview)

While the majority of athletes reported some positive changes in their parents' communication behaviours, some athletes said that they perceived negative or no changes in their parents' 
communication behaviours. For example, in some cases athletes reported that their parents maintained their positive communication behaviour throughout the study period. For instance, Victor said: "Nothing has changed, she's always been in a positive manner so it definitely hasn't changed. And [she] just always encourages me to get focused and into the zone" (Victor, Poststudy interview). In addition, some of the athletes' accounts revealed that they perceived no changes or negative changes in their parents' communication behaviour. For example, Luca illustrated this by stating that his mother had not changed her communication during games:

Sometimes in the middle of the game, she could kind of be annoying. Like she keeps on screaming, say the ball is all the way across the field, she's screaming to go get it, and like I have to run all the way out of my position to go get it, that's what she tells me to do. (Luca, Post-study interview)

Parents also commented on perceived changes in their communication behaviour. For instance, Chloe's dad, Chris, described how he felt that his tone had changed as a result of engaging in reflective practice. He said:

Tone, absolutely. Because of the wait, now I am also not as hyper or excited or angry, I have calmed down, and it has given me the opportunity also to reflect back and think and I'm not shooting from the hip anymore, it's not a knee jerk reaction anymore. Now that I also have time to come down and think, the messaging is better, the way I could've said something when I'm angry or upset or frustrated whatever it may be or even excited, even when I'm happy or even when I'm sad, the messaging may not be appropriate or right but with the time to calm down again both from the high of the happiness or the depression of the sadness, I think the messaging has definitely improved, definitely so. (Chris, Poststudy interview)

The above statement by Chris illustrates the connection between reflective practice and perceived positive changes in parents' communication. More specifically, through reflective practice, parents understood the importance of choosing the appropriate time to have a conversation with their child which led to parents acting calmer and communicating their message in a more positive way. 
In one of his audio diary entry Chris also elaborated on how such a positive change in his communication has influenced his car ride home with his daughter Chloe:

Personally, I think before I used to get annoyed or irritated very quickly if we were losing but overall over time, you know, to see that the players have grown, their personal growth, the team's growth, I think it has calmed me down a little bit. We have sort of ended up becoming a cheerleader more than trying to be a coach on the side or even when we go back home, in the car is a positive conversation irrespective of the outcome of the game. And I think overall it's been a positive change from when we started and how we are now and I think is just fantastic. I personally feel happier coming back after a games, again irrespective of that we lost, or won or tied and I think my daughter also now enjoys it, considering it's no longer a conversation she would try to avoid before. (Chris, Audio diary)

Nick also talked about how he was more of a facilitator of the discussion with his son rather than being the producer. He said:

I'm trying to ask more right, so I'll ask more like what do you think you did, or how do you think that game was and then once I see what his feedback is then I if I think there's something to offer I'll offer, if I don't think there's anything to offer, I'll just stay silent and go okay. (Nick, Post-study interview)

Furthermore, Nick talked about how he was trying to communicate with his younger son Nathan in the same way that he communicated with his older son Noah. He said:

So my communication with [Nathan] I'm gonna change, well working on changing, 'cause' I want it to be more like it is with [Noah] 'cause' now we more talk about the successes and failures or or areas that he needs work on instead of me telling him that he needs to work on those areas or telling him he failed or you know, I'm more of a cheerleader for him than a than a you know, 'you keep screwing up you're not doing this right,' right so I'm just that's what I'm trying to be more for [Nathan]. (Nick, Post-study interview) 


\subsubsection{Changes in parents' communication behaviour before, during, and/or after sporting events}

Parents and athletes also commented on specific changes that they perceived in their communication either before, during, or after trainings and games. Vicki commented on how she perceived the car ride home changed as a result of her participation in reflective practice:

Because of the whole recording and saying my personal goals after like, 'I'm going to let him speak first, I'm going to let him sort of tell me what he wants to talk about' I think that changed a little bit 'cause' I wasn't really, I don't, I mean I am a hockey mom, I understand everything but some of the stuff I just go over my head and I wouldn't even ask him about it, he would just be tired, and he would stop talking. But if I let him talk, he started it so I would just follow his path. (Vicki, Post-study interview)

Similarly, Vicki talked about how she was more patient to start a conversation with her son Victor. She said:

I would jump right in there right after the game, this was even when we were walking out, you know, 'hi how do you feeling? you okay?' what it made me do change is I got into the car I waited a few minutes maybe waited for him to start the conversation and then I would say [something]. (Vicki, Post-study interview)

Lisa reported that as a result of her participation in reflective practice, she decided to change her non-verbal communication. She said, "Well I don't think I'll be pacing up and down the field when he's playing, because I'm sure he notices that" (Lisa, Post-study interview).

Also, when Nick was asked about which portion of his communication he thinks has changed, he described the influence of reflective practice on his post-game communication with his sons Noah and Nathan. He said:

The after, right, so not as hard on him as I was probably prior 'cause' every time I think about saying something I think about this project so it kind is like a check and balance right? So makes me think 'okay maybe I need to change how I communicate with him' and I've noticed a bit of an improvement in, one, how we communicate and two, how he he is. Don't get me wrong, I still revert back to my old ways but I'm trying not [to] with 
him specifically [more] than I do with Noah right? So I'm trying to change my behaviour with how I communicate with [Nathan] slowly. (Nick, Post-study interview)

Tammy who is a high performance coach herself, commented on the changes that she perceived in her post-practice and post-game communication with her son Tyler. She said:

I think I'm a very verbal person as it is, I think we all talk a lot in our house we have we always had lots of chats. I would say it did affect more so little bit my post-game and practice, like I said it made me more conscious of what I was saying and maybe zip my mouth a little bit more sometimes if my inclination might have been to say something critical or to ask 'why were you so wide when the ball was central?' I'm trying to do less of that so it changed that part of it I would say. (Tammy, Post-study interview)

Chris also commented on how the change in his post-game communication with his daughter Chloe led to a more open and two-way communication with her regardless of her tendency to be quiet and closed off. He said:

Well, we had the car ride back from the practice, so we did all post-practice, and again usually, you know, I would just go on a barrage of complaining but this time it was more listen to her what she has to say, and I found actually interestingly if I keep quiet or speak less she actually opens up and speaks more, and which was quite interesting and was a very nice positive change. It really showed that you know she actually can talk if she wants to, it's whether if I want to give her the opportunity and if I'm willing to listen. That was the biggest eye opener for me. (Chris, Post-study interview)

Lastly, Lisa commented on how reflective practice positively influenced all aspects (before, during, and after) of her communication with her son Luca. She described:

Well I think they all they all changed 'cause' before I kind of helped him get into a positive mind frame, and then during I was kinda just sat in my chair and didn't impose you know my presence right? So just let him experience what he's experiencing and then and then after I was just, I just let him lead the conversation rather than me criticizing things that he did wrong during the practice. (Lisa, Post-study interview) 
In addition, athletes also commented on the changes that they perceived in their parents' communication behaviour throughout their involvement in reflective practice for six weeks. For instance, Brandon perceived that his dad Bob was more focused on him rather than the team during their car ride home from a game or a practice. Brandon said, "I guess it might have made him more targeted towards myself and not as much towards the general aspect of the game so I guess he's been focusing on me a little bit more" (Brandon, Post-study interview). Chloe also perceived that her dad's communication behaviour during games and practices had changed:

During games and practices, he's very busy, so like usually he's either talking to the parents, or which I appreciate, he's not taking on a manager role more like talking to coaches and or like a board member, he is acting like my dad, he's socializing with other parents, and talking, talking honestly, and I think that gives me some support because I know that he won't just be there for me as a manager or as a board member when it comes to me playing soccer. (Chloe, Post-study interview)

However, Chloe also highlighted that she did perceive a negative change in her dad's post practice and game communication. She stated:

Before I think it has improved, during definitely, like he's taking, he stopped acting more like a manager, which I talked to you about before in the first time, but after I don't think that it's changed. After it's, I don't think it's because of the research but it has gotten worse, I don't know if it's the stress from the tryouts or something but like I do feel like he's been more cold after practices than normally. (Chloe, Post-study interview)

In this case Chris might have been silent on the car ride home to provide Chloe with the opportunity to start the conversation, and express her point of views. However, Chloe perceived her dad's action as distant rather than supportive.

\subsubsection{Changes in preparing the athlete}

Parents also commented on some of the specific changes they made in preparing their child for a sporting event. To illustrate, Tammy said "I probably tried to say less, like I say, I try not to say a lot anyway when he's going to play, I probably tried to say even less" (Tammy, Post-study interview). Similarly, Ron mentioned "The only thing I changed I think we just I tried to stay 
consistent in the two way conversation, I didn't want to lose that I think that was up here that's what I was trying to do" (Ron, Post-study interview).

Furthermore, Lisa mentioned that she decided to focus more on the positive consequences of a certain behaviour rather than highlighting the negative consequence of not engaging in that behaviour. She said:

I instead of trying to get him to understand the importance of the situation I would use like you know 'if you do this' - on the early days I would try to use the negative consequences if you don't do something and then through this process I realized you would probably get more get him to understand better or receptive to what I'm saying if you tell him the positive benefits of doing something instead of the negative consequences of not doing something. (Lisa, Post-study interview)

\subsubsection{Changes in reaction to mistakes or bad performances}

Parents reported that they reacted differently when their child made a mistake during a game or did not produce a strong performance. For instance, Bob said:

I think you know, with this study, when he didn't perform that well or he didn't play to you know the best of his ability, I think going through this whole process makes you, I think it creates more awareness, and I think I was little more patient with the whole process. And whereas before, I'm pretty patient, but whereas before you, you might not be as patient if you didn't go through this whole process and self-reflect and look at the look at, you know, the specific message that you're, you're conveying to Brandon. (Bob, Post-study interview)

Tammy also said that she is trying to be less critical of her son's performance. She said:

My inclination is still to go like 'oh what were you doing that?' and then to wanna talk to him after, yeah, I think from now on I'll probably be, I'll police myself more, I think I'll try not to point those things out. (Tammy, Post-study interview) 
Chris also illustrated that even though he still feels frustrated after watching his daughter make a mistake, he was more conscious of expressing his frustration at a more appropriate time. He described:

No, I mean I still got upset, I think the difference has come in on how I convey the message now. When she makes a mistake on the field or she does something wrong, I still get upset immediately, I mean I'm human I'm being honest; however, before I would probably as soon as she gets in the car, even walk from the pitch to the car, I would let loose the tab. Now is slightly different. I mean I'm still upset, but maybe you know it's later on in the evening, or following day or maybe a different approach. 'How do you think the game went?' and if I see her more receptive of acknowledging her mistake then try to encourage her that 'ok you made a mistake, no problem. What do you think you can do better, or what do you think you wanna do?' rather than 'what the hell were you thinking?' kinda thing, and definitely it has changed. (Chris, Post-study interview)

\subsection{Perceived Changes in Parenting Style}

The third research question of the study aimed to investigate whether reflective practice and increased awareness of parent-child communication would lead to perceived changes in parents' parenting styles. In this section, two subthemes were identified in the analysis of parents' and athletes' data: changes in parenting style, and spillover effect.

\subsubsection{Changes in parenting style}

\subsubsection{Enhancing child autonomy}

Parents reported that through their experience of self-reflection they realized that they should take a step back and provide their child with opportunities to make decisions and enhance their child's problem solving skills. For instance, in his post-study interview Ron said:

It just made me more acutely aware as I was doing [the audio diaries] that I should just let him kind of go. I didn't wanna be breathing down his neck and I don't think that's right anyways as they grow up, you don't need parents over your head. He's my son, I want to make sure he's happy and he's comfortable and I want to make sure when I talk to him it's 
bigger than just soccer so I want to make sure that I give him the opportunity to speak, [and] give him the opportunity to make his own mistakes. (Ron, Post-study interview)

Similarly, Nick stated "I sometimes instead of just always pushing I need to step back and let them tell me what they want [or think]" (Nick, post-study interview). It appears that through selfreflection parents understood the importance of autonomy for their child, and as a result they decided to limit the extent to which they imposed their own point of view on their child. In addition, Tammy noted that through self-reflection she came to realize that her and her son Tyler might not view certain things the same way, and therefore she needed to let him be the one who makes decisions regarding his sporting involvement. Tammy said:

I think it's that I'm still, I don't know if control freak is the right word, maybe it is, I still when I watch certain things and I don't see things done to a certain standards, I think it still bothers me. But I find in our conversations the things that bother me don't bother him. So I gotta learn that those are just my own issues and to let him kinda be I guess the master of his own ship sort of speak. (Tammy, Audio diary)

Parents highlighted some of the changes that they perceived in their parenting style as a result of engaging in reflective practice. For instance, Mark said, "I tried, I definitely tried to change my parenting style a little bit, like I tried to be a little more conscious of it and try to be little more positive" (Mark, Post-study interview). Likewise, Vicki talked about a change in her style of parenting in order to provide more autonomy for her son Victor: "It helped me a little bit just to sometimes stand back and let Victor speak first instead of trying to [put it together] for him or solve it for him right away" (Vicki, Post-study interview). As well, Lisa said "Well it made me more, made me think about what I should do as supposed to just go into what I'm usually used to doing, think twice about it." (Lisa, Post-study interview)

Athletes also commented on the changes they perceived in their parents' parenting style following their participation in the study. Noah described the change he perceived in his dad's style of parenting as: "He wouldn't get mad right off, like sometimes me and my brother do something, he gets mad like right at the start. He'll try and he won't get mad right at the start, he'll just ask nicely or say something" (Noah, Post-study interview). As well, Chloe said: 
So I'm applying for the advanced placement program and so I think that my parents want me to get almost a $90 \%$ above so if I get even like an 89 or like my average doesn't meet 93 I think it was, then they would get mad at me and they'll like start questioning if I should be even playing soccer but like now I think he doesn't do that as much, he is better. (Chloe, Post-study interview)

In some cases athletes reported that they perceived no change in their parent's parenting style. To elaborate, Victor said "Nothing has changed, she's always, she's always been in a positive manner so it definitely hasn't changed." (Victor, Post-study interview)

\subsubsection{Spillover effect}

Some parents discussed their plan to change their style of parenting towards not only the child who was part of the study but also towards their other child(ren). For instance, Chris stated:

Like I said, the awareness on my side has improved, and I think this will help as the new season starts and not just for my daughter, I mean for my son also. I think it may not be an instantaneous change but I think it definitely has an effect on me for definitely a long term change. (Chris, Post-study interview)

In another case, Tammy mentioned that she wished she could go back a few years and change her parenting practices towards her older child, Tina. She said:

Tina who's you know now almost 18 sometimes I like with her I could be critical at times, I kinda wish with her I could go back a little bit and just lay off sometimes but she's very different kid, sometimes she needs a push. Even at that, I think I've realized you can't do it's got to come from them. (Tammy, Post-study interview)

Furthermore, Nick described that he is not planning on changing his parenting style towards his older son Noah. However, he mentioned that due to increased awareness of his communication behaviours, he was planning on changing his parenting style towards his younger son Nathan. Nick said "No, well not with Noah no, with Noah no. With my younger one [Nathan], it's getting me to change a little bit, yea, slowly" (Nick, Post-study interview). Additionally, he stated: 
I'm far more aggressive with him [Nathan] in my communication right? So pushing him, telling him he needs to work harder more where with Noah I'm just more of a sounding board and then I would reflect, make a statement say 'hey maybe you just need to work a little harder, keep trying' right? Where with my other son [Nathan] I'm continually on him. (Nick, Post-study interview)

He later on talked about the lesson that he has taken away from his participation in the study. Nick expressed "So for me I would say what I've taken away from this is that I need to make sure that how I'm communicating with one is the same as I'm communicating with the other." (Nick, Post-study interview)

\subsection{Quantitative Findings}

The following sections present the findings from the quantitative portion of the data. Within the present study, quantitative findings further build on what was found from the qualitative portion of the data. Pre- and post-study means and standard deviations for each subscale are reported for both parents and athletes. In addition, Appendix D consists of graphs that illustrate changes in parents' and athletes' quantitative data for all three subscales at times 1 and 2 . Due to the small sample size and the single-subject design, statistical analysis of the group scores was not appropriate; however, a summary of the results is provided below.

\subsubsection{Parent pressure and support}

Parental pressure and support was measured through the Parental Involvement in Activities Scale (PIAS) questionnaire (Anderson et al., 2003). Overall, athletes perceived less pressure and more support at time $2\left(M_{\text {Pressure }}=1.98, S D_{\text {Pressure }}=0.42 ; M_{\text {Support }}=3.64, S D_{\text {Support }}=0.39\right)$ compared to time $1\left(M_{\text {Pressure }}=2.13, S D_{\text {Pressure }}=0.36 ; M_{\text {Support }}=3.58, S D_{\text {Support }}=0.28\right)$. Parents reported slightly lower scores for parental pressure on their child at time $2\left(M_{\text {Pressure }}=2.06, S D_{\text {Pressure }}=\right.$ $0.33)$ compared to time $1\left(M_{\text {Pressure }}=2.18, S D_{\text {Pressure }}=0.49\right)$; however, they also perceived themselves to be slightly less supportive at time $2\left(M_{\text {Support }}=3.64, S D_{\text {Support }}=0.31\right)$ compared to time $1\left(M_{\text {Support }}=3.75, S D_{\text {Support }}=0.25\right)$. 


\subsubsection{Parenting styles}

Parenting style was identified through the Parental Authority Questionnaire (PAQ) developed by Buri (1991). Overall, athletes reported highest scores for authoritative parenting style at time 1 and time 2 compared to authoritarian and permissive parenting (Time 1: $M_{\text {Permissive }}=27.72$, $S D_{\text {Permissive }}=6.14 ; M_{\text {Authoritarian }}=30.2 S D_{\text {Authoritarian }}=4.91 ; M_{\text {Authoritative }}=38.9 S D_{\text {Authoritative }}=4.17$; Time 2: $M_{\text {Permissive }}=26.4, S D_{\text {Permissive }}=5.75 ; M_{\text {Authoritarian }}=30.1, S D_{\text {Authoritarian }}=6.74 ; M_{\text {Authoritative }}=$ 37.7, $S D_{\text {Authoritative }}=7.34$ ). In other words, athletes perceived that their parents maintained their authoritative style of parenting during the six week study period. Likewise, parents also reported highest scores for authoritative parenting style at time 1 and time 2 compared to authoritarian and permissive parenting ( Time 1: $M_{\text {Permissive }}=22.3, S D_{\text {Permissive }}=6.58 ; M_{\text {Authoritarian }}=26.98$, $S D_{\text {Authoritarian }}=6.79 ; M_{\text {Authoritative }}=38.9, S D_{\text {Authoritative }}=2.46$; Time $2: M_{\text {Permissive }}=23.2, S D_{\text {Permissive }}=$ 5.09; $\left.M_{\text {Authoritarian }}=26.3, S D_{\text {Authoritarian }}=9.22 ; M_{\text {Authoritative }}=43.6 S D_{\text {Authoritative }}=14.05\right)$. It appeared that parents' scores for authoritative parenting increased from time 1 to time 2 (e.g., 38.9 vs. 43.6), while athletes' perceptions of authoritative parenting were similar at both time points (e.g., 38.9 vs. 37.7$)$.

\subsubsection{Quality of communication}

Quality of communication was measured based on the extent of openness and problems in parent-athlete communication. Results from the Parent-Adolescent Communication Scale (PACS) revealed that athletes reported similar scores in the overall quality of communication with their parents at time $2\left(M_{\text {Openness }}=39, S D_{\text {Openness }}=9.52 ; M_{\text {Problems }}=35.27, S D_{\text {Problems }}=9.95\right.$; $\left.M_{\text {Overall Quality }}=74.27, S D_{\text {Overall Quality }}=15.17\right)$ compared to time $1\left(M_{\text {Openness }}=40.4, S D_{\text {Openness }}=\right.$ $\left.5.54 ; M_{\text {Problems }}=33.9, S D_{\text {Problems }}=5.83 ; M_{\text {Overall Quality }}=74.3, S D_{\text {Overall Quality }}=9.75\right)$. Likewise, parents reported similar scores in the overall quality of communication with their child at time 2 $\left(M_{\text {Openness }}=39.1, S D_{\text {Openness }}=4.79 ; M_{\text {Problems }}=35.2, S D_{\text {Problems }}=5.78 ; M_{\text {Overall Quality }}=74.3\right.$, $\left.S D_{\text {Overall Quality }}=10.24\right)$ compared to time $1\left(M_{\text {Openness }}=40.17, S D_{\text {Openness }}=5.09 ; M_{\text {Problems }}=34.8\right.$, $\left.S D_{\text {Problems }}=7.53 ; M_{\text {Overall Quality }}=74.97, S D_{\text {Overall Quality }}=12.35\right)$.

\subsubsection{Summary of quantitative findings}

Examining the graphs of the quantitative findings (see Appendix D) illustrates that parents and athletes' perceptions of pressure and support, parenting style, and communication were not always the same. In some cases the child viewed things more positively than their parent. For 
instance, within the dyad of David and Dean, the child rated the quality of communication more positively than the parent (refer to Appendix D). Likewise, within the dyad of Ron and Ryan, the child perceived an increase in parental support and openness in communication, whereas the parent perceived a decrease in those variables (refer to Appendix D).

Conversely, in other cases parents viewed things more positively than their child. For instance, within the dyad of Sarah and Sophie the parent perceived openness of communication and overall quality of communication more positively than the child; Sarah (parent) reported higher scores for authoritative parenting at time 2 compared to time 1, although Sophie (child) reported lower scores for authoritative parenting at time 2; and lastly, Sarah perceived a decrease in pressure and authoritarian style of parenting, while Sophie perceived an increase in those variables. Similarly, within the dyad of Chris and Chloe the parent (Chris) perceived the degree of support to be higher than the child (Chloe); the parent perceived the level of parental pressure to be lower compared to the child's perceived parental pressure; and lastly, the parent perceived greater openness of communication compared to the child. 


\section{Chapter 5 Discussion}

\section{Discussion}

The purpose of this study was to examine how parental awareness of communication influences parent-athlete communication. The findings demonstrated that the process of reflective practice encouraged parents to engage in critical self-evaluation. Through such self-evaluation, parents reported that they became more aware of their child's development, their role and responsibilities as a parent, and were more cognizant of the timing of their conversations with their child. The results also indicated that parents perceived their increased awareness of their communication resulted in them demonstrating more positive and supportive behaviour in conflict resolution, and before, during, and after practices and games. Lastly, the results suggest that increased awareness of parent-child communication may have led parents to engage in more autonomy supportive parenting style. Considering these findings in relation to the previously published research on reflective practice and parents in youth sports, the findings from the present study provide additional support for previously published research on parent-athlete communication and expand the current state of research on the benefits of reflective practice in sport settings.

\subsection{Communication in Sport}

Researchers have shown that children of all ages prefer their parents to be supportive at sport events, and not act like demanding coaches or crazed fans (Knight, Neely, \& Holt, 2011; Omli \& Wiese-Bjornstal, 2011; Tamminen, Poucher, \& Povilaitis, 2017). For instance, Knight, Neely, and Holt (2011) reported that before competition, female youth sport athletes wanted their parents to make sure they are mentally and physically prepared for the competition so that their team has the best chance of being successful. During competitions, athletes preferred their parents maintain a relaxed and positive environment by providing positive and encouraging feedback, and to interact with referees in a positive way. After competitions, athletes wanted their parents to allow the team time to process the outcome of the game, provide positive comments to all members of the team, and ensure the athletes are ready for the next game if necessary (Knight et al., 2011). The results of the present study indicate that reflective practice can be an effective tool in encouraging parents to demonstrate supportive behaviours that also 
align with children's preferences. It appears that the inclusion of the workshop and the audio diaries contributed to parents behaving in a more positive and supportive manner before sport events, less critical and more encouraging during sport competitions, and more patient with their child after sport competitions. Thus, while previous research has provided information on the types of behaviours and communication that athletes might prefer from parents surrounding sport competitions, the present study extended this area of research by adopting an approach to try and help parents to enact changes in these behaviours and communication practices.

The findings of the present study also provide insight on how reflective practice impacted parents' communication behaviour during post-game and post-practice debriefing. Debriefing is a symbol of parental involvement in sport and it demonstrates parents' interest and support for their child's sporting activity (Elliott \& Drummond, 2017). However, researchers have shown that during debriefing, parents often assess their children's sporting performance and offer their feedback through negative, constructive, or critical comments (Elliott \& Drummond, 2017). Findings from the present study illustrated that increases in parents' awareness of their communication behaviour through reflective practice may have driven parents to engage in more supportive and positive behaviours in their post-game and post-practice debriefing.

It is possible that the process of engaging in reflective practice may have changed parents' goals that were relevant to their interpersonal communication. According to the multiple goals perspective, parents' verbal behaviour is formed by a combination of instrumental, identity and relational goals (Caughlin, 2010; Dorsch et al., 2015). Within organized youth sport, instrumental goals could lead parents to communicate in a controlling fashion, whereas identity goals could prompt parents to communicate in ways that generate a popular image of themselves and their child (Dorsch et al., 2015). In contrast, relational goals encourage parents to communicate in ways that foster feelings of closeness with those whom they share an interest (Dorsch et al., 2015). The findings in the present study suggested that towards the end of the 6week period parents' communication behaviour was more aligned with relational goals than instrumental or identity goals. Hence, it is possible that parents' participation in reflective practice may have prompted them to adopt different goals than at the outset of the study. This assertion would need to be tested in subsequent research to determine whether parents' goals changed over the course of the study and as a function of engaging in reflective practice about their communication with their child. However, this study does offer some promising guidance 
on using reflective practice as a strategy that could potentially help parents to adopt different goals in relation to their child's sport participation.

It may be useful to consider the links between one-on-one communication between parents and children and communication in group or public settings such as during games (i.e., parent sideline behaviours) According to Holt et al. (2008), parents' verbal reactions to their children's performance can be labelled as "praise/encouragement, performance contingent feedback, instruction, striking a balance, negative comments, and derogatory comments" (p. 663). Furthermore, previous research has shown that engagement of parents in more supportive, and less controlling behaviours could increase the likelihood of their children in achieving more positive outcomes in sport (Holt et al., 2008). The findings from parents' audio diary entries and the post-study interviews demonstrate that parents appear to have transformed their verbal behaviours from performance contingent feedback, instruction, and negative comments to praise/encouragement and striking a balance. Thus, transformation of parents' verbal behaviours towards praise/encouragement and striking a balance could have a lasting positive impact on youth athletes. Similarly, findings from previous research demonstrate that parents also play an important role in facilitating adolescent athletes' learning about coping with stressors in sport. In particular, parents can help athletes learn about various coping strategies by creating a supportive environment for learning (Tamminen \& Holt, 2012). Monitoring their own behaviours, listening to the athlete, establishing trust, reading the athlete, and promoting independence are ways through which parents can build a supportive learning environment (Tamminen \& Holt, 2012). In the present study, it appeared that reflective practice prompted parents to take a step back, and enhance their child's feeling of autonomy and independence while providing guidance where it was deemed necessary.

Using Deci and Ryan's (2008) self-determination theory (SDT), Goldstein and Iso-Ahola (2008) explored the determinants of parents' sideline behaviours at youth sports games. They concluded that parents' personality characteristics - autonomy-oriented vs. control-oriented - affected their situational tendencies and motivations. More specifically, they suggested that autonomy-oriented parents were less likely to become ego defensive and as a result, engaged in less aggressive behaviours (Goldstein \& Iso-Ahola, 2008). The findings of the present study may also suggest that parents' engagement in reflective practice led them to became more autonomy-oriented, and less control-oriented towards their children. Therefore, encouraging parents to engage in 
reflective practice may improve their one-on-one, and sideline communication behaviour. A question remains, however, regarding whether reflective practice may be facilitated in a group setting (e.g., at parent meetings) in order to promote more positive communication behaviours among a large group of parents. Previous research on group-based reflection in nursing has shown that a reflective practice group may lead to deeper levels of reflection within an environment that values trust and support (Dawber, 2013). Hence, future researchers should explore ways to develop a group based reflective practice intervention for parents within an environment with a culture of support and trust.

\subsection{Parenting Styles and Practices in Sport}

Parents' style of parenting can be categorized into authoritative, authoritarian, permissive, and rejecting-neglecting (Baumrind, 1991). The findings from the present study showed that parents perceived some changes in their parenting styles between time 1 and time 2. A six-year longitudinal research study conducted by Williams, Ciarrochi, and Heaven (2012) examined the relationship between parenting style and psychological flexibility of children in grade 7 through to grade 12. Their study demonstrated that as children approached grade 12, parents' style of parenting changed from authoritative (high warmth, high control) to authoritarian (low warmth, high control) (Williams et al., 2012). Williams and colleagues (2012) noted that there have been no previous research studies that have explored the systematic changes in parenting styles over time. However, it appears that changes in parenting techniques such as relaxation of parental authority, maintaining or developing warm involvement, and less rule-setting could lead to changes in parenting styles (Williams et al., 2012). Such parenting techniques are often referred to as parenting practices, which are specific techniques that reflect parents' goals for their children (Baumrind, 1991; Holt et al., 2009). As stated by Darling and Steinberg (1993), one's parenting style is "expressed partly through parenting practices" (p. 493). Therefore, it appears that reflective practice may have led parents to make small changes to their parenting practices, which in turn could have impacted their parenting style. However, authoritative parenting style was rated highest overall at both time 1 and time 2 among both parents and athletes, suggesting that parents participating in this study were already engaging in behaviours that reflected an authoritative style of parenting. 
In summary, it seems that six weeks may not be an adequate time frame to implement a protocol that could produce a long-term change in one's parenting style. In addition, the sport organizations through which athletes and parents were recruited may not have fully adhered to the guidelines within the DMSP model. As a result, athletes' stages of development and the time of their specialization could have been different than what is suggested in the DMSP model (e.g., athletes in the present study may have been engaged in early specialization rather than sampling). Also, parents may have interacted with their athletes in a different manner than recommended. Hence, one challenge for researchers developing empirically-supported interventions based on theoretical models and guidelines is that sport organizations and administrators' practices do not reflect youth sports researchers' recommendations. Thus, there may be a disconnect between what researchers suggest and what coaches, parents, and athletes actually 'do' in practice. This highlights an existing gap in the translation of research to practice in recreational and high performance youth sports programs in Ontario. However, the present findings showed that reflective practice can be used as a tool to facilitate change in parenting practices. In accordance with previous research, the findings of the present study revealed that through reflective practice it is possible to make small changes to one's parenting practices. Thus, it is perhaps more realistic for future researchers to implement interventions that focus on developing and enhancing parenting practices that are appropriate for specific age groups. Future research may seek to examine patterns of parenting practices among sport parents over a longer period of time, and to also examine whether parents exhibit changes in parenting practices and associated parenting styles as their child develops.

\subsection{Benefits and Potential of Reflective Practice}

Parents said that they found reflective practice as a useful tool for self-reflection and to increase their awareness of their communication. It appeared that perceived changes in parental communication transpired as a result of parents' increased awareness of their communication behaviour and parents' engagement in self-evaluation through the process of reflective practice. The notion that reflective practice can promote self-reflection and increase self-awareness is consistent with previous research suggesting that reflective practice may assist individuals in redefining their understanding of professional knowledge, developing personal knowledge or selfawareness, and evaluating the appropriateness of their actions (Forrest, 2008). However, it is important to note that within the present study, parents engaged in multiple modes of reflection 
including pre-and post-study surveys, pre-and post-study interviews, and audio diaries. Therefore, all components of the study contributed to parents' reflective practice to a greater or lesser extent, and within the present study it was not possible to untangle the unique contributions of each element of the study to parents' communication awareness. Future researchers should explore what strategies would be more effective for eliciting reflection to determine the most effective mode of promoting improved awareness of communication among parents.

Among coaches, researchers have found that reflective practice helped inexperienced coaches in identifying their strengths and weaknesses, and assisted them in identifying what part of their communication and coaching style needed to be improved (Carson, 2008). A study by Koh, Mallett, Camiré, and Wang (2015) examined the impact of a guided reflection intervention for high performance basketball coaches. Their findings demonstrated that reflective practice increased coaches' self-awareness, improved their understanding of coaching practices, increased coaches' awareness of players' feelings and concerns, and increased athletes' satisfaction (Koh et al., 2015). Lastly, Taylor, Werthner, Culver, and Callary (2015) found that through reflective practice, coaches were investing a significant amount of time to think over and reflect on their coaching practices, actions, and current knowledge.

Among athletes, studies have shown that reflective practice resulted in an improvement in players' shared understanding of the situation, and strengthened team identity in performance context (Richards, Mascarenhas, \& Collins, 2009). In addition, Hanton, Cropley, and Lee (2009) concluded that through reflection athletes can generate knowledge and understanding of their competitive experiences, and rationalize their competitive anxiety symptoms. Likewise, it has been shown that through reflective practice athletes can advance their evaluative skills, increase their levels of self-awareness, and holistically aid their performance (Faull \& Cropley, 2009).

In other domains such as sport management, critical reflection has been described as a mean to reconstruct our social worlds, and form an appreciation of learning experiences (Edwards, 1999). In healthcare, reflective practice has been shown to increase midwives' self-awareness, selfidentity, and personal growth (Wain, 2017). Similarly, within the context of health counselling and health promotion, researchers concluded that effective tools of reflective learning are needed 
to support student nurses' learning from practice through critical reflection (Liimatainen, Poskiparta, Karhila, \& Sjögren, 2001).

Parents in the present study reported higher emotional self-awareness for themselves and higher awareness of their child's emotions as a result of participating in reflective practice. Previous research demonstrates outcomes for children of parents with poor emotional control or who are emotionally volatile (Strayer \& Roberts, 2004; González-Díez, Orue, \& Calvete, 2017; Milojevich \& Haskett, 2018); thus, results of the present study suggest that in addition to the positive perceived changes in communication, reflective practice may have additional benefits for parents' emotional control and parental communication (Haverfield \& Theiss, 2017; Baumrind, 1991). However, it is important to note that some parents and athletes in the present study reported no changes following their participation in reflective practice. This finding is particularly important as it suggests that reflective practice interventions might not be beneficial for parents who are already reflective, or who already have positive communication with their child and demonstrate positive parenting. Therefore, for reflective practice to be effective, it may need to be targeted towards particular groups of individuals who stand to benefit most from the intervention, and it needs to integrate strategies that are embedded within individuals' daily experiences (Smith \& Trede, 2013). That is to say, reflective practice may not be a "one size fits all” approach, and that it needs to be a personalized process which reflects each participant's goals and intentions (Edwards \& Thomas, 2010). Future studies should explore the impact of participants' intentions and goals on the effectiveness of reflective practice. Lastly, I suggest that parents should engage in the process of self-reflection at every stage of their child's athletic development. I make this suggestion because: (a) parents' leadership role during the sampling stage transforms to more of a following and supporting role in the specializing and investment stages of development (Fraser-Thomas, Côté, \& Deakin, 2008); (b) each stage of an athlete's development consists of goals that may not be similar to ones in the previous stage; and (c) parents' behaviours are likely to be different depending on their child's needs and stage of development. Hence, to ensure a healthy transition of athletes from one stage to another, it is important for parents to engage in the process of self-reflection.

There has been a great deal of research examining the relationship between reflective practice and self-awareness. However, the present study is one of the first to examine the influence of reflective practice on parents' awareness of their communication behaviour in youth sport. Also, 
in contrast to previous research, the present study incorporated a workshop as a component of its intervention to provide parents with a reference for their reflection. Even though the current findings add to the work of previous researchers on reflective practice, there is still very little known about the mechanism(s) through which reflective practice enhances one's self-awareness. Therefore, future researchers would make an important contribution to this body of literature by investigating the factors that help establish the relationship between reflective practice and selfawareness.

\subsection{Parent and Athlete Perceptions of Parental Behaviours}

Analysis of the qualitative data suggested that reflective practice and increased awareness of parent-child communication led parents to engage in more autonomy supportive parenting style, and to be less critical of their child's performance. However, examination of the quantitative data suggested that in most cases parents and athletes' perceptions of parental support, communication, and parenting style were not congruent. This outcome further confirms previous researchers' work stating that parents and athletes may interpret pressure and other behaviours differently (Fraser-Thomas, Côté, \& Deakin, 2008; Knight et al., 2011), and research indicating that children perceive their mother's and father's contributions differently in their sport involvement (Babkes \& Weiss, 1999). Additionally, researchers have shown that parents and athletes may not have the same perception of pre-competition stress. According to Purdy, Haufler, and Eitzen (1981), irrespective of competition level or the gender of the athlete, parents generally underestimate the level of their children's pre-competition stress.

However, disagreement between the views of a parent and a child should not be deemed as random. In other words, structural differences exist between parent and child interpretation of family communication norms, involvement, and control (Austin, 1993). Factors such as the transition from pre-adolescence to early adolescence, family structure, and children's characteristics could greatly impact the level of agreement on parental behaviours between father and a child or mother and a child (Tein, Roosa, \& Michaels, 1994). In addition, it might be that parents and children "simply did not share the same definitions of, experiences of, or sensitivity to" certain parental behaviours (Tein et al., 1994, p. 350). Other factors such as parenting style, openness in communication, and mutual trust have been identified as important elements in predicting differences in parent-child perceptions (Katz, Lee, \& Byrne, 2015). Since 
authoritarian parents have a certain degree of control over their children, children of authoritarian parents may avoid communicating with their parents about specific topics. As a result, authoritarian parents and their children experience less openness in their communication, which in turn may lead to differences in perceptions (Katz, Lee, \& Byrne, 2015). Lastly, according to critical realists, one's reality is created through interactions with social and natural objects (Easton, 2010; Tsang, 2014). Therefore, differences in parents' and athletes' perceptions of communication could be simply due to different perspectives that each brings to the situation.

Discrepancies in parent-child perceptions may create two different scenarios. If parents overestimate their children's abilities and set unrealistically high goals for them, children may view themselves as "failures" for not achieving the goals that were set for them by their parents. Secondly, if children evaluate their own abilities significantly higher than what they perceive their parents' evaluation to be, they will then view their parents as "unsupportive" (McElroy \& Kirkendall, 1981). When differences in perspectives are perceived by children, they may start to question whose view is correct. However, because children view their parents as central significant others in their life, discrepancies in perceptions could greatly affect children's psychological development (McElroy \& Kirkendall, 1981). In addition, differences in parentchild perceptions could negatively influence youth sport participation (Kanters, Bocarro, \& Casper, 2008). This is in part due to the fact that children seek similarities between their own views and those of their parents (McElroy \& Kirkendall, 1981). Hence, if athletes view their parents as "overzealous", they may feel that they can never meet their parents' expectations. Likewise, if athletes perceive their parents to be unsupportive of their sport activities, they may feel that dropping out of their sport may in turn satisfy their parents.

\subsection{Applied Implications}

The present study and its findings have both theoretical and practical implications. Considering that this is the first research study to examine the use of reflective practice using Gibbs' (1988) reflective cycle on parental communication in youth sport, the findings serve as a foundation for the use of reflective practice in various domains of sports. Theoretically, the present study was the first study to use Gibbs' (1988) reflective cycle in youth sports. To our knowledge previous researchers had only used Gibbs' (1988) reflective cycle in domains such as nursing to improve nurse-patient relationship (Wilding, 2008; Söderberg et al., 2017). Therefore, this study 
demonstrates that Gibbs' (1988) reflective cycle is adaptive and can be used in an applied manner with parents.

Furthermore, the findings advance the current state of research on parent-child communication in sport by providing a framework for parents to improve their communication with their child using reflective practice. Also, the present study consisted of various components which contributed to parents' reflective experience, and ultimately increased parents' self-awareness of their communication behaviours. Therefore, it is important to acknowledge the strengths, accessibility, and convenience of various methods while designing an intervention. Simply put, to increase the uptake of intervention components, sport organizations should consider tools that are accessible, user-friendly, and can be used by participants in a timely manner. From a practical point of view, it is best to engage youth sport parents in the process of self-reflection during pre-season parent meetings and prior to the start of their children's sporting activities.

It is particularly important for sport organizations to engage parents in the process of selfreflection rather than just providing them with information on this topic. One of the unique aspects of the present study was that it engaged parents in an active process of reflective practice, rather than simply delivering information to parents in a passive manner. Thus, reflective practice interventions that are designed by sport organizations for parents should consist of a brief educational component which highlights the importance of the topic and the work of previous researchers and their findings. In addition, incentives should be provided by sport organizations to encourage parents to reflect on their communication through a series of audio diaries or written reflection journals.

Lastly, the findings of the present study may assist sport organizations in optimizing athletes' development. Previous research (Tamminen, Poucher, \& Povilaitis, 2017) and the present study demonstrated that parental communication could be destructive at times. Therefore, sport organizations such as Hockey Canada, Canada Soccer, and Golf Canada can use this information to implement a parental education course where parents are encouraged to engage in reflective practice on their communication behaviour. 


\subsection{Strengths and Limitations}

One limitation of this study was the absence of athletes from recreational level sports. Parents of high performance athletes deal with organizational, competitive, and developmental stressors (Harwood \& Knight, 2009). Hence, including them as part of the study was deemed appropriate. However, inclusion of recreational athletes would have provided the opportunity for the researcher to compare how the dynamic of a parent-athlete interaction differs between a high performance sport parent and a recreational sport parent.

Furthermore, the absence of athletes from individual sports or co-acting sports was another limitation of the present study. Previous research has shown that athletes who participate in individual sports may experience higher levels of state and somatic anxiety, and lower selfconfidence than athletes who participate in team sports (Ramis, Viladrich, Sousa, \& Jannes, 2015). Considering that higher level of stress may lead to lower relationship satisfaction and quality of communication with their parents, future researchers should examine the impact of reflective practice on parent-child communication among athletes from individual or co-acting sports.

Lastly, parenting style was assessed through the Parental Authority Questionnaire (PAQ) developed by Buri (1991). This questionnaire only measured Baumrind's (1971) permissive, authoritative, and authoritarian parenting styles and did not include measures for rejectingneglecting parenting style.

One of the strengths of this study was the inclusion of member checking in the second interview. Member checking has been recommended by other researchers as a tool to enhance the rigour in qualitative research (Birt, Scott, Cavers, Campbell, \& Walter, 2016). Member checking enhances the inclusion of participants in the research process, and provides them with the opportunity to offer their interpretation of the data (Birt et al., 2016). Member checking provided the participants with the opportunity to further comment on their initial interview, and elaborate on their experiences from the study. Therefore, participants were often asked to elaborate and critically think about some of the comments they had previously made regarding their communication with their children. Hence, for the purpose of the present study member checking can be reframed and thought of as member reflections (Smith \& McGannon, 2018): rather than having participants confirm the 'accuracy' of the transcripts or the veracity of their comments, 
the second interviews were used as an opportunity to engage the participants in reflecting on the researcher's developing interpretations of the themes within the study and to clarify their experiences described within their audio diaries.

An additional strength of the present study was the inclusion of both qualitative and quantitative methods. Mixed method research and triangulation of qualitative and quantitative methods have often been conceived as either disjunctive or conjunctive (Howe, 2012). Disjunctive conception considers that there is a clear division between qualitative and quantitative methods, and that if triangulated each method aims to answer a different research question (Howe, 2012). For this study, the researcher adopted a conjunctive view on triangulation of methods, wherein qualitative and quantitative methods have their own distinct roles but they work in a more intertwined fashion together to answer the same research question (Howe, 2012), namely, to examine how parental awareness of communication influences parent-athlete communication. Hence, while there are strengths and limitations in both qualitative and quantitative methods (Lakshman, Sinha, Biswas, Charles, \& Arora, 2000), I believed it was appropriate to integrate the two methods and in turn use the strengths of each method to reduce the limitations of the other.

In addition, participants were recruited through purposeful sampling (Palinkas et al., 2015) to ensure the inclusion of rich information cases. Other strengths of the study are the steps that were taken to ensure trustworthiness through all phases of the study. Weekly meeting were scheduled with the research supervisor who acted as a critical friend (Foulger, 2010) throughout the study. As a critical friend, the research supervisor evaluated the research design, and provided alternative interpretations. Also, keeping a reflexive journal throughout the study helped to maintain philosophical assumptions and made the researcher aware of his inherent biases and assumptions and how they could influence the research process. Lastly, the inclusion of audio diaries as one of the methods for data collection is another strength of the present study. A key advantage of audio diaries as a method of data collection is that the construction of personal experience was directed by the participant, and was a creative way to form verbal monologue (Crozier \& Cassell, 2016). Another advantage of collecting data through audio diaries was the minimal influence that researcher had over participants' responses, allowing participants to describe situations that were personally meaningful to them (Crozier \& Cassell, 2016). 


\section{Chapter 6 \\ Conclusion}

\section{Conclusion}

Parents are integral in their children's sport, and are recognized for their role in providing the necessary financial and logistical support to enable sporting opportunities (Elliott \& Drummond, 2017). Parents can also enhance their children's intrinsic motivation by providing positive and supportive feedback within an autonomy supportive environment (Holt et al., 2009). Given that there is limited research available that has explored ways for parents to learn to engage in these supportive behaviours with their child, the purpose of this study was to examine whether increasing parents' awareness of communication influences parent-athlete communication behaviours. The study addressed the following research questions: (a) How does reflective practice influence parents' self-awareness of their own communication behaviour? (b) Does increased awareness of parent-child communication lead to perceived changes in parents' communication behaviour? (c) Do reflective practice and increased awareness of parent-child communication lead to perceived changes in parents' parenting styles?

The researcher adopted a critical realist paradigm which assumes a transcendental realist ontology and an eclectic realist epistemology (Easton, 2010). The study was designed as a mixed method single subject research design, which consisted of a parent education workshop, as well as audio diaries, surveys, and semi-structured interviews to collect data. Through purposeful sampling (Palinkas et al., 2015) ten athletes between 13 to 15 years of age, and one of their parents were recruited (total $N=20$ ). Parents and athletes completed pre- and post-study interviews and surveys. In addition, parents also participated in a workshop during which they were provided with an overview of the current literature on parent-child communication. Following their participation in the workshop, parents completed at least one audio diary entry per week over the course of six weeks, which was structured to encourage reflective practice of their communication behaviour in youth sport.

Overall, qualitative findings demonstrated that reflective practice increased parents' selfawareness of their communication behaviour which led parents to engage in more autonomy supportive parenting style, and have a more positive view towards their child's performance. However, quantitative findings showed that despite some changes in the overall quality of 
parent-athlete communication, in most cases parents were not congruent with their child's perceptions of communication. Factors such as the transition from pre-adolescence to early adolescence, family structure, and children's characteristics could greatly impact the level of agreement on parental behaviours between father and a child or mother and a child (Tein, Roosa, \& Michaels, 1994).

The present study addresses a gap in the literature surrounding parental communication in youth sport. The findings make a novel theoretical and practical contribution to future research on parental communication and reflective practice in sport. While other studies have examined the potential of reflective practice in various domains such as sport management and healthcare (Liimatainen et al., 2001; Faull \& Cropley, 2009; Carson, 2008; Hanton et al., 2009; Taylor et al., 2015; Richards et al., 2009; \& Edwards, 1999), the present study is one of the first to examine the use of reflective practice among parents of youth sport athletes. Parents in the current study reported engaging in self-evaluation and enhancing their awareness of their child's development and their role as a parent through reflective practice. These results reinforce the findings from previous research regarding the potential benefits of reflective practice; however, the current study expanded the use of reflective practice among parents, which has not to date been examined in the sport literature. Thus, the present study makes a novel contribution to the literature by examining the use of reflective practice as a mean to increase parents' awareness of their communication within youth sport settings. 


\section{References}

Anderson, J. C., Funk, J. B., Elliott, R., \& Smith, P. H. (2003). Parental support and pressure and children's extracurricular activities: Relationships with amount of involvement and affective experience of participation. Journal of Applied Developmental Psychology, 24(2), 241-257.

Andrews, M., Gidman, J., \& Humphreys, A. (1998). Reflection: Does it enhance professional nursing practice? British Journal of Nursing, 7(7), 413-417.

Atkins, M. R., Johnson, D. M., Force, E. C., \& Petrie, T. A. (2013). "Do I still want to play?" parents' and peers' influences on girls' continuation in sport. Journal of Sport Behavior, 36(4), 329-345.

Austin, E. W. (1993). The importance of perspective in parent-child interpretations of family communication patterns. Journalism \& Mass Communication Quarterly, 70(3), 558-568.

Babkes, M. L., \& Weiss, M. R. (1999). Parental influence on children's cognitive and affective responses to competitive soccer participation. Pediatric Exercise Science, 11(1), 44-62. doi:10.1123/pes.11.1.44

Bailey, R. (2006). Physical education and sport in schools: A review of benefits and outcomes. Journal of School Health, 76(8), 397-401. doi:10.1111/j.17461561.2006.00132.x

Bakker, A. B., \& Bal, M. P. (2010). Weekly work engagement and performance: A study among starting teachers. Journal of Occupational and Organizational Psychology, 83(1), 189206. doi:10.1348/096317909X402596

Barnes, H. L., \& Olson, D. H. (1985). Parent-adolescent communication and the circumplex model. Child Development, 56(2), 438-447. doi:10.2307/1129732

Baumrind, D. (1989). Rearing competent children. Child development today and tomorrow (W. Damon Ed.) (p. 349-378). San Francisco, CA: Jossey-Bass Publisher.

Baumrind, D. (1991). The influence of parenting style on adolescent competence and substance use. The Journal of Early Adolescence, 11(1), 56-95. doi:10.1177/0272431691111004

Birt, L., Scott, S., Cavers, D., Campbell, C., \& Walter, F. (2016). Member checking: A tool to enhance trustworthiness or merely a nod to validation? Qualitative Health Research, 26, 1802-1811. doi:10.1177/1049732316654870

Buchanan, D. A. (1991). Vulnerability and agenda: Context and process in project management. British Journal of Management, 2(3), 121-132. doi:10.1111/j.14678551.1991.tb00021.x

Buri, J. R. (1991). Parental authority questionnaire. Journal of Personality Assessment, 57(1), 110-119. doi:10.1207/s15327752jpa5701_13 
Butcher, J., Lindner, K. J., \& Johns, D. P. (2002). Withdrawal from competitive youth sport: A retrospective ten-year study. Journal of Sport Behavior, 25(2), 145-163.

Cannon, J. E., Guardino, C., Antia, S. D., \& Luckner, J. L. (2016). Single-case design research: Building the evidence-base in the field of education of deaf and hard of hearing students. American Annals of the Deaf, 160(5), 440-452.

Carr, E. C. J., \& Worth, A. (2001). The use of the telephone interview for research. NT Research, 6(1), 511-524. doi:10.1177/136140960100600107

Carson, F. (2008). Utilizing video to facilitate reflective practice: Developing sports coaches. International Journal of Sports Science \& Coaching, 3(3), 381-390. doi:10.1260/174795408786238515

Caughlin, J. P. (2010). Invited review article. Journal of Social and Personal, 27(6), 824-848. doi: $10.1177 / 0265407510373262$

Côté, J. (1999). The influence of the family in the development of talent in sport. The Sport Psychologist, 13, 395-417.

Côté, J., \& Vierimaa, M. (2014). The developmental model of sport participation: 15 years after its first conceptualization. Science \& Sports, 29, 63-69.

Côté, J., Baker, J., \& Abernethy, B. (2007). Practice and play in the development of sport expertise. Handbook of sport psychology ( $3^{\text {rd }}$ ed.) (pp. 184-202). Hoboken, NJ: Wiley.

Crane, J., \& Temple, V. (2015). A systematic review of dropout from organized sport among children and youth. European Physical Education Review, 21(1), 114-131. doi:10.1177/1356336X14555294

Cropley, B., Hanton, S., Miles, A., \& Niven, A. (2010). The value of reflective practice in professional development: An applied sport psychology review. Sport Science Review, 19, 179-208. doi:10.2478/v10237-011-0025-8

Crozier, S. E., \& Cassell, C. M. (2016). Methodological considerations in the use of audio diaries in work psychology: Adding to the qualitative toolkit. Journal of Occupational and Organizational Psychology, 89(2), 396-419. doi:10.1111/joop.12132

Dahl, Ø. (2013). Chapter 3: Communication is creating something together. Human encounter, introduction to intercultural communication (pp. 41-66). Oslo, NO: Glydendal Akademisk.

Darling, N., \& Steinberg, L. (1993). Parenting style as context: An integrative model. Psychological Bulletin, 113(3), 487-496.

Dawber, C. (2013). Reflective practice groups for nurses: A consultation liaison psychiatry nursing initiative: Part 1 - the model. International Journal of Mental Health Nursing, 22(2), 135-144. doi:10.1111/j.1447-0349.2012.00839.x 
Deci, E. L., \& Ryan, R. M. (2008). Self-determination theory: A macrotheory of human motivation, development, and health. Canadian Psychology/Psychologie Canadienne, 49(3), 182-185.

DiCicco-Bloom, B., \& Crabtree, B. F. (2006). The qualitative research interview. Medical Education, 40(4), 314-321.

Diggs, O. N., Neppl, T. K., Jeon, S., \& Lohman, B. J. (2017). The association of harsh parenting, parent-child communication, and parental alcohol use with male alcohol use into emerging adulthood. Journal of Adolescent Health, 61(6), 736-742. doi:10.1016/j.jadohealth.2017.06.025

Dorsch, T. E., Smith, A. L., \& McDonough, M. H. (2015). Early socialization of parents through organized youth sport. Sport, Exercise, and Performance Psychology, 4(1), 3-18. doi: $10.1037 /$ spy0000021

Dorsch, T. E., Smith, A. L., Wilson, S. R., \& McDonough, M. H. (2015). Parent goals and verbal sideline behavior in organized youth sport. Sport, Exercise, and Performance Psychology, 4(1), 19-35. doi:10.1037/spy0000025

Durkin, K. (1995). Developmental social psychology: From infancy to old age. Oxford, UK: Blackwell.

Easton, G. (2010). Critical realism in case study research. Industrial Marketing Management, 39(1), 118-128.

Edwards, A. (1999). Reflective practice in sport management. Sport Management Review, 2(1), 67-81.

Edwards, G., \& Thomas, G. (2010). Can reflective practice be taught? Educational Studies, 36(4), 403-414. doi:10.1080/03055690903424790

Elliott, S. K., \& Drummond, M. J. N. (2017). Parents in youth sport: What happens after the game? Sport, Education and Society, 22(3), 391-406.

doi:10.1080/13573322.2015.1036233

Faull, A., \& Cropley, B. (2009). Reflective learning in sport: A case study of a senior level triathlete. Reflective Practice, 10(3), 325-339. doi:10.1080/14623940903034655

Fisher, C. D., \& Noble, C. S. (2004). A within-person examination of correlates of performance and emotions while working. Human Performance, 17(2), 145-168. doi:10.1207/s15327043hup1702_2

Forrest, M. E. S. (2008). On becoming a critically reflective practitioner. Health Information \& Libraries Journal, 25(3), 229-232. doi:10.1111/j.1471-1842.2008.00787.x

Foulger, T. (2010). External conversations: An unexpected discovery about the critical friend in action research inquiries. Action Research, 8(2), 135-152.

doi:10.1177/1476750309351354 
Fraser-Thomas, J., Côté, J., \& Deakin, J. (2008). Examining adolescent sport dropout and prolonged engagement from a developmental perspective. Journal of Applied Sport Psychology, 20(3), 318-333. doi:10.1080/10413200802163549

Fraser-Thomas, J., Côté, J., \& Deakin, J. (2008). Understanding dropout and prolonged engagement in adolescent competitive sport. Psychology of Sport and Exercise, 9(5), 645-662. doi:10.1016/j.psychsport.2007.08.003

Fredricks, J. A., \& Eccles, J. S. (2002). Children's competence and value beliefs from childhood through adolescence: Growth trajectories in two male-sex-typed domains. Developmental Psychology, 38(4), 519-533.

Ghaye, T., \& Lillyman, S. (2000). Reflection: Principles and practices for healthcare professionals. Wiltshire, UK: Quay Books.

Gibbs, G. (1988). Learning by doing: A guide to teaching and learning methods. London: Further Education Unit.

Given, L. M. (2008). The SAGE encyclopedia of qualitative research methods. Thousand Oaks, CA: SAGE Publications Ltd. doi: 10.4135/9781412963909

Goldstein, J. D., \& Iso-Ahola, S. E. (2008). Determinants of parents' sideline-rage emotions and behaviors at youth soccer games. Journal of Applied Social Psychology, 38(6), 14421462. doi:10.1111/j.1559-1816.2008.00355.x

González-Díez, Z., Orue, I., \& Calvete, E. (2017). The role of emotional maltreatment and looming cognitive style in the development of social anxiety symptoms in late adolescents. Anxiety, Stress, \& Coping, 30(1), 26-38.

Grolnick, W. S. (2003). Psychology of parenting control: How well-meant parenting backfires. Mahwah, NJ: Lawrence Erlbaum.

Guba, E. G. (1981). Criteria for assessing the trustworthiness of naturalistic inquiries. Education, Communication, and Technology Journal, 29(2), 75-91. doi:10.1007/BF02766777

Hanton, S., Cropley, B., \& Lee, S. (2009). Reflective practice, experience, and the interpretation of anxiety symptoms. Journal of Sports Sciences, 27(5), 517-533.

Harwood, C. G., Keegan, R. J., Smith, J. M. J., \& Raine, A. S. (2015). A systematic review of the intrapersonal correlates of motivational climate perceptions in sport and physical activity. Psychology of Sport and Exercise, 18, 9-25.

Harwood, C., \& Knight, C. (2009). Stress in youth sport: A developmental investigation of tennis parents. Psychology of Sport and Exercise, 10(4), 447-456.

doi:10.1016/j.psychsport.2009.01.005

Hatton, N., \& Smith, D. (1995). Reflection in teacher education: Towards definition and implementation doi:http://dx.doi.org/10.1016/0742-051X(94)00012-U 
Haverfield, M. C., \& Theiss, J. A. (2017). Parental communication of responsiveness and control as predictors of adolescents' emotional and behavioral resilience in families with alcoholic versus nonalcoholic parents. Human Communication Research, 43(2), 214-236. doi:10.1111/hcre. 12102

Hiller, H. H., \& Diluzio, L. (2004). The interviewee and the research interview: Analysing a neglected dimension in research. Canadian Review of Sociology/Revue Canadienne De Sociologie, 41(1), 1-26.

Holt, N. L., \& Knight, C. J. (2014). Parenting in youth sport: From research to practice. New York: Routledge.

Holt, N. L., Tamminen, K. A., Black, D. E., Mandigo, J. L., \& Fox, K. R. (2009). Youth sport parenting styles and practices. Journal of Sport \& Exercise Psychology, 31(1), 37-59. doi:10.1123/jsep.31.1.37

Holt, N. L., Tamminen, K. A., Black, D. E., Sehn, Z. L., \& Wall, M. P. (2008). Parental involvement in competitive youth sport settings. Psychology of Sport and Exercise, 9(5), 663-685. doi:10.1016/j.psychsport.2007.08.001

Howe, K. (2012). Mixed methods, triangulation, and causal explanation. Journal of Mixed Methods Research, 6(2), 89-96. doi:10.1177/1558689812437187

Husebø, S. E., O'Regan, S., \& Nestel, D. (2015). Reflective practice and its role in simulation. Clinical Simulation in Nursing, 11(8), 368-375.

doi:10.1016/j.ecns.2015.04.005

Kanters, M. A., Bocarro, J., \& Casper, J. M. (2008). Supported or pressured? An examination of agreement among parents and children on parent's role in youth sports. Journal of Sport Behavior, 31(1), 64-80.

Katz, S. J., Lee, T., \& Byrne, S. (2015). Predicting parent-child differences in perceptions of how children use the internet for help with homework, identity development, and health information. Journal of Broadcasting \& Electronic Media, 59(4), 574-602. doi:10.1080/08838151.2015.1093479

Kazdin, A. E. (2011). Single-case research designs: Methods for clinical and applied settings. New York: Oxford University Press.

Keijsers, L., Poulin, F., Keijsers, L., \& Poulin, F. (2013). Developmental changes in ParentChild communication throughout adolescence. Developmental Psychology, 49(12), 23012308. doi: $10.1037 / \mathrm{a} 0032217$

Kidman, L., McKenzie, A., \& McKenzie, B. (1999). The nature and target of parents' comments during youth sport competitions. Journal of Sport Behavior, 22, 54-68.

Klein, V., Becker, I., \& Štulhofer, A. (2018). Parenting, communication about sexuality, and the development of adolescent women's' sexual agency: A longitudinal assessment. Journal of Youth and Adolescence, 47(7), 1486-1498. 
Knight, C. J., Neely, K. C., \& Holt, N. L. (2011). Parental behaviors in team sports: How do female athletes want parents to behave? Journal of Applied Sport Psychology, 23(1), 7692. doi:10.1080/10413200.2010.525589

Koh, K. T., Mallett, C. J., Camiré, M., \& Wang, C. K. J. (2015). A guided reflection intervention for high performance basketball coaches. International Sport Coaching Journal, 2(3), 273-284. doi:10.1123/iscj.2014-0135

Lakshman, M., Sinha, L., Biswas, M., Charles, M., \& Arora, N. (2000). Quantitative vs qualitative research methods. The Indian Journal of Pediatrics, 67(5), 369-377. doi:10.1007/BF02820690

Lavelli, M., Fogel, A., Lavelli, M., \& Fogel, A. (2005). Developmental changes in the relationship between the infant's attention and emotion during early face-to-face communication: The 2-month transition. Developmental Psychology, 41(1), 265-280. doi:10.1037/0012-1649.41.1.265

Liimatainen, L., Poskiparta, M., Karhila, P., \& Sjögren, A. (2001). The development of reflective learning in the context of health counselling and health promotion during nurse education. Journal of Advanced Nursing, 34(5), 648-658.

Matsumoto, D. (2010). Apa handbook of interpersonal communication. Washington, DC: American Psychological Association.

McCorry, L. K., \& Mason, J. (2011). Chapter 3: Verbal communication. Communication skills for the healthcare professional (pp. 34-53). Baltimore, MD: Lippincott Williams \& Wilkins.

McElroy, M. A., \& Kirkendall, D. R. (1981). Conflict in perceived Parent/Child sport ability judgments. Jsp, 3(3), 244-247. doi:10.1123/jsp.3.3.244

Milojevich, H. M., \& Haskett, M. E. (2018). Longitudinal associations between physically abusive parents' emotional expressiveness and children's self-regulation. Child Abuse \& Neglect, 77, 144-154.

Moon, J. A. (2013). Reflection in learning and professional development: Theory and practice. New York: Routledge Falmer.

Morgan, G. (2009). Reflective practice and self-awareness. Perspectives in Public Health, 129(4), 161-162. doi:10.1177/1757913908105954

Omli, J., \& LaVoi, N. M. (2009). Background anger in youth sport: A perfect storm? Journal of Sport Behavior, 32, 242-260.

Omli, J., \& Wiese-Bjornstal, D. M. (2011). Kids speak. Research Quarterly for Exercise and Sport, 82(4), 702-711. doi:10.1080/02701367.2011.10599807

Palinkas, L., Horwitz, S., Green, C., Wisdom, J., Duan, N., \& Hoagwood, K. (2015). Purposeful sampling for qualitative data collection and analysis in mixed method implementation 
research. Administration and Policy in Mental Health and Mental Health Services

Research, 42(5), 533-544. doi:10.1007/s10488-013-0528-y

Parletta, N., Peters, J., Owen, A., Tsiros, M. D., \& Brennan, L. (2012). Parenting styles, communication and child/adolescent diets and weight status: Let's talk about it. Early Child Development and Care, 182(8), 1089-1103. doi:10.1080/03004430.2012.678597

ParticipACTION. (2018, June 19). The 2018 ParticipACTION report card on physical activity for children and youth. Retrieved from https://www.participaction.com/en-ca/thoughtleadership/report-card/2018

Pomerantz, E. M., Grolnick, W. S., \& Price, C. E. (2005). The role of parents in how children approach achievement: A dynamic process perspective. Handbook of competence and motivation (A. J. Elliot \& C. S. Dweck Ed.) (p. 259-278). New York: Guilford Press.

Potter, C. (2015). Leadership development: An applied comparison of Gibbs' reflective cycle and Scharmer's theory U. Industrial and Commercial Training, 47(6), 336-342.

Purdy, D. A., Haufler, S. E., \& Eitzen, D. S. (1981). Stress among child athletes: Perceptions by parents, coaches, and athletes. Journal of Sport Behavior, 4, 32-44.

Radziszewska, B., Richardson, J. L., Dent, C. W., \& Flay, B. R. (1996). Parenting style and adolescent depressive symptoms, smoking, and academic achievement: Ethnic, gender, and SES differences. Journal of Behavioral Medicine, 18, 289-305. doi:10.1007/BF01857770.

Ramis, Y., Viladrich, C., Sousa, C., \& Jannes, C. (2015). Exploring the factorial structure of the sport anxiety scale-2: Invariance across language, gender, age and type of sport. Psicothema, 27, 174-181.

Richards, P., Mascarenhas, D. R. D., \& Collins, D. (2009). Implementing reflective practice approaches with elite team athletes: Parameters of success. Reflective Practice, 10(3), 353-363. doi:10.1080/14623940903034721

Rogers, A. A., Ha, T., Stormshak, E. A., \& Dishion, T. J. (2015). Quality of Parent-Adolescent conversations about sex and adolescent sexual behavior: An observational study. Journal of Adolescent Health, 57(2), 174-178. doi:10.1016/j.jadohealth.2015.04.010

Rolfe, G., Freshwater, D. \& Jasper, M. (2001). Critical reflection in nursing and the helping professions: A user's guide. Basingstoke: Palgrave Macmillan.

Russell, W. D., \& Limle, A. N. (2013). The relationship between youth sport specialization and involvement in sport and physical activity in young adulthood. Journal of Sport Behavior, 36(1), 82-98.

Schön, D. A. (1983). The reflective practitioner: How professionals think in action. New York: Basic Books. 
Seidman, I. E. (1991). Interviewing as qualitative research: A guide for researchers in education and the social sciences. New York: Teachers College Press.

Smith, B., \& McGannon, K. R. (2018) Developing rigor in qualitative research: problems and opportunities within sport and exercise psychology, International Review of Sport and Exercise Psychology, 11(1), 101-121, doi: 10.1080/1750984X.2017.1317357

Smith, M., \& Trede, F. (2013). Reflective practice in the transition phase from university student to novice graduate: Implications for teaching reflective practice. Higher Education Research \& Development, 32(4), 632-645. doi:10.1080/07294360.2012.709226

Socha, T. J., \& Stamp, G. H. (1995). Parent-child communication within the family system. Parents, children, and communication (pp. 3-23). Mahwah, NJ: Lawrence Erlbaum Association.

Söderberg, A., Sundbaum, J. K., \& Engström, Å. (2017). Nursing students' reflections after meetings with patients and their relatives enacted by professional actors: Being touched and feeling empathy. Issues in Mental Health Nursing, 38(2), 139-144.

doi:10.1080/01612840.2016.1251517

Sparkes, A. C., \& Smith, B. (2014). Qualitative research methods in sport, exercise and health from process to product. New York: Routledge.

Steinberg, L., Lamborn, S., Dornbusch, S., \& Darling, N. (1992). Impact of parenting practices on adolescent achievement: Authoritative parenting, school involvement, and encouragement to succeed. Child Development, 63, 1266-1281. doi: 10.2307/1131532.

Strayer, J., \& Roberts, W. (2004). Children's anger, emotional expressiveness, and empathy: Relations with parents' empathy, emotional expressiveness, and parenting practices. Social Development, 13(2), 229-254. doi:10.1111/j.1467-9507.2004.000265.x

Tamminen, K. A., \& Holt, N. L. (2012). Adolescent athletes' learning about coping and the roles of parents and coaches. Psychology of Sport \& Exercise, 13(1), 69-79. doi:10.1016/j.psychsport.2011.07.006

Tamminen, K. A., Poucher, Z. A., \& Povilaitis, V. (2017). The car ride home: An interpretive examination of parent-athlete sport conversations. Sport, Exercise, and Performance Psychology, 6(4), 325-339.

Taylor, S., Werthner, P., Culver, D., \& Callary, B. (2015). The importance of reflection for coaches in parasport. Reflective Practice, 16(2), 269-284. doi:10.1080/14623943.2015.1023274

Tein, J. Y., Roosa, M. W., \& Michaels, M. (1994). Agreement between parent and child reports on parental behaviors. Journal of Marriage and Family, 56(2), 341-355.

Tod, D., Marchant, D., \& Andersen, M. B. (2007). Learning experiences contributing to servicedelivery competence. The Sport Psychologist, 21, 317-334. 
Tsang, E. W. K. (2014). Case studies and generalization in information systems research: A critical realist perspective. Journal of Strategic Information Systems, 23(2), 174-186.

Wain, A. (2017). Learning through reflection. British Journal of Midwifery, 25(10), 662-666. doi:10.12968/bjom.2017.25.10.662

Wankel, L. M., \& Berger, B. G. (1990). The psychological and social benefits of sport and physical activity. Journal of Leisure Research, 22(2), 167-182.

Wilding, P. M. (2008). Reflective practice: A learning tool for student nurses. British Journal of Nursing, 17(11), 720-724.

Williams, K., Ciarrochi, J., \& Heaven, P. (2012). Inflexible parents, inflexible kids: A 6-year longitudinal study of parenting style and the development of psychological flexibility in adolescents. Journal of Youth and Adolescence, 41(8), 1053-1066. doi:10.1007/s10964012-9744-0

Wilson, V. (2014). Research methods: Triangulation. Evidence Based Library and Information Practice, 9(1), 601. doi:10.18438/B8WW3X

Wood, J. T. (2010). Chapter 5: The world beyond words. Interpersonal communication: Everyday encounters ( $7^{\text {th }}$ Ed.) (p. 117-141). Boston, MA: Wadsworth.

Wylleman, P., \& Lavallee, D. (2004). A developmental perspective on transitions faced by athletes. In M. R. Weiss (Ed.) Developmental sport and exercise psychology: A lifespan perspective (pp. 507-527). Morgantown, WV: Fitness Information Technology. 


\section{Appendices}

\section{Appendix A \\ PARENT/GUARDIAN INDIVIDUAL INFORMATION LETTER Parental Communication and Reflective Practice among Youth Sport Parents}

\author{
Primary Investigator: \\ Sina Azimi \\ University of Toronto \\ Faculty of Kinesiology and Physical \\ Education \\ 55 Harbord Street \\ Toronto, ON M5S 2W6
}

\author{
Research Supervisor: \\ Katherine Tamminen \\ University of Toronto \\ Faculty of Kinesiology and Physical \\ Education \\ 55 Harbord Street \\ Toronto, ON M5S 2W6
}

\section{Study overview:}

You and your child are invited to participate in a study about improving parental communication in youth sport settings. The purpose of this study is to understand how parents communicate with their child in sport settings.

\section{What is involved in the study?}

We are asking athletes ages 13-15 as well as a parent/guardian who is involved in the athlete's sporting activities through transporting their child to and from sport practices and/or games, watching their child's sport practices and/or games, and is responsible for the enrolment of their child in various sporting activities to participate in our study. Our study consists of pre-and postsurveys and interviews for parents and athletes, and we will also ask parents to keep an audio diary for 6 weeks.

The interview will be tape-recorded and will last approximately 30-45 minutes. During the interview, we will ask questions about the kinds of sports or physical activities your child takes part in, and the types of interactions you have with your child before, during and after his/her training/competition and your relationship with your child. In the event that you have more than one child who fit the criteria for participation (e.g., plays sports, between 13-15 years old), then both children can participate in separate interviews if they want to. Your child will also be asked to participate in an interview that will ask about their experiences in sport, and about their interactions with you before and after games and practices.

After completing the interview and surveys, parents will be asked to participate in a 30-45 min. workshop on parent communication in sport. Parents will then be asked to complete at least one audio diary per week for 6 weeks. These audio diaries will ask parents to answer questions provided to them on a prompt sheet after their child's training/competition. We ask each participating parent to choose one context (e.g., after practice), for answering the audio diary questions. In the beginning of each week, parents will receive a brief text message from the primary investigator, reminding them to complete their audio diary entry for the week. At the 
end of the 6-week period, you and your child will be invited back to complete a follow-up interview and survey.

Should you wish to withdraw from the study, you are required to inform the primary investigator prior to January $30^{\text {th }} 2018$. Once the primary investigator receives the your request to withdraw, any information/data provided up until that point will be removed and will no longer be analyzed. If you inform the primary investigator after January $30^{\text {th }} 2018$, you are free to withdraw without any consequences but your data/information may still be subject to analysis.

Each athlete will receive $\$ 5.00$ for completing pre-study survey and interview. Each athlete will also receive $\$ 5.00$ for completing post-study survey and interview ( $\$ 10.00$ per athlete). Each parent will receive $\$ 5.00$ for completing pre-study survey and interview. Each parent will also receive $\$ 5.00$ for completing post-study survey and interview. As well, at the end of the six-week period, each parent will receive $\$ 20.00$ for completing the audio diaries ( $\$ 30.00$ per parent). In summary each parent-athlete dyad will receive $\$ 40.00$ for completing the study.

Compensation will be given per completion of each stage of the study. If parents/athlete decide to withdraw after completing the first stage of the study (pre-study survey and interview), they will each receive $\$ 5.00$ for their participation. If parents decide to withdraw halfway through the audio diary period, they will receive partial compensation based on the number of audio diaries they have completed.

The total time commitment for parents is approximately 3.5 hours; the time commitment for athletes is approximately 2 hours.

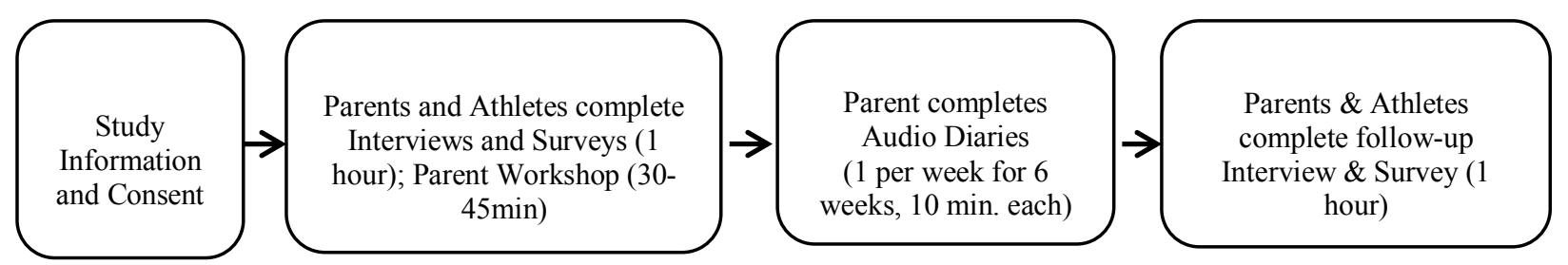

\section{What are the benefits of this study? Are there any risks?}

We think this study will provide important information about child and parent sport interactions. The results of this study will serve as a foundation for the future creation of interventions aimed at promoting more positive parental involvement in youth sport. This study is designed to help parents think about their personal behaviours through audio diaries, which will hopefully result in enhancement of parents' understanding of their behaviours in youth sport.

Discussing parent/child conversations and interactions could pose some psychological or emotional discomfort during the interview. You/your child do not have to answer any questions that are uncomfortable, and you/your child are free to refuse to answer any questions during the interview. In the event that you would like to further discuss any feelings regarding the topics in the interviews, you may wish to contact support services (see attached information page).

Your/your child's answers during the interviews, surveys and audio diaries will be confidential; we will not share your answers to the audio diaries and interview questions with your child, and we will not share your child's answers with you in order to maintain confidentiality. While your 
information will be kept confidential, if during the interview, you/your child disclosed instances of abuse, legally it must be reported to the appropriate authorities (e.g., Children's Aid Society). That means if you/your child disclosed things like emotional abuse (e.g., bullying) or physically abuse, we would have to report that information. Your identity will only be known by the members of the research team and we will assign a 'false name' (a pseudonym) to your/your child's interviews once they are completed so that you cannot be identified. We will not tell the coach, club, or league director/administration about who chooses to participate or who chooses not to participate in the study. If you do not want to participate in this study, it will not impact your/your child's position/reputation/relationship with the team/club.

You can stop the interview and audio diaries at any time, and you can withdraw from the study for any reason up until the data is analyzed (two months after your interview is completed). If you would like to withdraw from the study, you can contact the research supervisor, Dr. Katherine Tamminen or the primary investigator, Sina Azimi.

\section{What will happen with the information we provide?}

Survey results will be collected and held at the University of Toronto in the Faculty of Kinesiology and Physical Education. Interviews and audio diaries will be transcribed and held at the University of Toronto in the Faculty of Kinesiology and Physical Education. Only the researchers will have access to information collected from the surveys, interviews, and audio diaries. The information is kept for five years, after which it will be destroyed. Once we have completed the study, members of the research team will present the results at a conference. They may also write a paper which will be published in an academic journal. If the results are presented at a conference or in a paper, no one will be identified by name. We will present group information so that no one can be identified with their information (e.g., " $40 \%$ of parents discussed game strategy with their child"). A summary of the results and copies of any resulting publications will be provided at your request.

If you have questions about this study, or about the information used for research purposes, you may contact Dr. Katherine Tamminen, who is an assistant professor at the University of Toronto, Faculty of Kinesiology, and Physical Education, as well as the primary investigator for this study. You may also contact the Office of Research Ethics at ethics.review@utoronto.ca or 416946-3273 if you have questions about your rights as a participant. 


\section{Appendix B}

\section{Parent/Guardian Consent Form}

Title of the Study: Parental Communication and Reflective Practice among Youth Sport Parents

\section{Primary Investigator:}

Sina Azimi

University of Toronto

Faculty of Kinesiology and Physical

Education

55 Harbord Street

Toronto, ON M5S 2W6

\author{
Research Supervisor: \\ Katherine Tamminen \\ University of Toronto \\ Faculty of Kinesiology and Physical \\ Education \\ 55 Harbord Street \\ Toronto, ON M5S 2W6
}

I agree to participate in a study examining parent-child communication in sport. I understand that my participation is entirely voluntary: I can withdraw from the study at any time and this will have no negative impact on my child's sport participation, nor will it have any other negative consequences.

The following points have been explained to me:

1. The purpose of this study is to understand how parents communicate with their child before, during and after their training and/or competition.

2. My child and myself have been asked to individually participate in interviews and complete survey questionnaires. I have also been asked to complete at least one audio diary per week for 6 weeks. During these audio diaries, I will be answering questions on provided to me on a prompt sheet after my child's training/competition. Benefits I may expect from the study are: (a) an appreciation for youth sport psychology research, and (b) an opportunity to contribute to scientific research.

3. The researchers do not anticipate any foreseeable risk to me or my child for participating in this study. My child and I have the right to stop any part of the study and/or withdraw at any time with no negative consequences. My choice will not have any negative implications for myself or influence any future interactions with the primary investigator or the research supervisor.

4. The data collected will remain confidential. Only the primary investigator and the research supervisor will have access to the information. No data will be associated with my name but will be replaced with a code. Results may be published in scholarly publications or presented at academic conference, which are publicly available documents/presentations. No one will be identified by name in any publications or presentations.

5. The survey data, and audio diaries may be retained for training purposes and future data analyses. If you do not want your data used for future training or research purposes, please initial here: 
6. The researcher will be open to any questions or concerns about the experiment. For any other information, please contact the research supervisor Dr. Katherine Tamminen or the Office of Research Ethics (Phone: 416-946-3273 or Email: ethics@utoronto.ca).

7. I have been told that the following methods will be employed in this study:

- 6 Audio Recordings (Sony audio recorder will be provided for 6 weeks)

- Parent and Athlete Surveys

- Parent and Athlete Interview

8. The total time to participate will depend on the number of audio diaries that are completed. The total time commitment for parents is approximately 3.5 hours; the time commitment for athletes is approximately 2 hours. Most parents will complete a minimum of 6 audio diaries $\times 10$ each $=$ approx. 60 minutes. The surveys and interviews will take approximately 1 hour total to complete. Parents can choose to do more than one audio diary per week.

9. Each athlete will receive $\$ 5.00$ for completing pre-study survey and interview. Each athlete will also receive $\$ 5.00$ for completing post-study survey and interview (\$10.00 per athlete). Each parent will receive $\$ 5.00$ for completing pre-study survey and interview. Each parent will also receive $\$ 5.00$ for completing post-study survey and interview. As well, at the end of the six-week period, each parent will receive $\$ 20.00$ for completing the audio diaries ( $\$ 30.00$ per parent). In summary each parentathlete dyad will receive $\$ 40.00$ for completing the study.

10. Compensation will be given per completion of each stage of the study. If parents/athlete decide to withdraw after completing the first stage of the study (prestudy survey and interview), they will each receive $\$ 5.00$ for their participation. If parents decide to withdraw halfway through the audio diary period, they will receive partial compensation based on the number of audio diaries they have completed.

11. The research study you are participating in may be reviewed for quality assurance to make sure that the required laws and guidelines are followed. If chosen, (a) representative(s) of the Human Research Ethics Program (HREP) may access studyrelated data and/or consent materials as part of the review. All information accessed by the HREP will be upheld to the same level of confidentiality that has been stated by the research team.

12. Should you wish to withdraw from the study, you are required to inform the primary investigator prior to January 30th 2018. Once the primary investigator receives the your request to withdraw, any information/data provided up until that point will be removed and will no longer be analyzed. If you inform the primary investigator after January 30th 2018 , you are free to withdraw without any consequences but your data/information may still be subject to analysis. 
You are being given a copy of this informed consent to keep for your own records.

I agree to my child and myself participating in this study:

Printed Name:

Child's Name:

Signature:

Date: 


\section{Appendix C}

\section{CHILD INDIVIDUAL INFORMATION LETTER AND ASSENT FORM Parental Communication and Reflective Practice among Youth Sport Parents}

\author{
Primary Investigator: \\ Sina Azimi \\ University of Toronto \\ Faculty of Kinesiology and Physical \\ Education \\ 55 Harbord Street \\ Toronto, ON M5S 2W6
}

\author{
Research Supervisor: \\ Katherine Tamminen \\ University of Toronto \\ Faculty of Kinesiology and Physical \\ Education \\ 55 Harbord Street \\ Toronto, ON M5S 2W6
}

\section{Study overview:}

You and your parent/guardian are invited to participate in a study about improving parental communication in youth sport settings. The purpose of this study is to understand how parents communicate with their child in sport settings.

\section{What is involved in the study?}

We are asking athletes ages 13-15 as well as a parent/guardian who is involved in your sporting activities through transporting you to and from sport practices and/or games, watching your sport practices and/or games, and is responsible for the your enrolment in various sporting activities to participate in our study. Our study consists of pre-and post-surveys and interviews for parents and athletes, and we will also ask parents to keep an audio diary for 6 weeks.

The interview will be tape-recorded and will last approximately 30-45 minutes. During the interview, we will ask questions about the kinds of sports or physical activities you take part in, and the types of interactions you have with your parent/guardian before, during and after your training/competition and your relationship with your parent/guardian. Your parents will also be asked to complete an interview on these topics.

After completing the interview and surveys, your parents will be asked to participate in a 30-45 min. workshop on parent communication in sport. Parents will then be asked to complete at least one audio diary per week for 6 weeks. These audio diaries will ask parents to answer questions provided to them on a prompt sheet after your training/competition. We ask each participating parent to choose one context (e.g., after practice), for answering the audio diary questions. At the end of the 6-week period, you and your parent/guardian will be invited back to complete a follow-up interview and survey.

Should you wish to withdraw from the study, you are required to inform the primary investigator prior to January $30^{\text {th }} 2018$. Once the primary investigator receives the your request to withdraw, any information/data provided up until that point will be removed and will no longer be analyzed. If you inform the primary investigator after January $30^{\text {th }} 2018$, you are free to withdraw without any consequences but your data/information may still be subject to analysis. 
Each athlete will receive $\$ 5.00$ for completing pre-study survey and interview. Each athlete will also receive $\$ 5.00$ for completing post-study survey and interview ( $\$ 10.00$ per athlete). Each parent will receive $\$ 5.00$ for completing pre-study survey and interview. Each parent will also receive $\$ 5.00$ for completing post-study survey and interview. As well, at the end of the six-week period, each parent will receive $\$ 20.00$ for completing the audio diaries ( $\$ 30.00$ per parent). In summary each parent-athlete dyad will receive $\$ 40.00$ for completing the study.

Compensation will be given per completion of each stage of the study. If parents/athlete decide to withdraw after completing the first stage of the study (pre-study survey and interview), they will each receive $\$ 5.00$ for their participation. If parents decide to withdraw halfway through the audio diary period, they will receive partial compensation based on the number of audio diaries they have completed.

The total time commitment for parents is approximately 3.5 hours; the time commitment for athletes is approximately 2 hours.

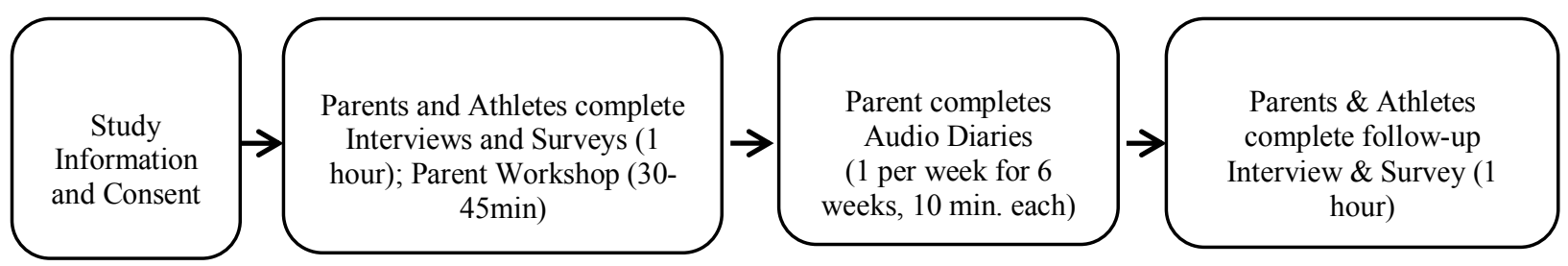

\section{What are the benefits of this study? Are there any risks?}

We think this study will provide important information about child and parent sport interactions. The results of this study will serve as a foundation for the future creation of interventions aimed at promoting more positive parental involvement in youth sport. This study is designed to help parents think about their personal behaviours through audio diaries, which will hopefully result in enhancement of parents' understanding of their behaviours in youth sport.

Talking about conversations with your parents might make some people uncomfortable. You do not have to answer any questions you do not want to. You can also refuse to answer any questions during the interview. If you would like to talk about your feelings after the interview, you can contact support services (see the attached information page). You can also contact Kids Help Phone to talk without giving your name to anyone (1-800-668-6868; http://www.kidshelpphone.ca/Teens/Home.aspx)

Your answers during the interviews will be confidential; we will not share your answers to the interview questions with your parent/guardian, and we will not share your parent/guardian's answers with you. While your information will be kept confidential, if during the interview you disclosed any abuse, legally it must be reported to the appropriate authorities (e.g., Children's Aid Society). That means if you disclosed things like parents hurting you emotionally (e.g., bullying) or physically hurting you, we would have to report that information. Only the researchers will know your identity and we will assign a 'false name' (a pseudonym) to your interview once it is done so that you cannot be identified. We will not tell your coach whether you participated in the study or not. If you do not want to participate in this study, it will not impact your position on the team. 
Participation in this study is voluntary. You will not get any money for participating. Nothing bad will happen if you or your parent does not participate. If you want to participate but your parent does not want to participate, that is fine. You can still participate in an interview even if your parent does not want to do an interview. If your parent wants to participate but you do not want to participate, that is also fine. Your parent can still participate in an interview even if you do not want to. You can stop the interview at any time. You can withdraw from the study for any reason up to two months after your interview is over. You can contact Katherine Tamminen if you would like to withdraw from the study (416-946-4068, email:

katherine.tamminen@utoronto.ca).

\section{What will happen with the information we provide?}

Interviews and audio diaries will be transcribed and held at the University of Toronto in the Faculty of Kinesiology and Physical Education. Only the researchers will have access to this information. The information is kept for five years, after which it will be destroyed. Once we have completed the study, members of the research team will present the results at a conference. The researchers will write a paper which will be published in an academic journal. When the results are presented no one will be identified by name. We will present group information so that no one can be linked with their information (e.g., " $40 \%$ of parents discussed game strategy with their child"). You can ask for a report of the results after the study is over. If you have questions about this study you may contact Dr. Katherine Tamminen. She is an assistant professor at the University of Toronto in the Faculty of Kinesiology, and Physical Education (416-946-4048, or email: katherine.tamminen@utoronto.ca). You may contact the Office of Research Ethics if you have questions your rights as participants (ethics.review@utoronto.ca or 416-946-3273.

You are being given a copy of this informed consent to keep for your own records.

I, , have read the information letter and fully

understand its content.

If you would like to participate in this research study, please sign your name on the line below:

Child's Name/Signature (Written by child)

Signature of Primary Investigator

\section{Date}

Date 
Appendix D

\section{Graphs}




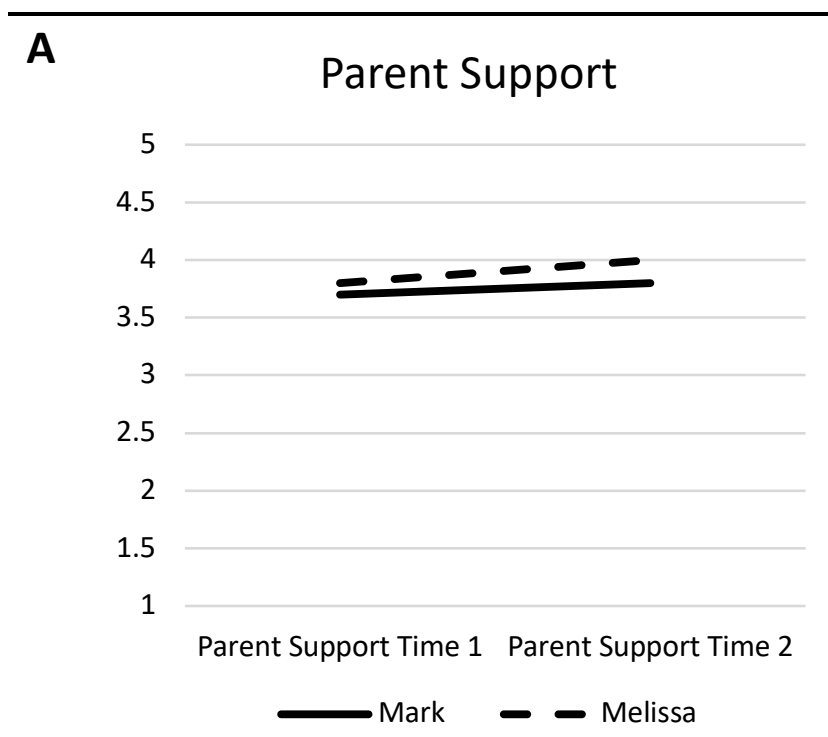

B

Parent Pressure

C

\section{Authoritarian Parenting}

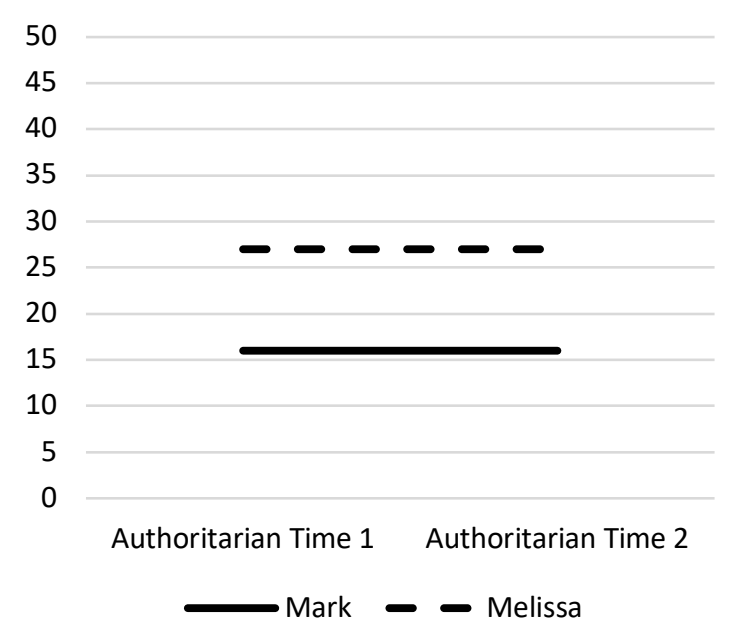

\section{D}

\section{Authoritative Parenting}

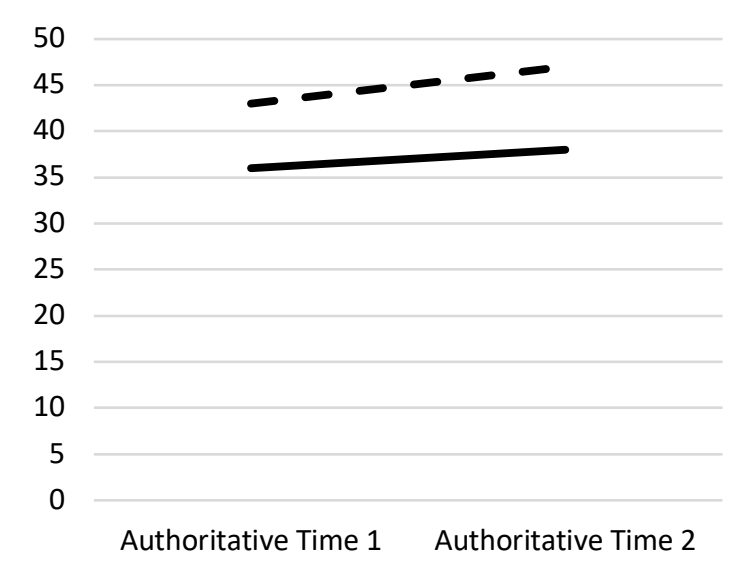

-Mark - Melissa

Figure 3. Changes perceived by Mark (parent) and Melissa (child). (A) Perceived changes in parental support, (B) Perceived changes in parental pressure, (C) Perceived changes in authoritarian parenting, and (D) perceived changes in authoritative parenting. 


\section{E}

\section{Permissive Parenting}

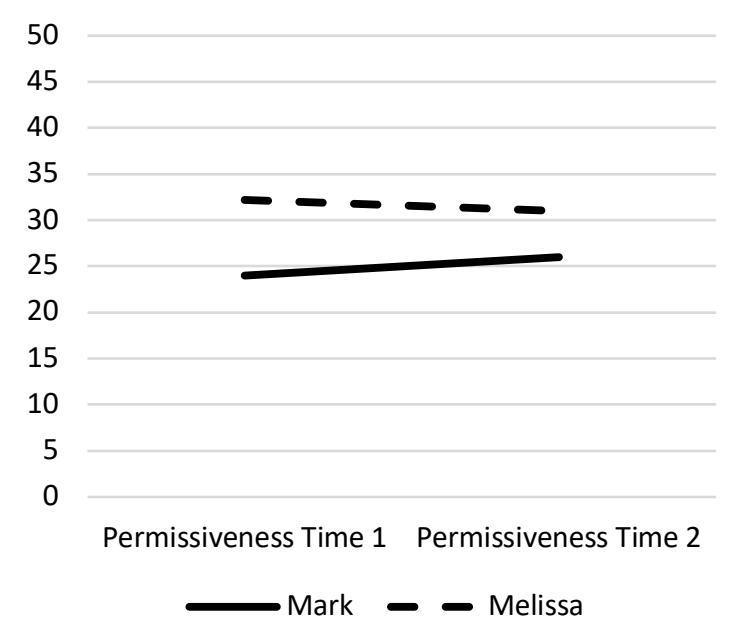

G

\section{Problems in Communication}

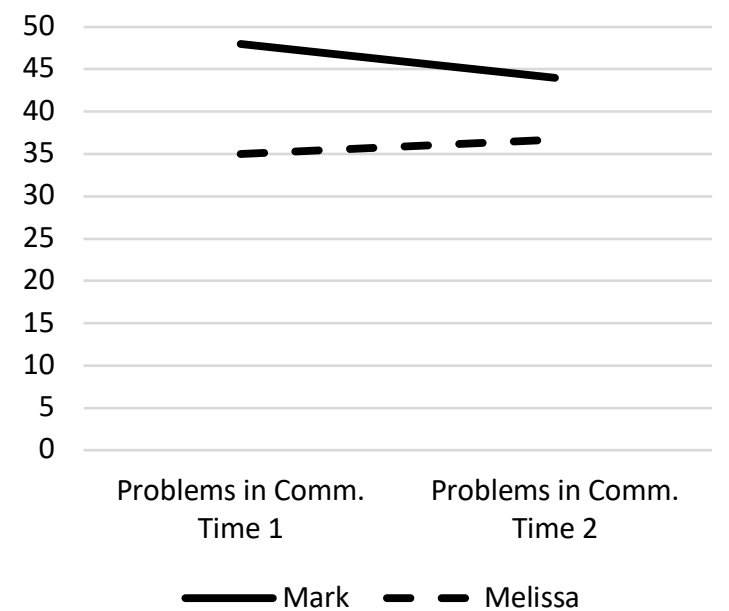

$\mathbf{F}$

\section{Open Communication}

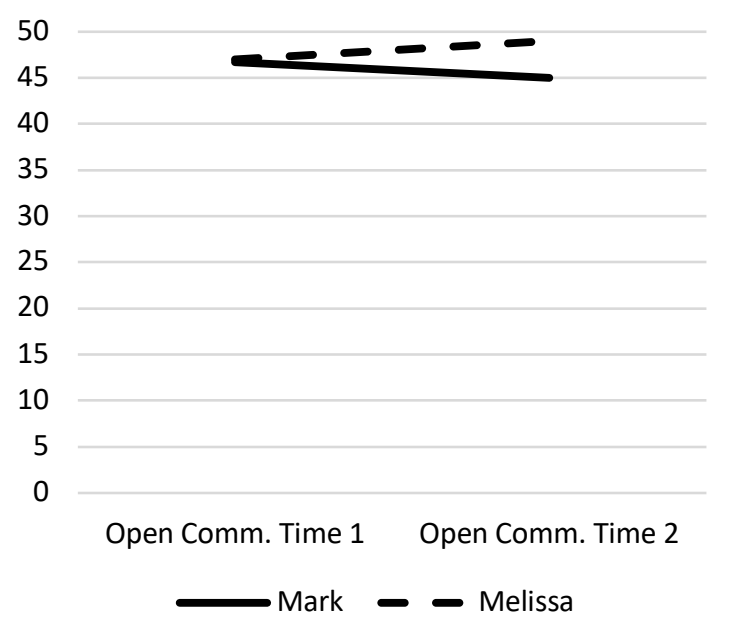

H

\section{Overall Quality of \\ Communication}

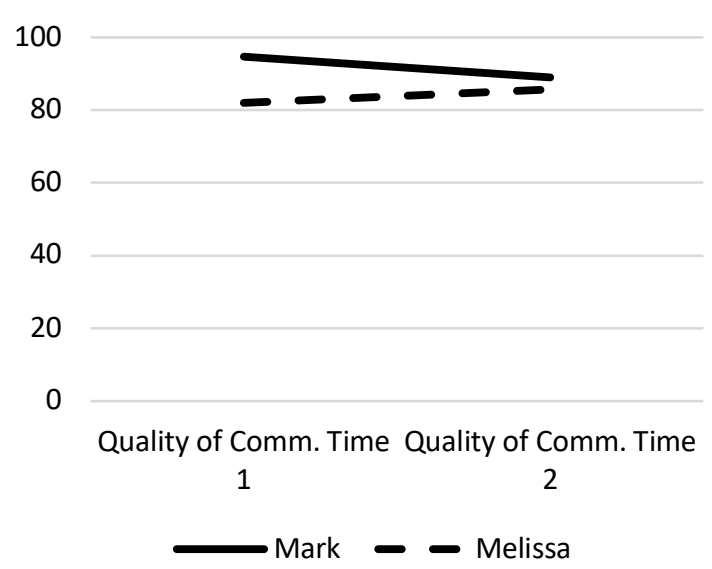

Figure 2. Changes perceived by Mark (parent) and Melissa (child). (E) Perceived changes in permissive parenting, (F) Perceived changes in open communication, (G) Perceived changes in problem in communication, and $(\mathrm{H})$ perceived changes in overall quality of communication. 


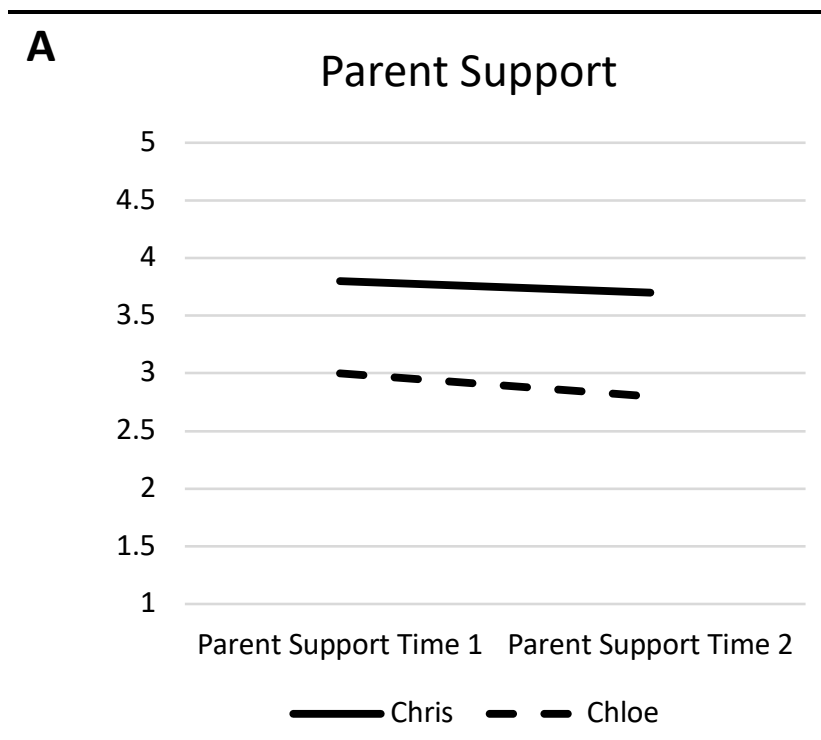

B

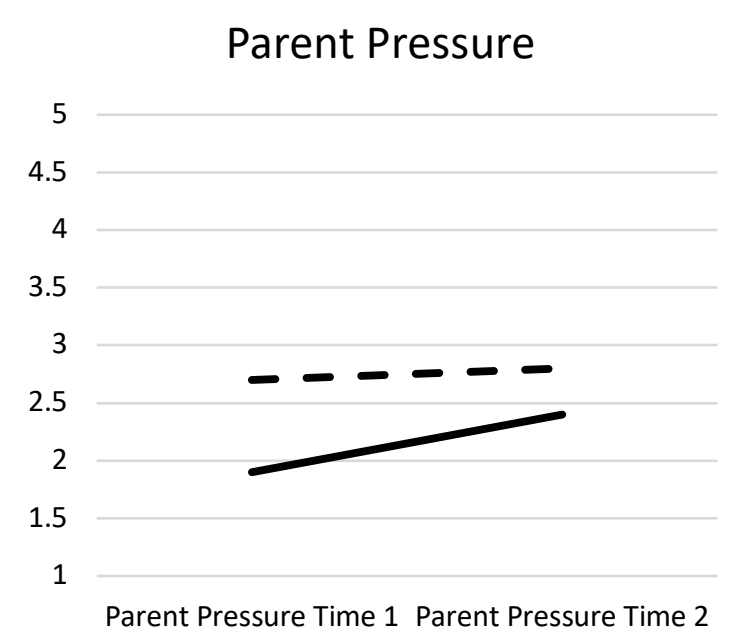

C

\section{Authoritarian Parenting}

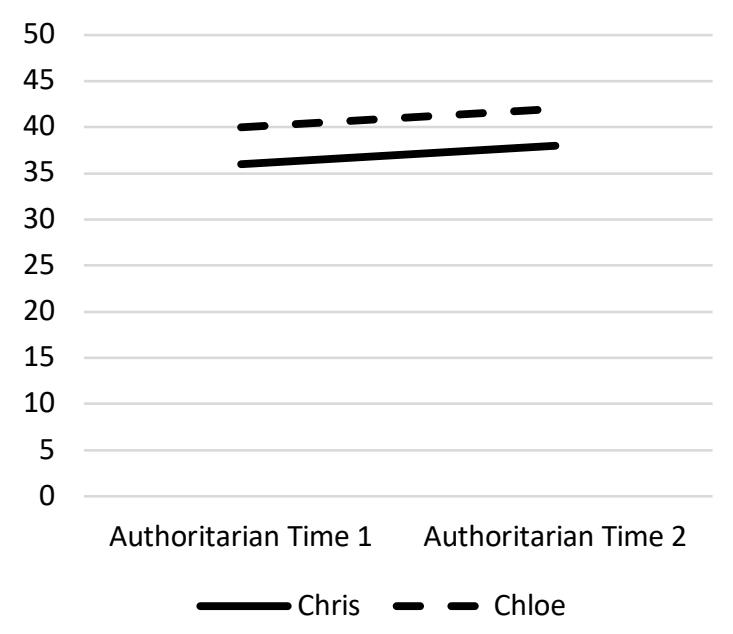

D

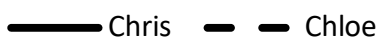

Authoritative Parenting

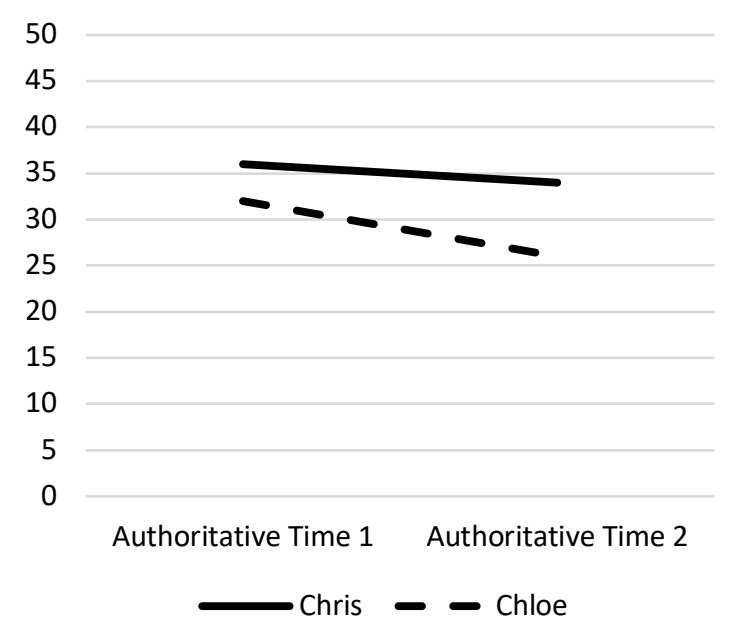

Figure 3. Changes perceived by Chris (parent) and Chloe (child). (A) Perceived changes in parental support, (B) Perceived changes in parental pressure, (C) Perceived changes in authoritarian parenting, and (D) perceived changes in authoritative parenting. 


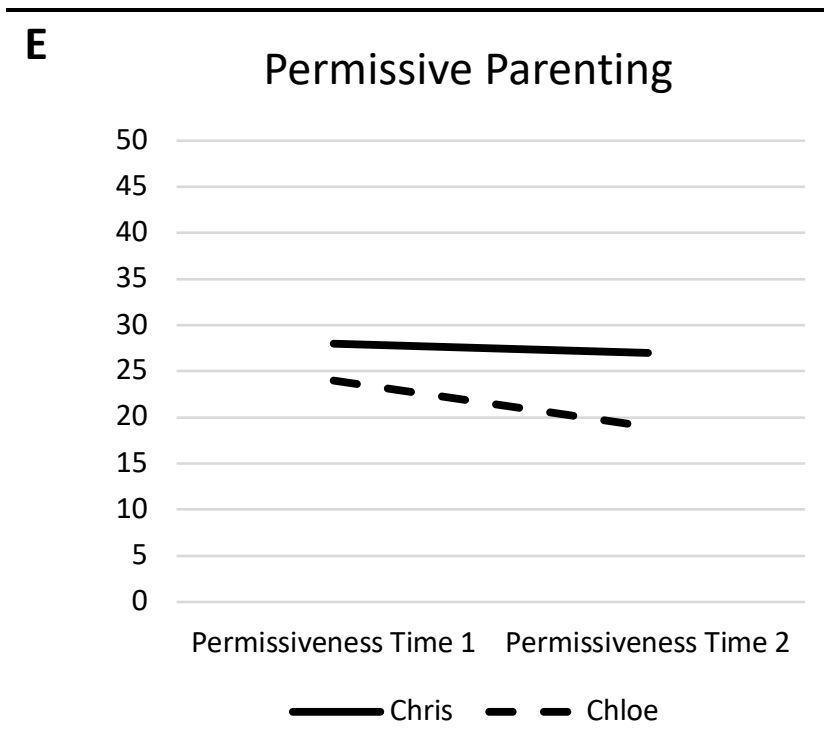

$\mathbf{F}$

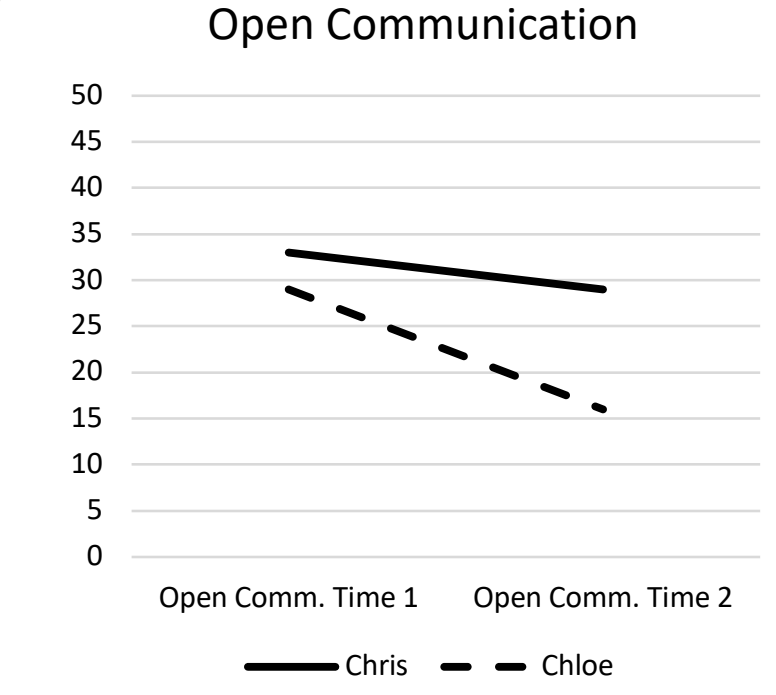

G

\section{Problems in Communication}

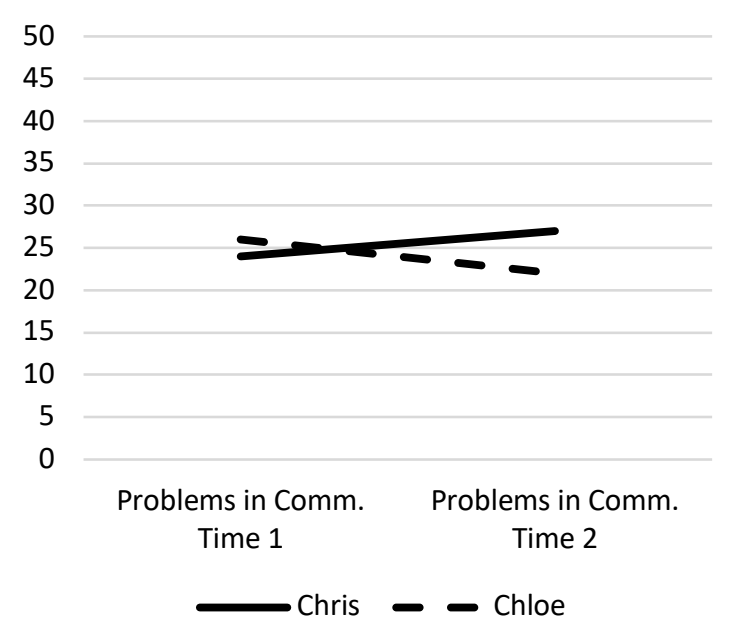

H

\section{Overall Quality of \\ Communication}

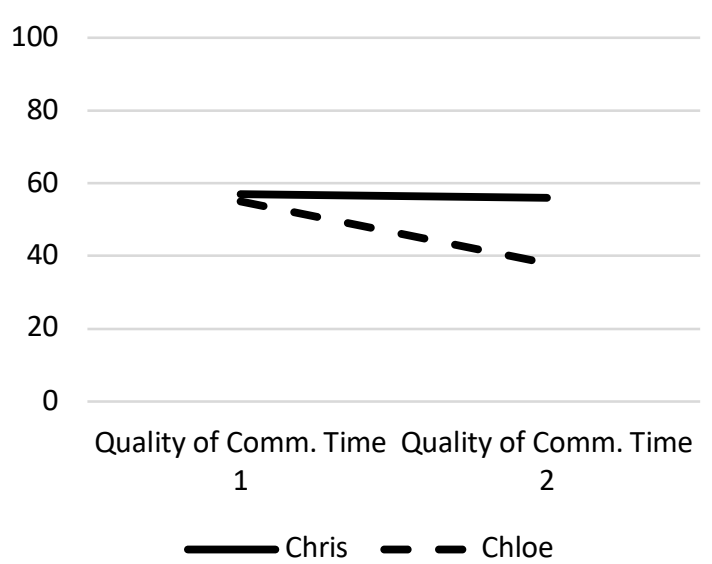




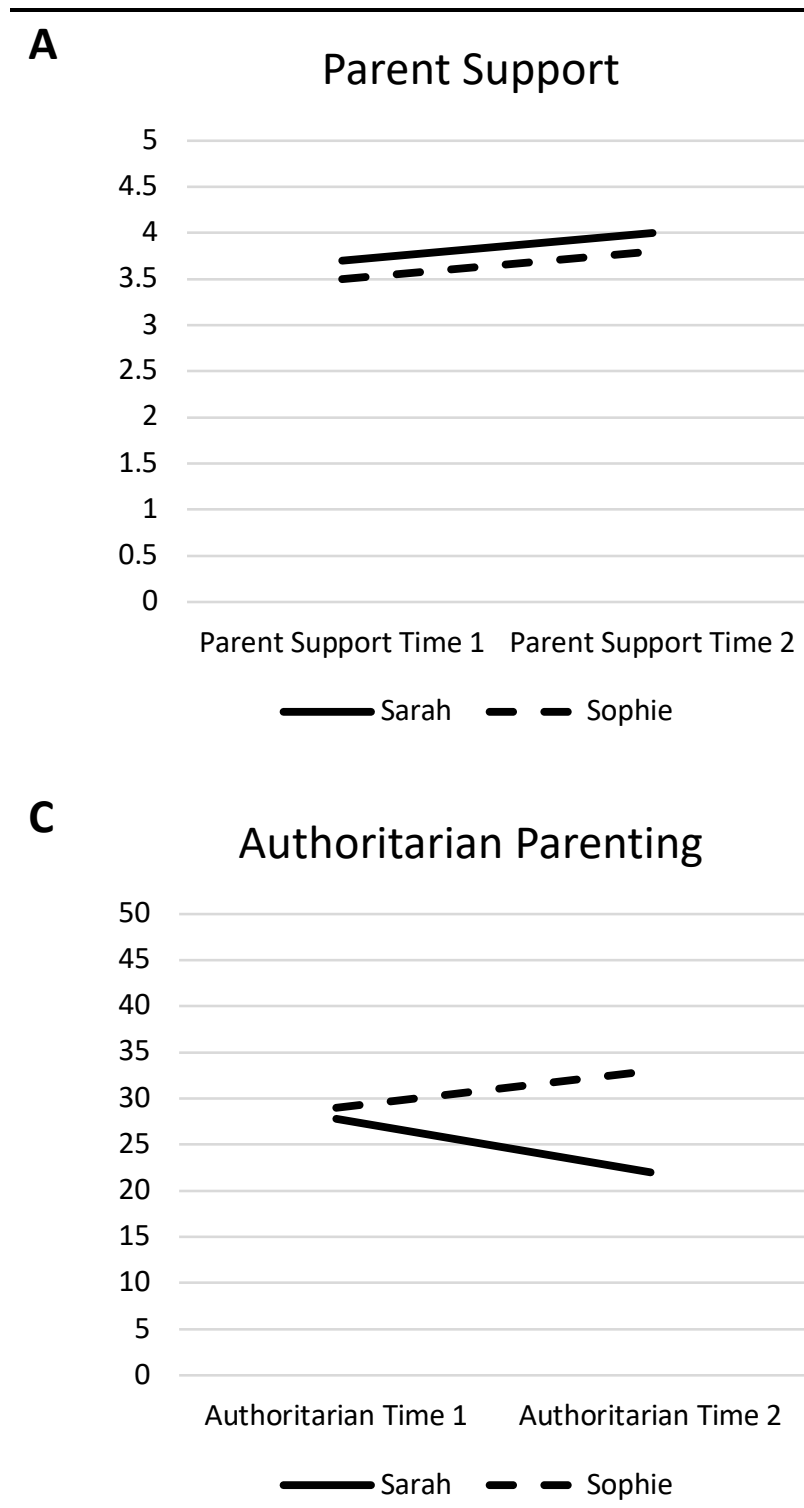

B
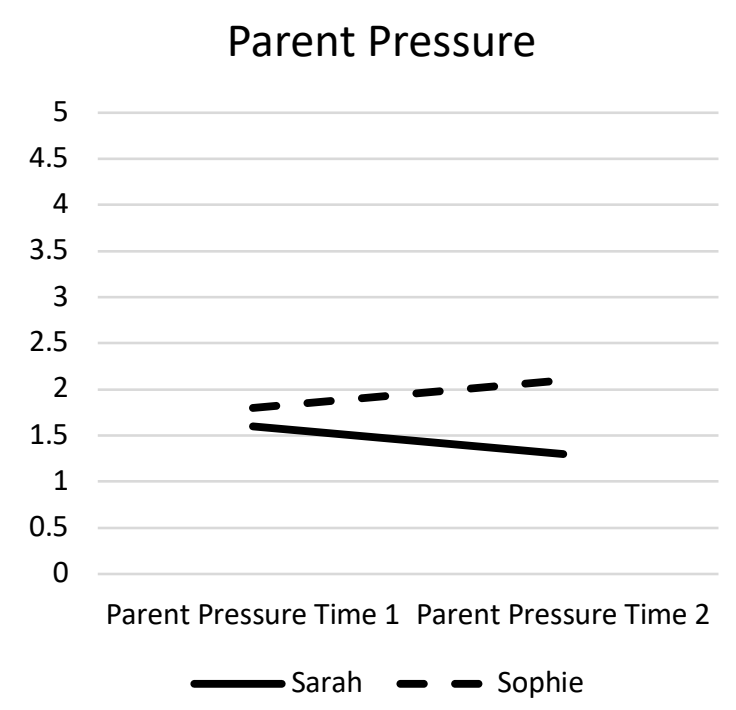

D

\section{Authoritative Parenting}

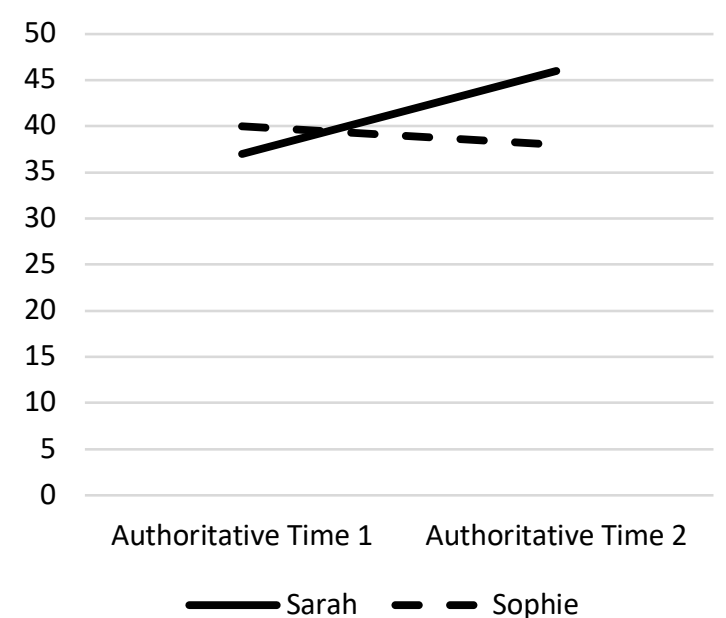

Figure 5. Changes perceived by Sarah (parent) and Sophie (child). (A) Perceived changes in parental support, (B) Perceived changes in parental pressure, (C) Perceived changes in authoritarian parenting, and (D) perceived changes in authoritative parenting. 


\section{E}

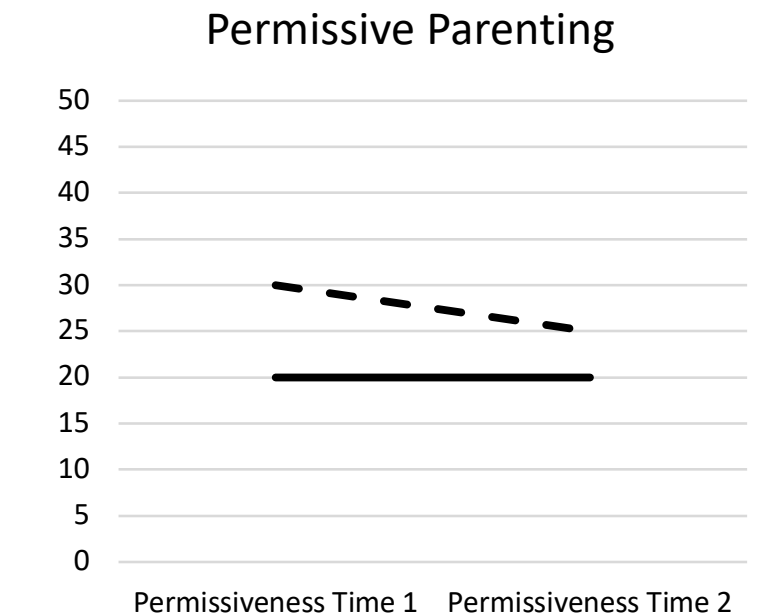

Sarah

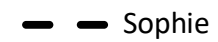

G

\section{Problems in Communication}

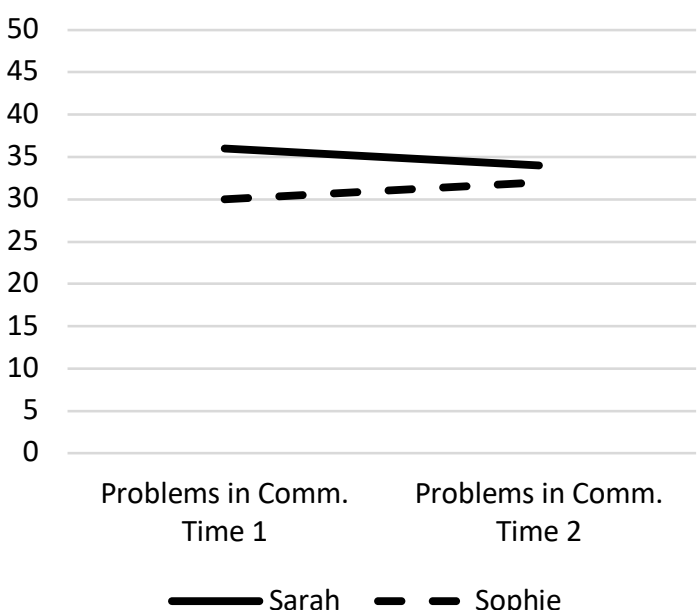

$\mathbf{F}$

\section{Open Communication}

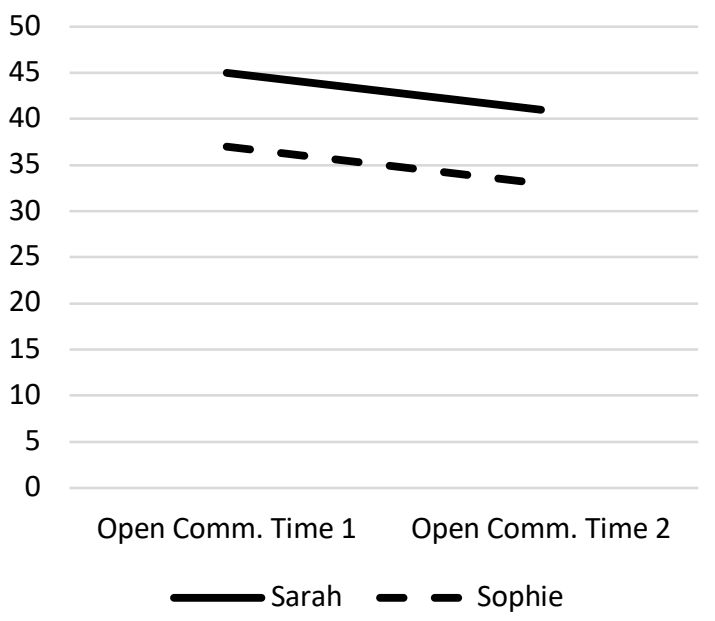

H

\section{Overall Quality of}

Communication

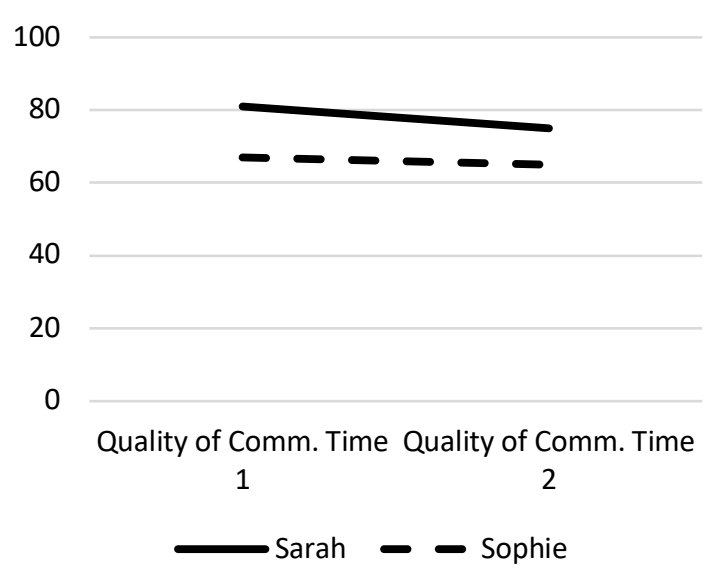

Figure 6. Changes perceived by Sarah (parent) and Sophie (child). (E) Perceived changes in permissive parenting, (F) Perceived changes in open communication, (G) Perceived changes in problem in communication, and $(\mathrm{H})$ perceived changes in overall quality of communication. 


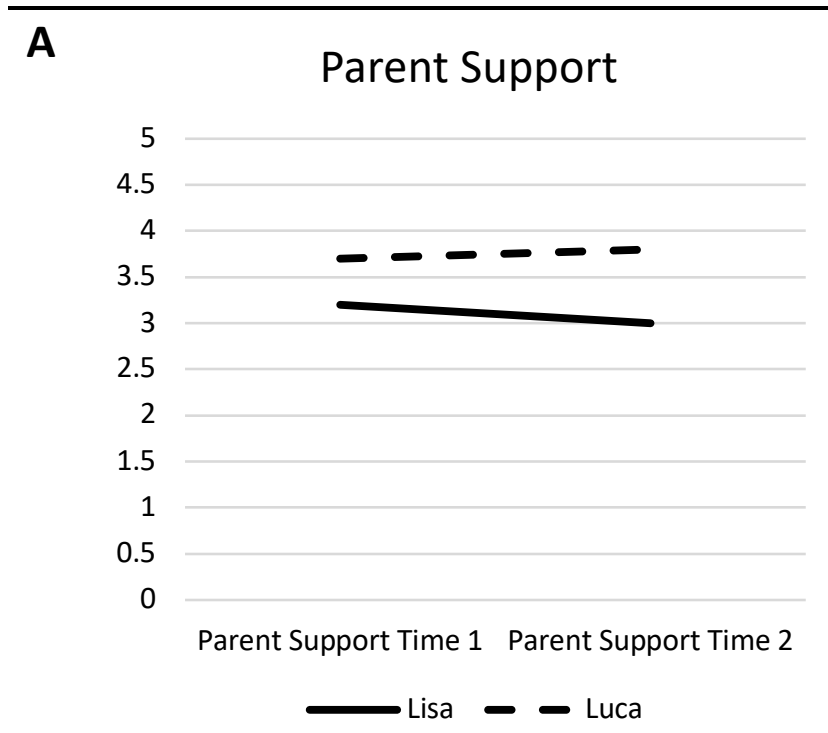

B

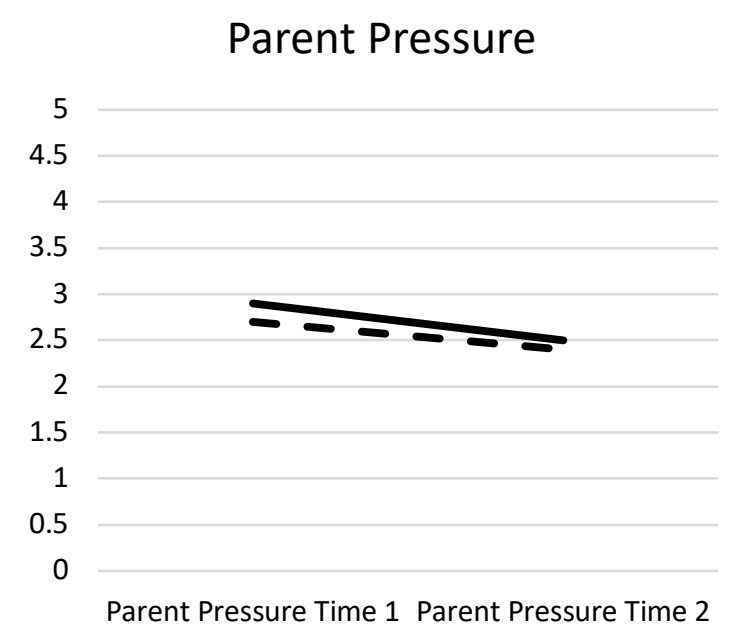

\section{C}

\section{Authoritarian Parenting}

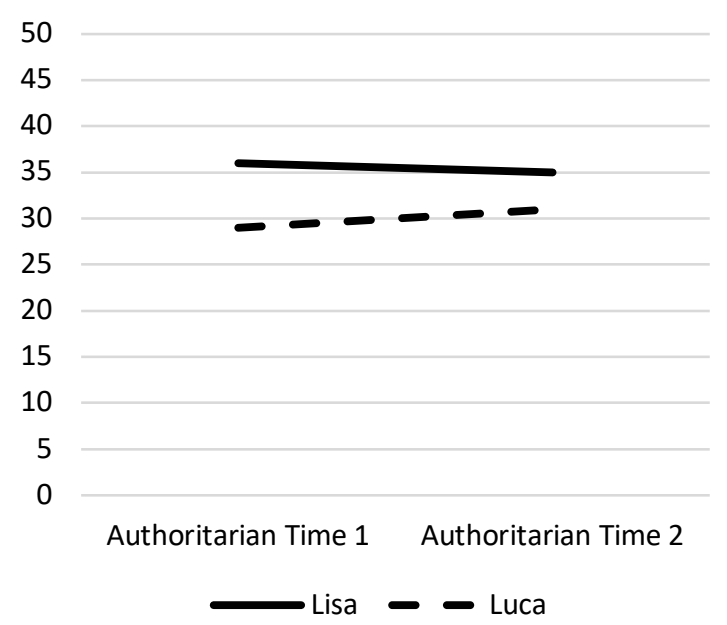

D

\section{Authoritative Parenting}

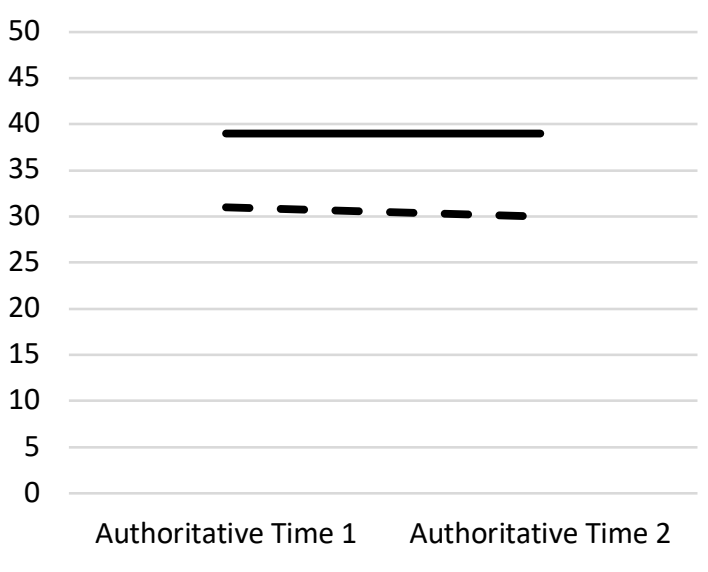

Lisa - - Luca

Figure 7. Changes perceived by Lisa (parent) and Luca (child). (A) Perceived changes in parental support, (B) Perceived changes in parental pressure, (C) Perceived changes in authoritarian parenting, and (D) perceived changes in authoritative parenting. 


\section{E}

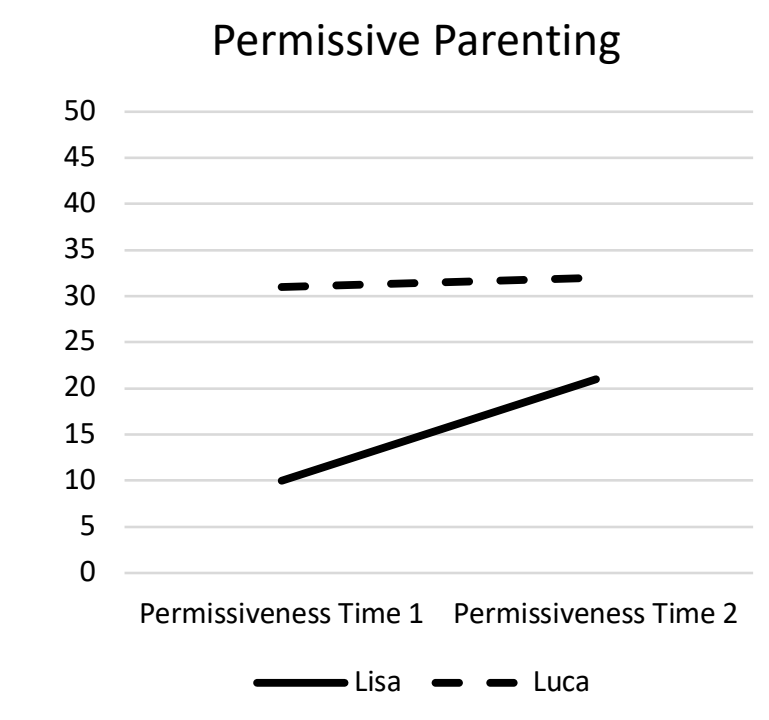

G

\section{Problems in Communication}

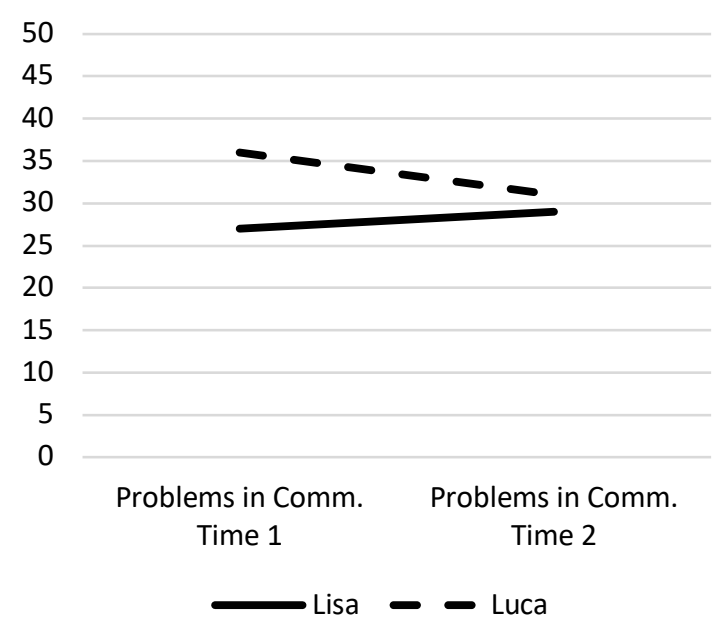

$\mathbf{F}$

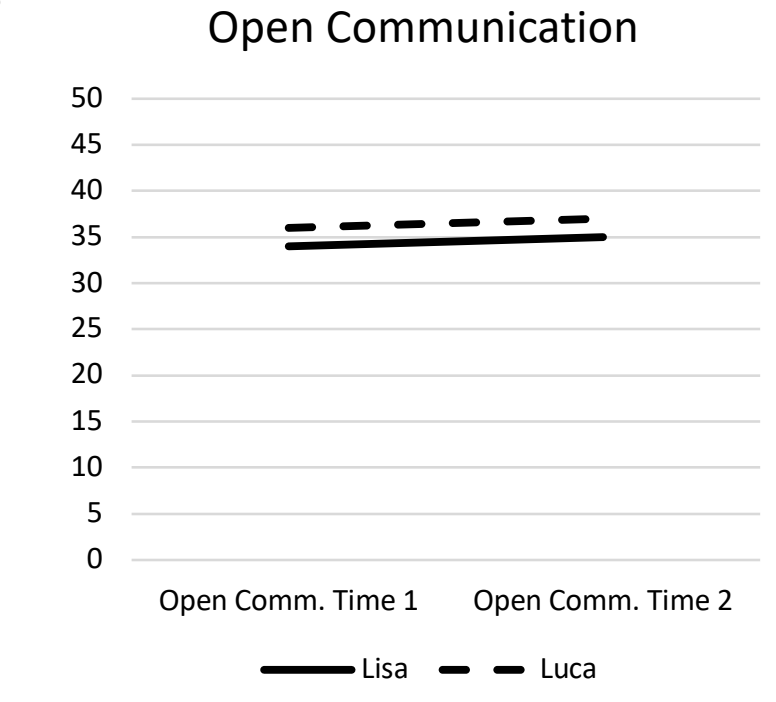

H

\section{Overall Quality of \\ Communication}

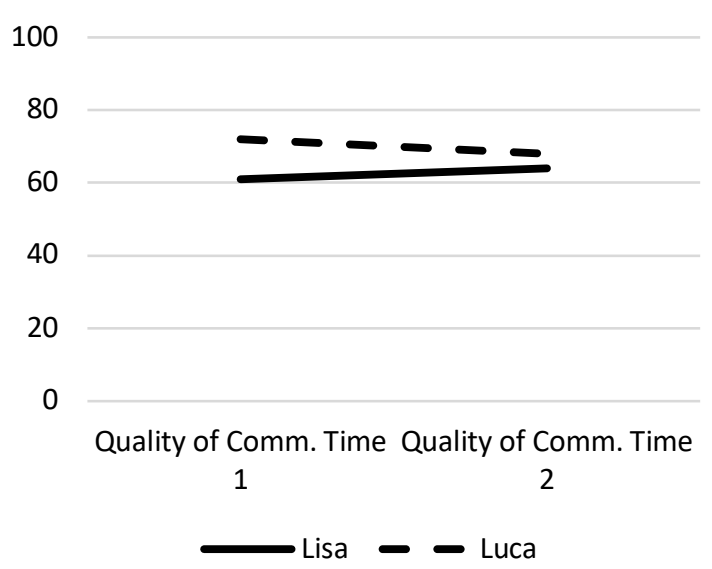

Figure 8. Changes perceived by Lisa (parent) and Luca (child). (E) Perceived changes in permissive parenting, (F) Perceived changes in open communication, (G) Perceived changes in problem in communication, and $(\mathrm{H})$ perceived changes in overall quality of communication. 


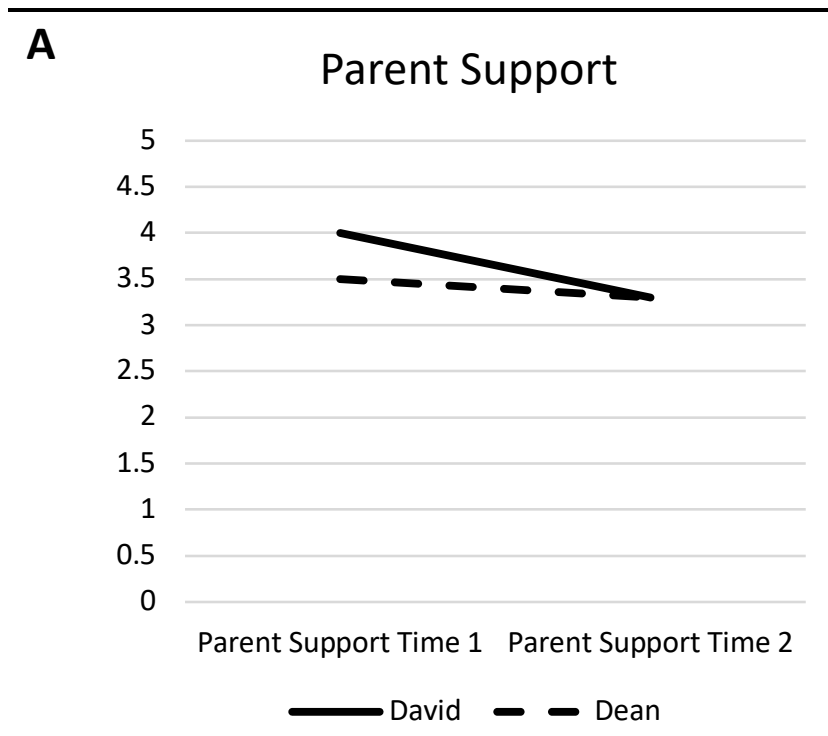

B

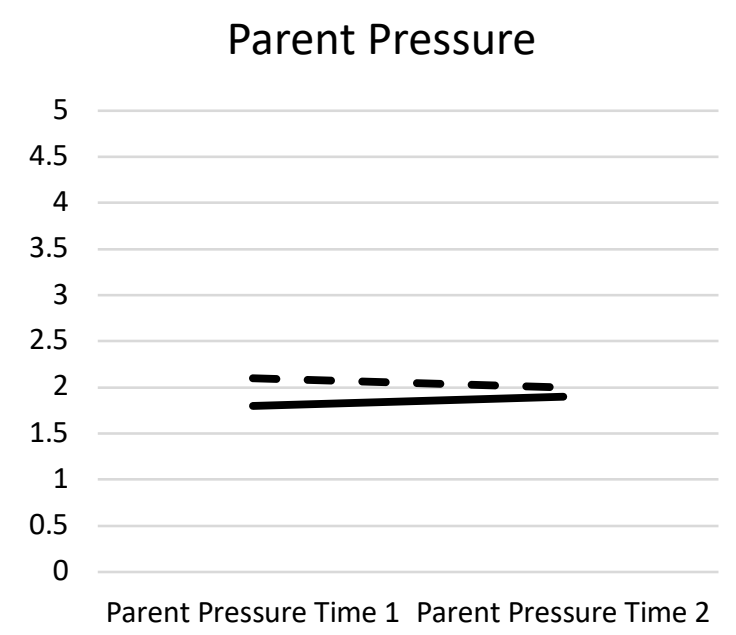

\section{C}

\section{Authoritarian Parenting}

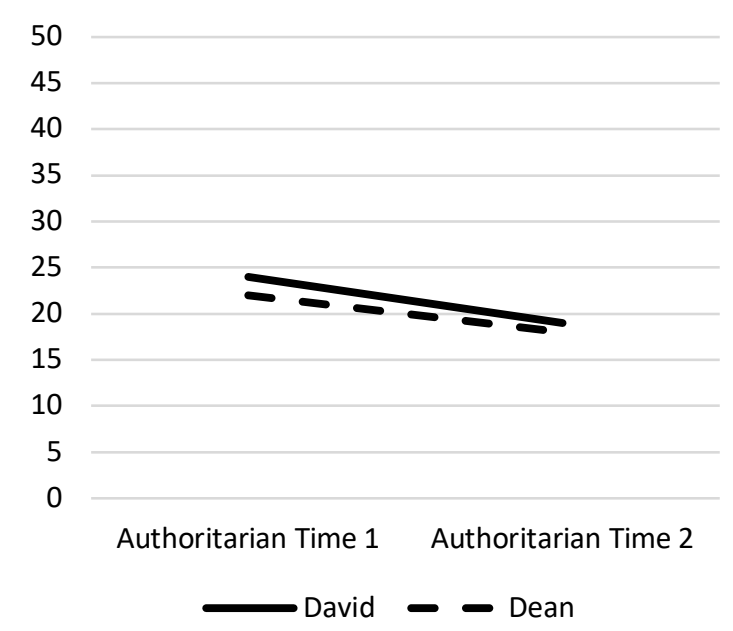

\section{D}

\section{Authoritative Parenting}

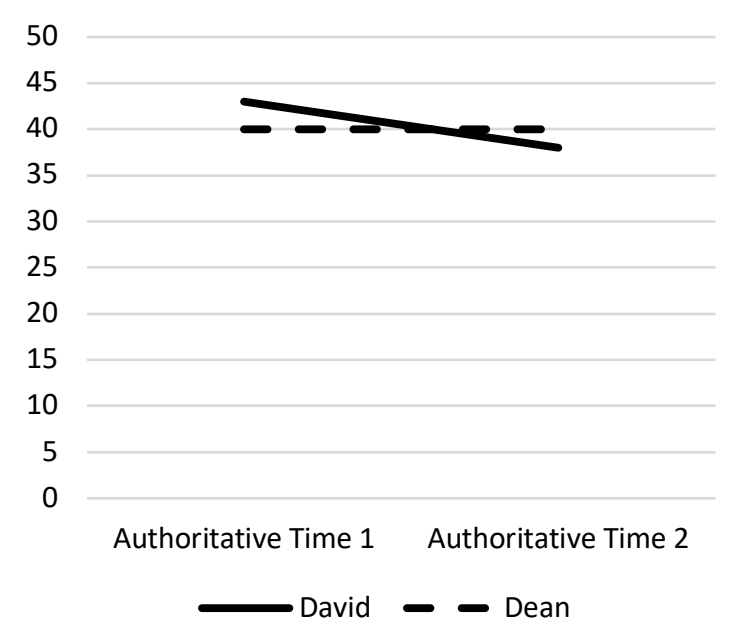

Figure 9. Changes perceived by David (parent) and Dean (child). (A) Perceived changes in parental support, (B) Perceived changes in parental pressure, (C) Perceived changes in authoritarian parenting, and (D) perceived changes in authoritative parenting. 


\section{E}

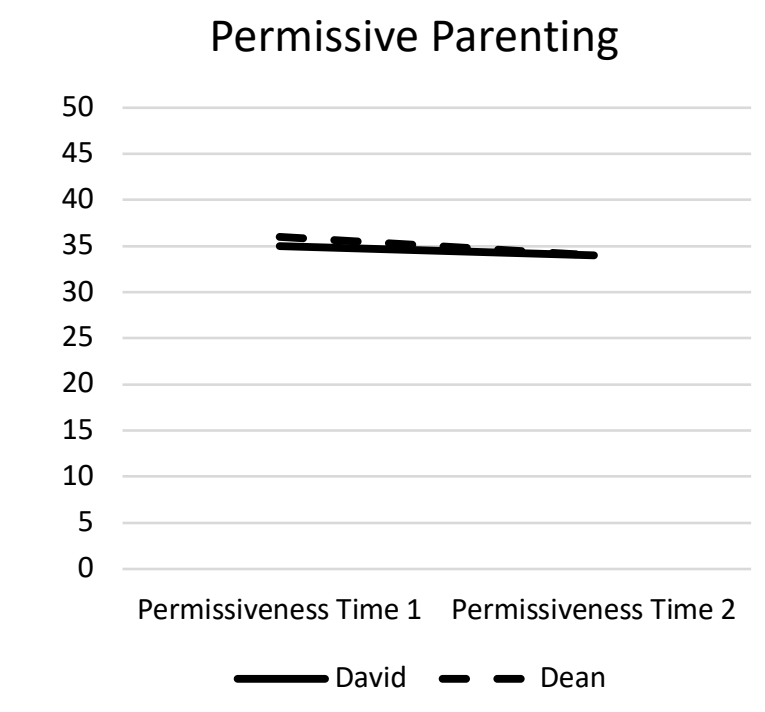

G

\section{Problems in Communication}

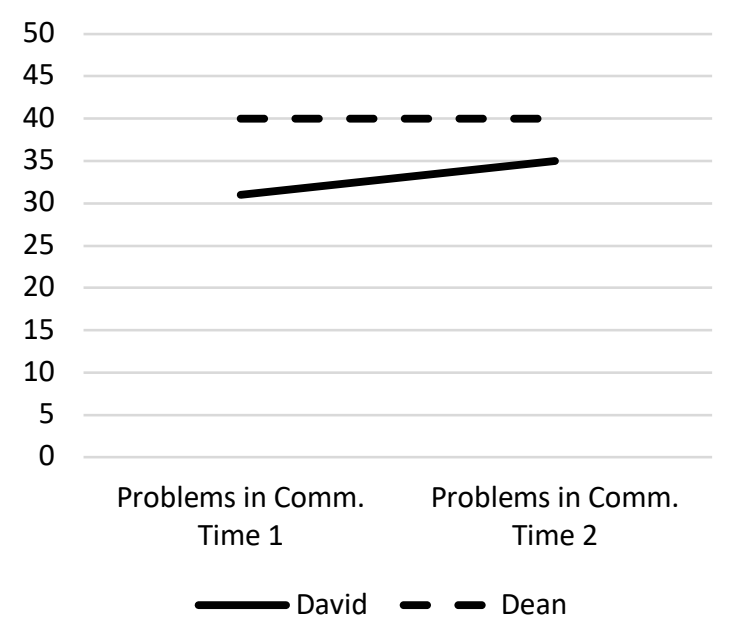

$\mathbf{F}$

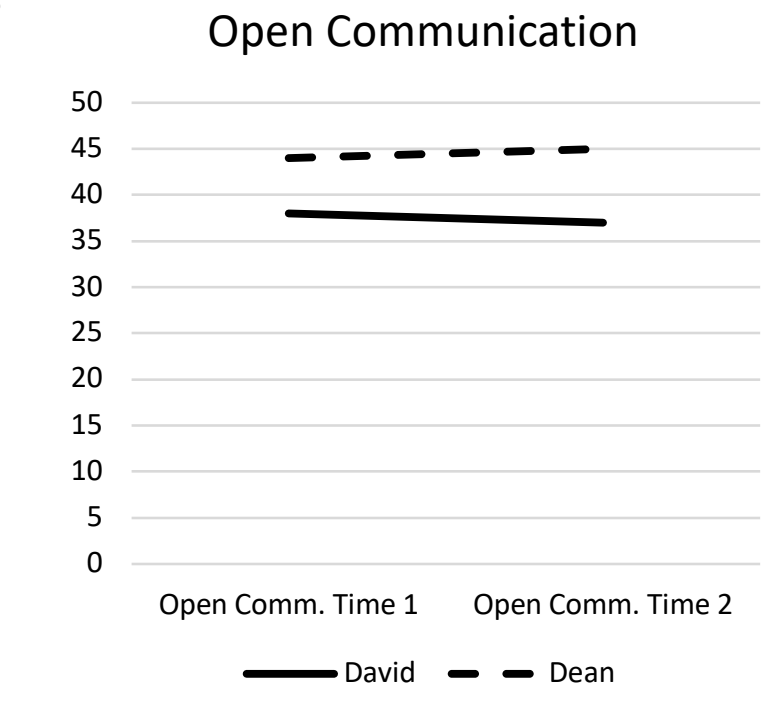

H

\section{Overall Quality of \\ Communication}

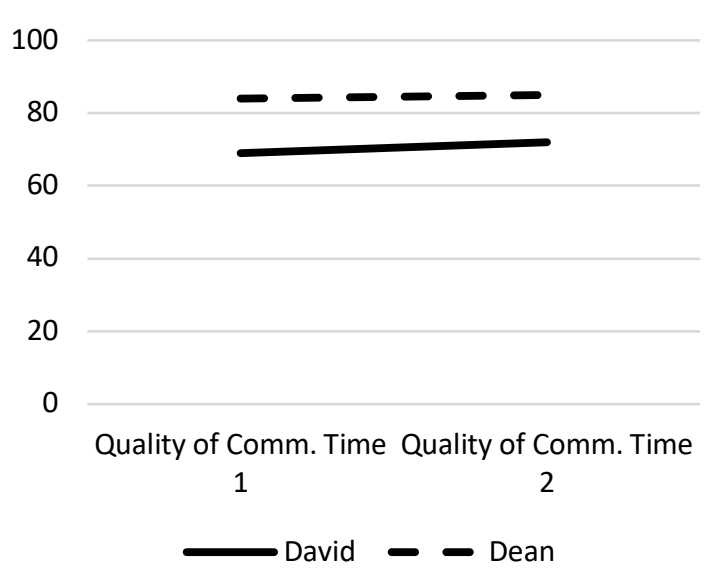

Figure 10. Changes perceived by David (parent) and Dean (child). (E) Perceived changes in permissive parenting, (F) Perceived changes in open communication, (G) Perceived changes in problem in communication, and $(\mathrm{H})$ perceived changes in overall quality of communication. 


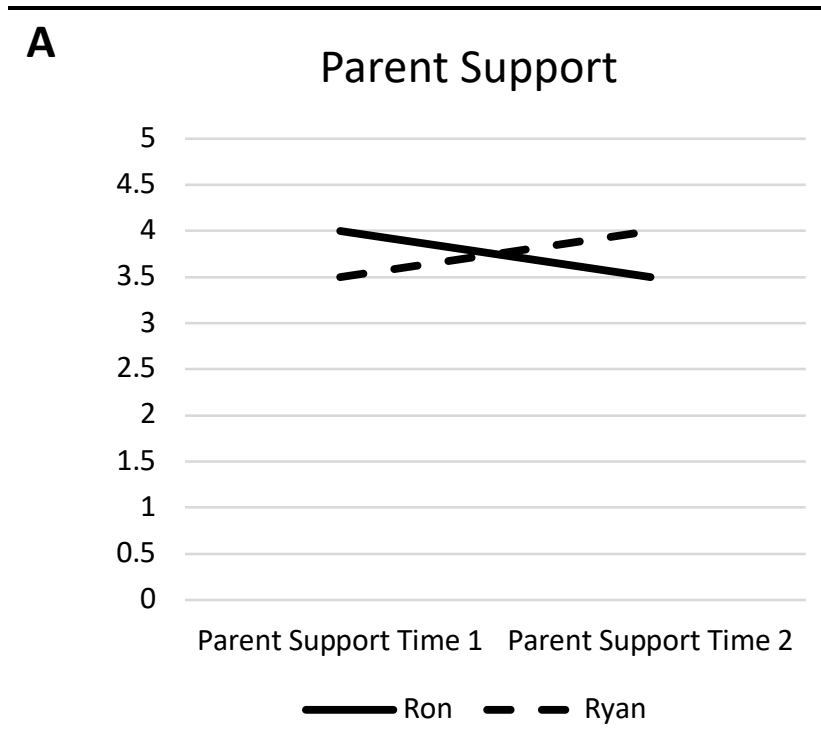

B

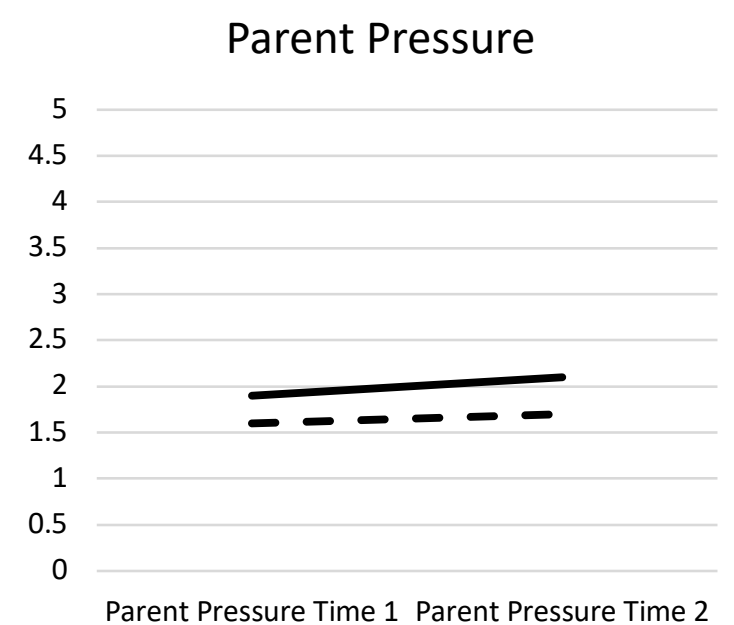

Parent Pressure Time 1 Parent Pressure Time 2

C

\section{Authoritarian Parenting}

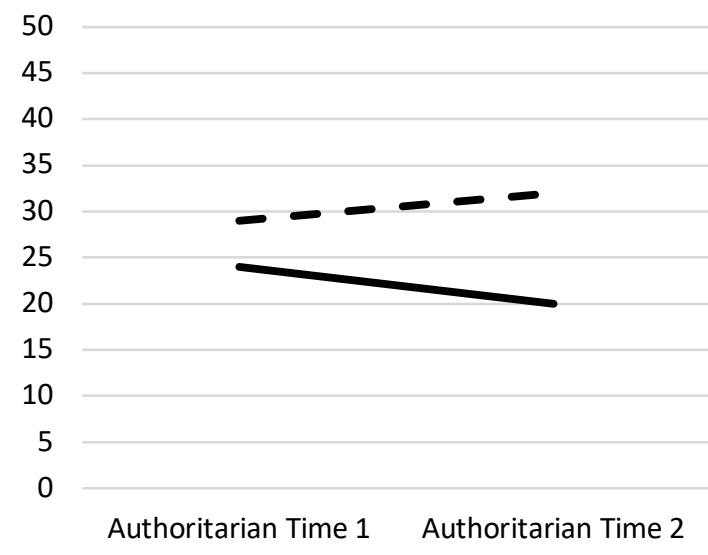

$$
\longrightarrow \text { Ron }- \text { Ryan }
$$

Figure 11. Changes perceived by Ron (parent) and Ryan (child). (A) Perceived changes in parental support, (B) Perceived changes in parental pressure, (C) Perceived changes in authoritarian parenting, and (D) perceived changes in authoritative parenting. 


\section{E}

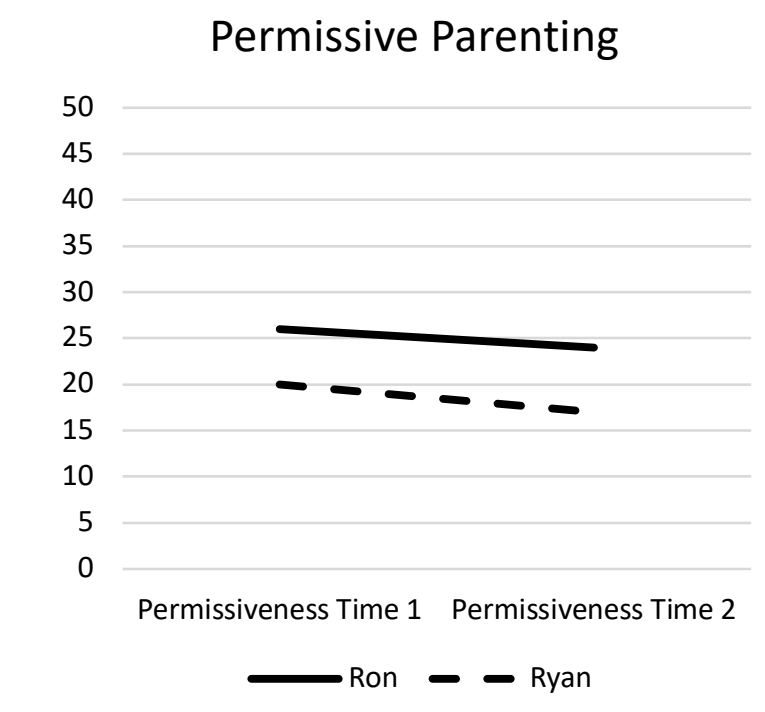

G

\section{Problems in Communication}

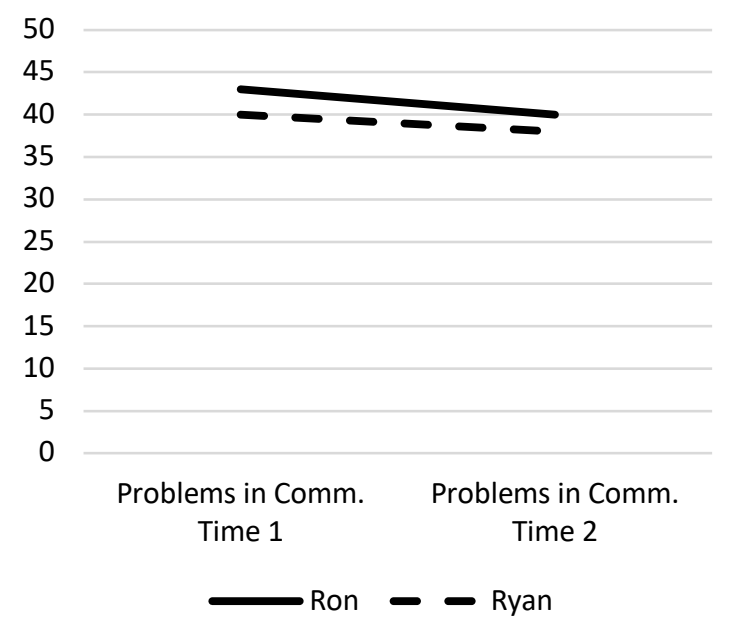

$\mathbf{F}$

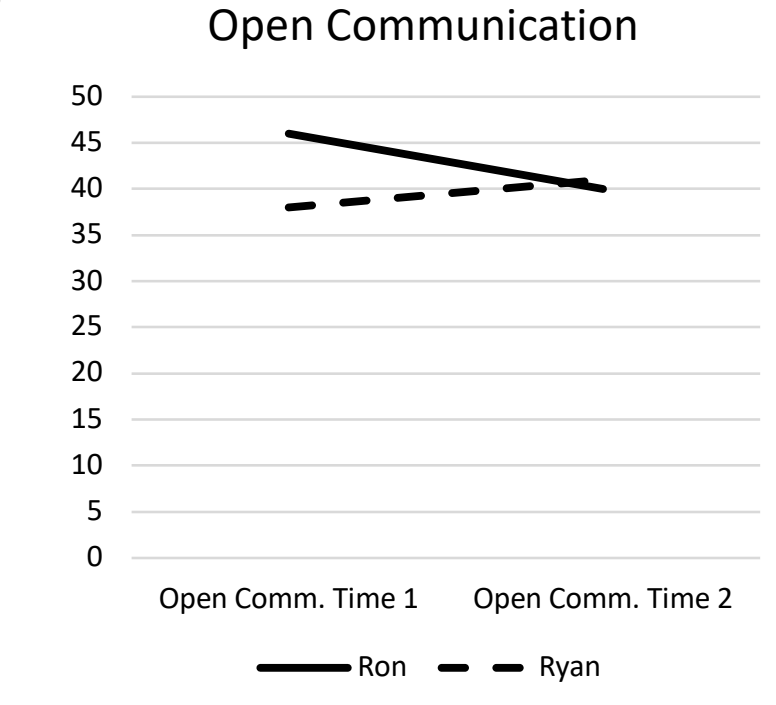

H

Overall Quality of

Communication

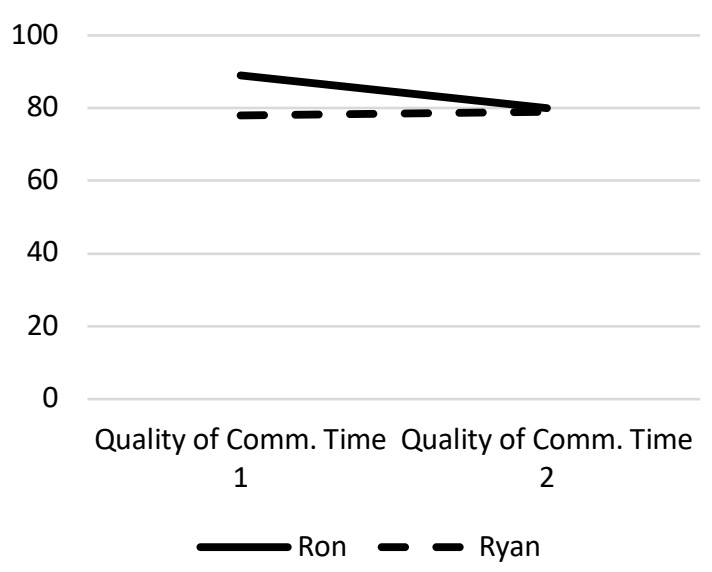

Figure 12. Changes perceived by Ron (parent) and Ryan (child). (E) Perceived changes in permissive parenting, (F) Perceived changes in open communication, (G) Perceived changes in problem in communication, and $(\mathrm{H})$ perceived changes in overall quality of communication. 


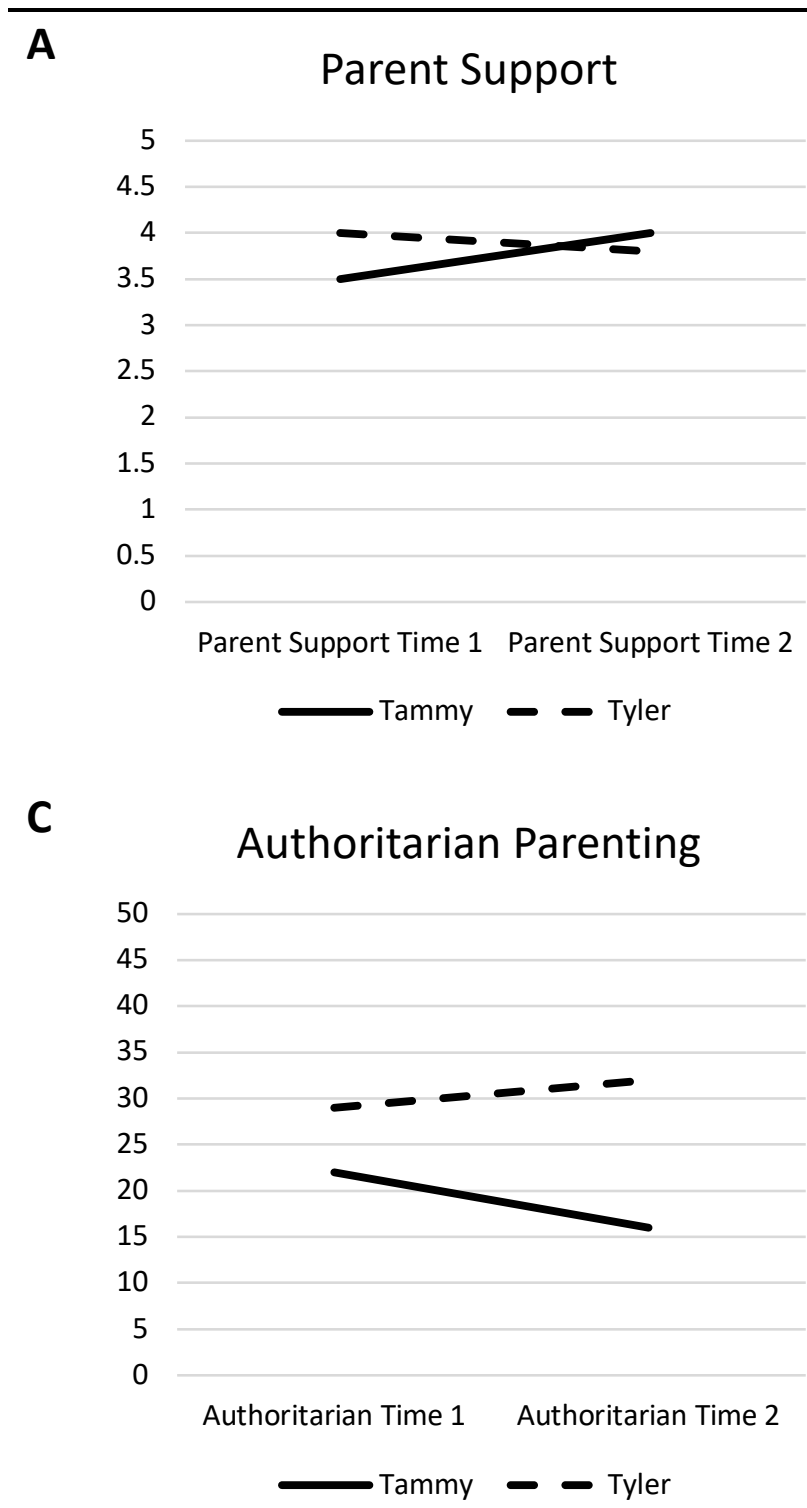

B
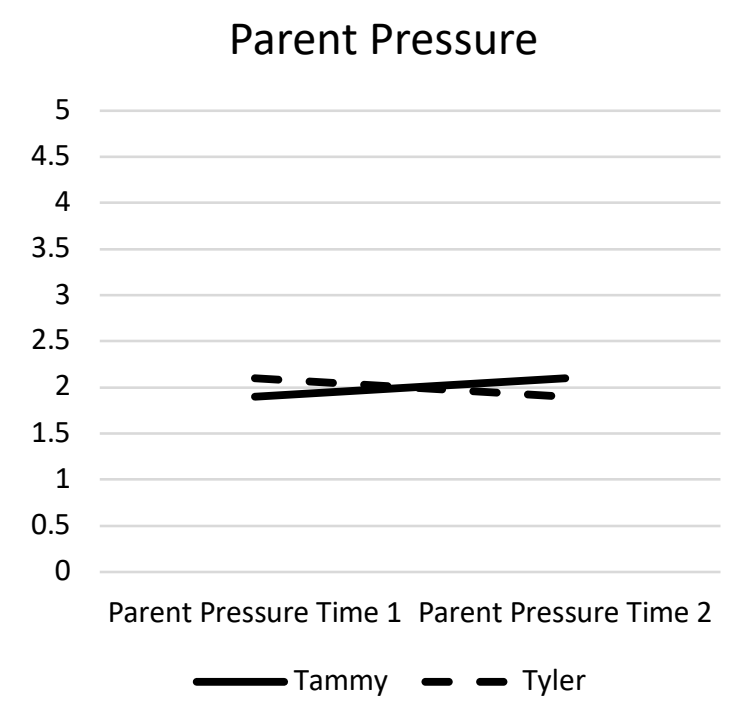

D

\section{Authoritative Parenting}

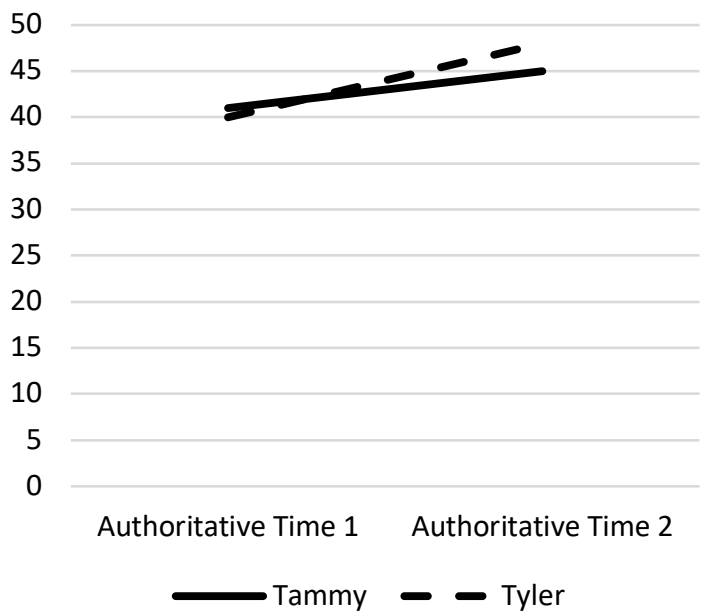

Figure 13. Changes perceived by Tammy (parent) and Tyler (child). (A) Perceived changes in parental support, (B) Perceived changes in parental pressure, (C) Perceived changes in authoritarian parenting, and (D) perceived changes in authoritative parenting. 


\section{E}

Permissive Parenting

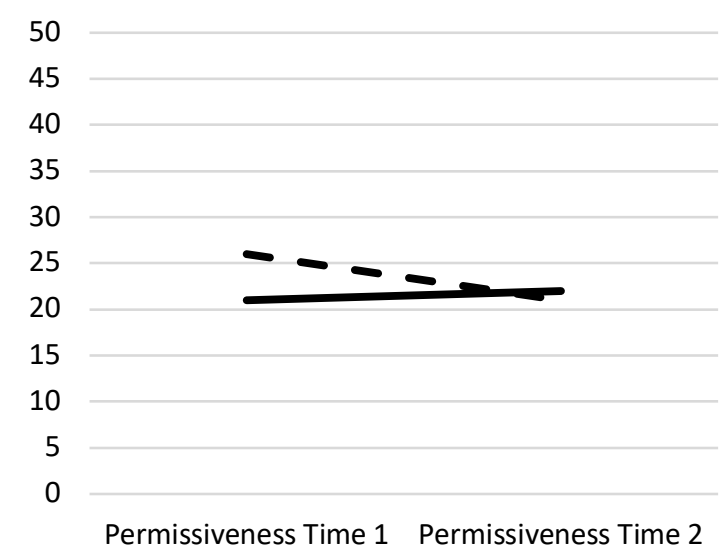

—Tammy — - Tyler

G

\section{Problems in Communication}

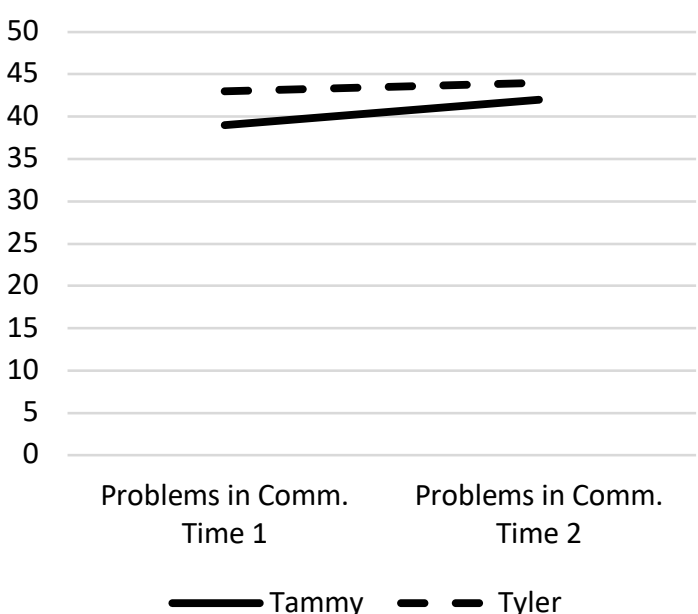

$\mathbf{F}$

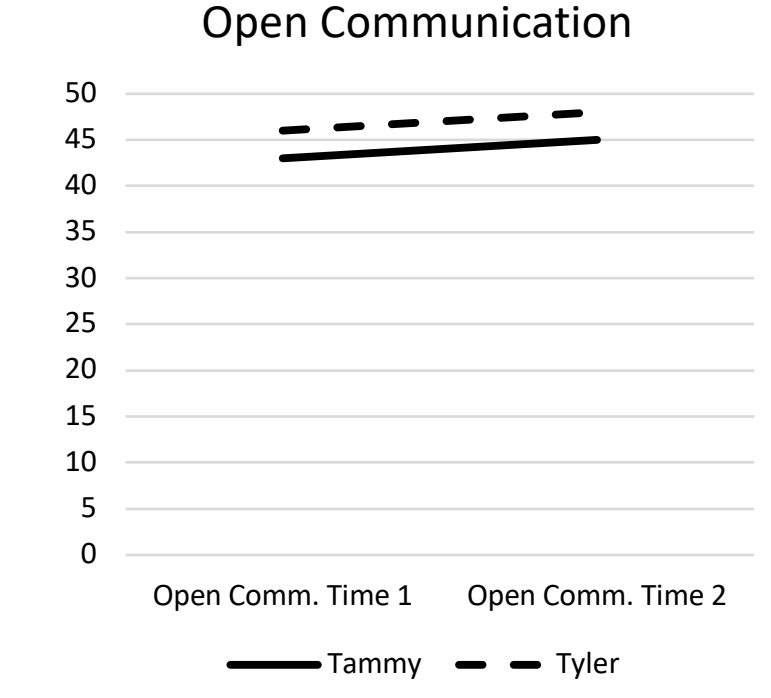

H

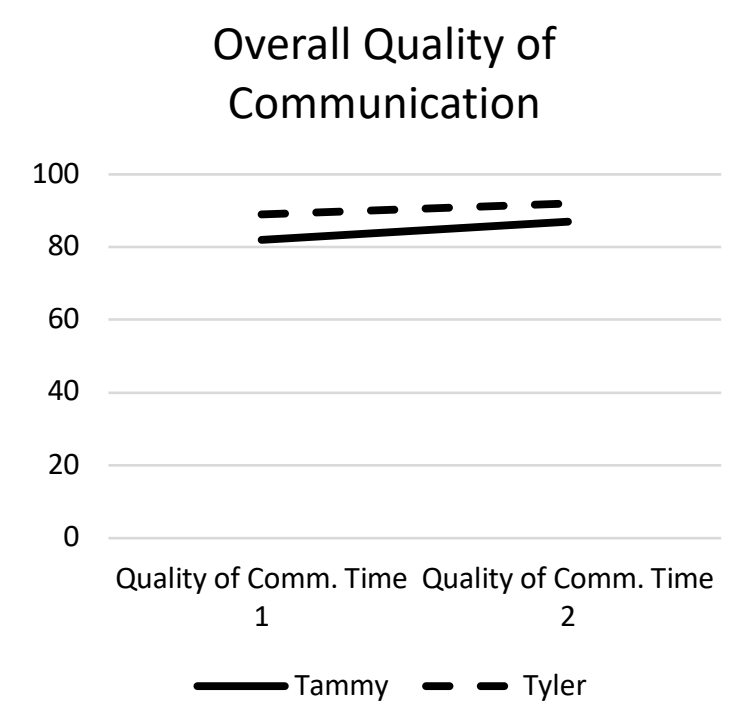

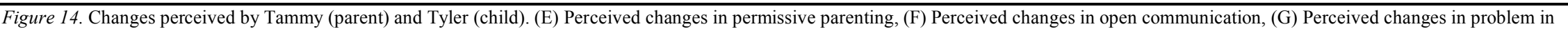
communication, and $(\mathrm{H})$ perceived changes in overall quality of communication. 


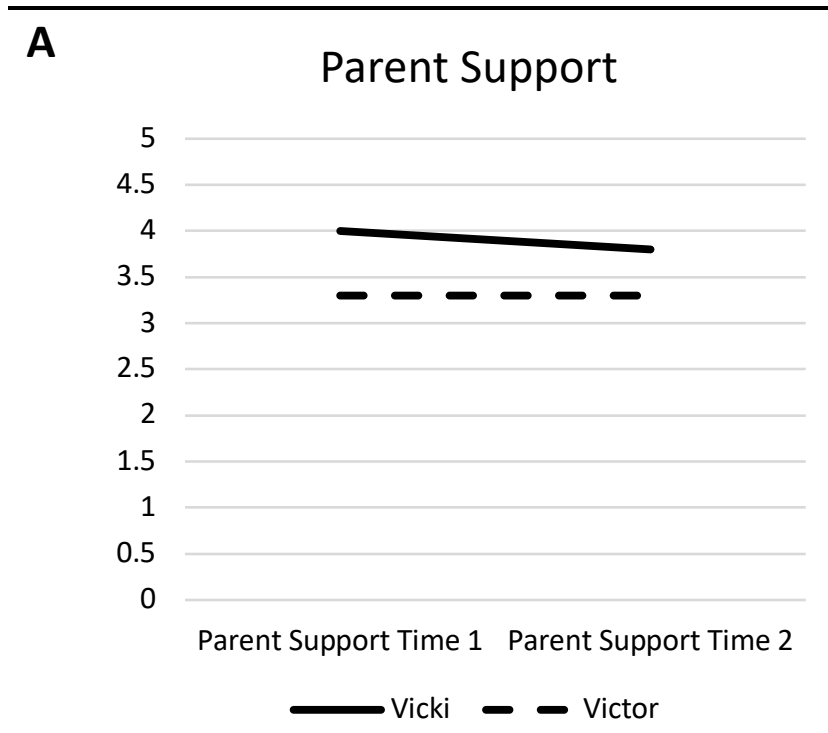

B

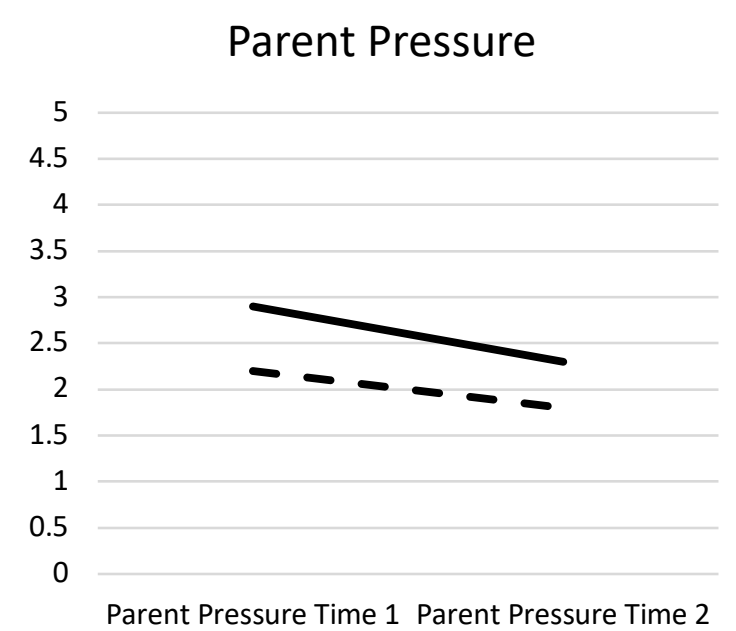

\section{C}

\section{Authoritarian Parenting}

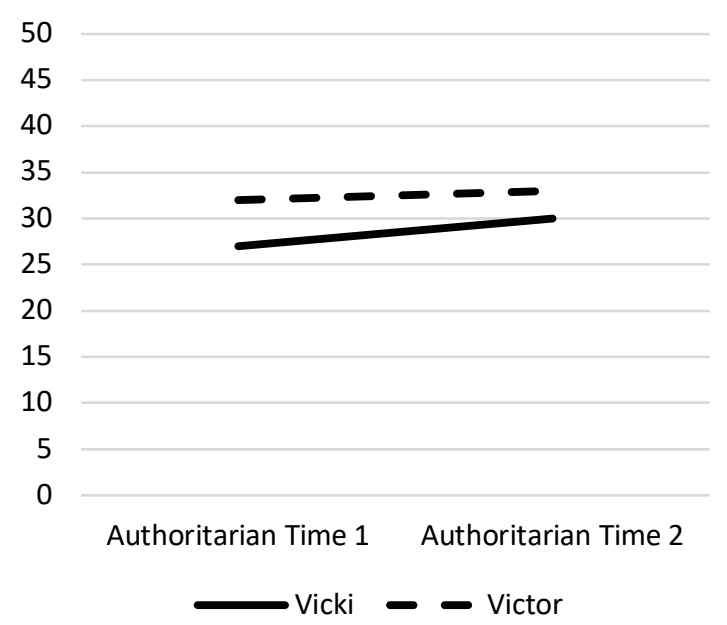

\section{D}

\section{Authoritative Parenting}

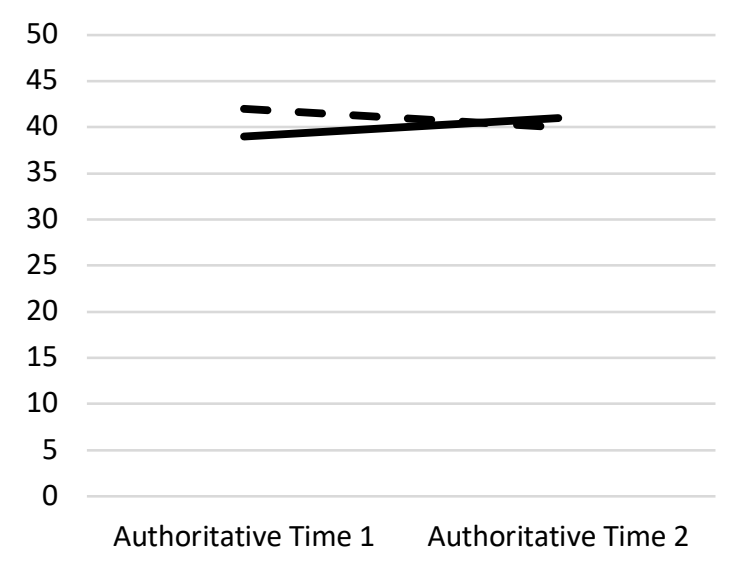

Figure 15. Changes perceived by Vicki (parent) and Victor (child). (A) Perceived changes in parental support, (B) Perceived changes in parental pressure, (C) Perceived changes in authoritarian parenting, and (D) perceived changes in authoritative parenting. 


\section{E}

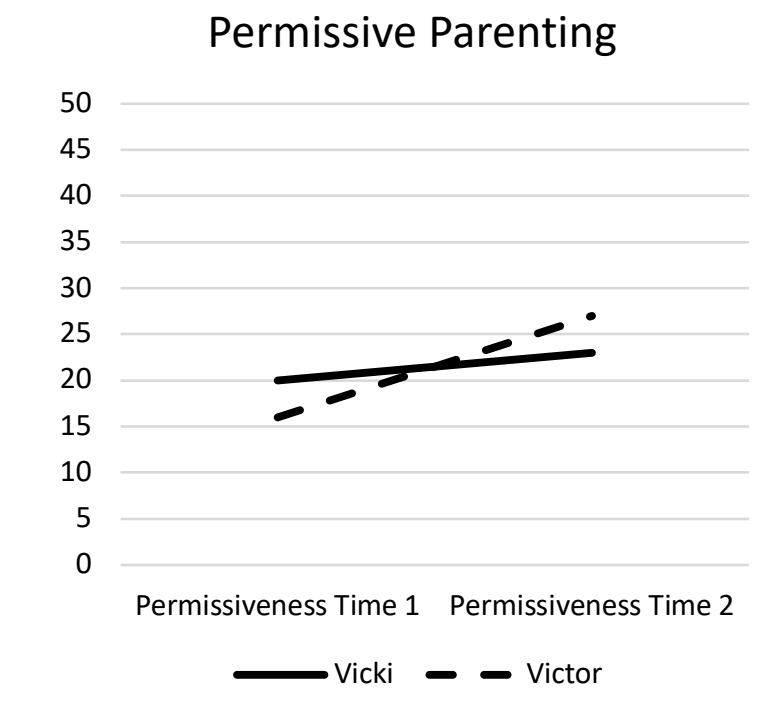

$\mathbf{G}$

\section{Problems in Communication}

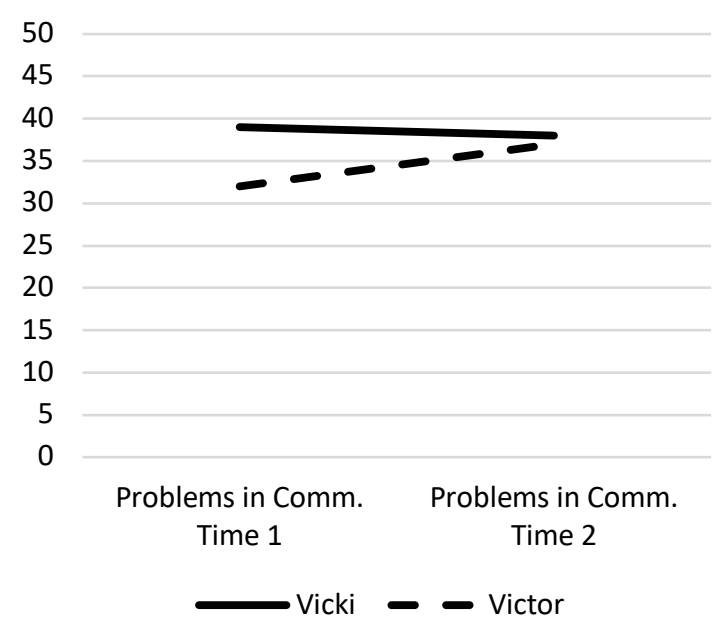

$\mathbf{F}$

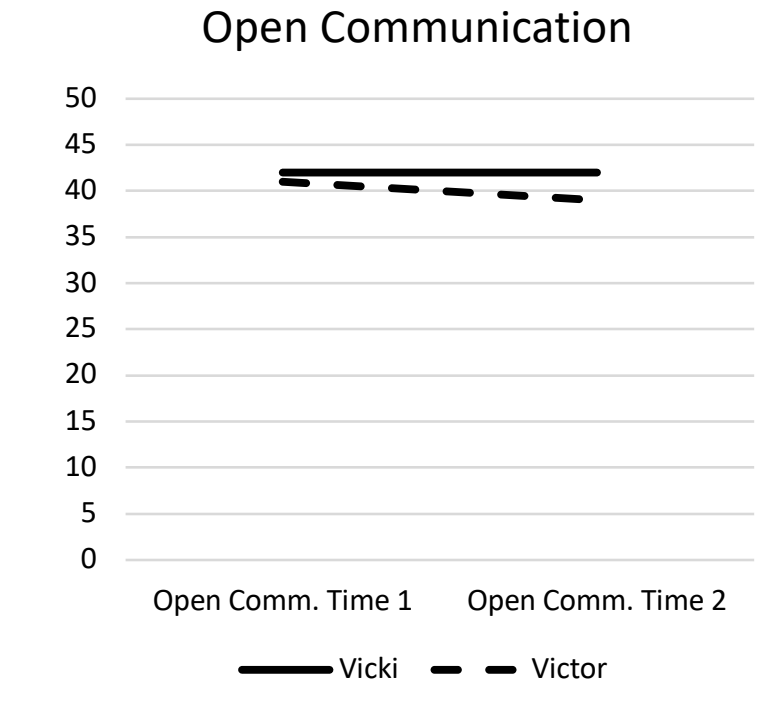

H

\section{Overall Quality of \\ Communication}

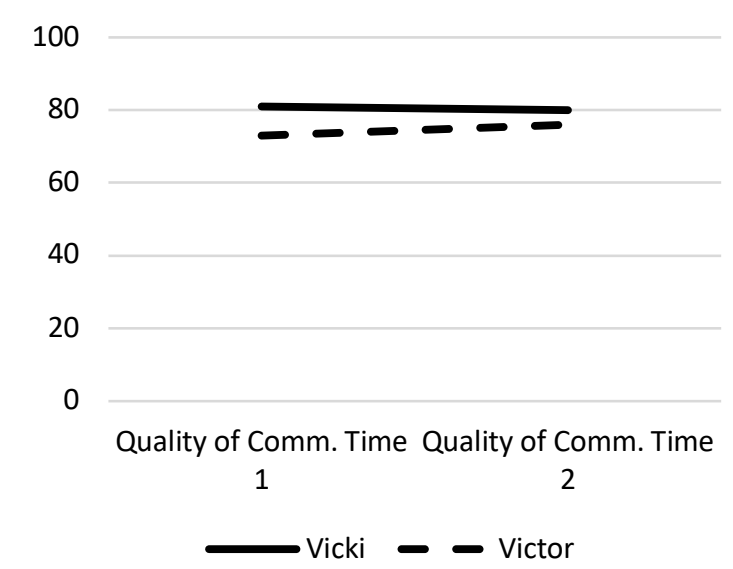

Figure 16. Changes perceived by Vicki (parent) and Victor (child). (E) Perceived changes in permissive parenting, (F) Perceived changes in open communication, (G) Perceived changes in problem in communication, $(\mathrm{H})$ and perceived changes in overall quality of communication. 


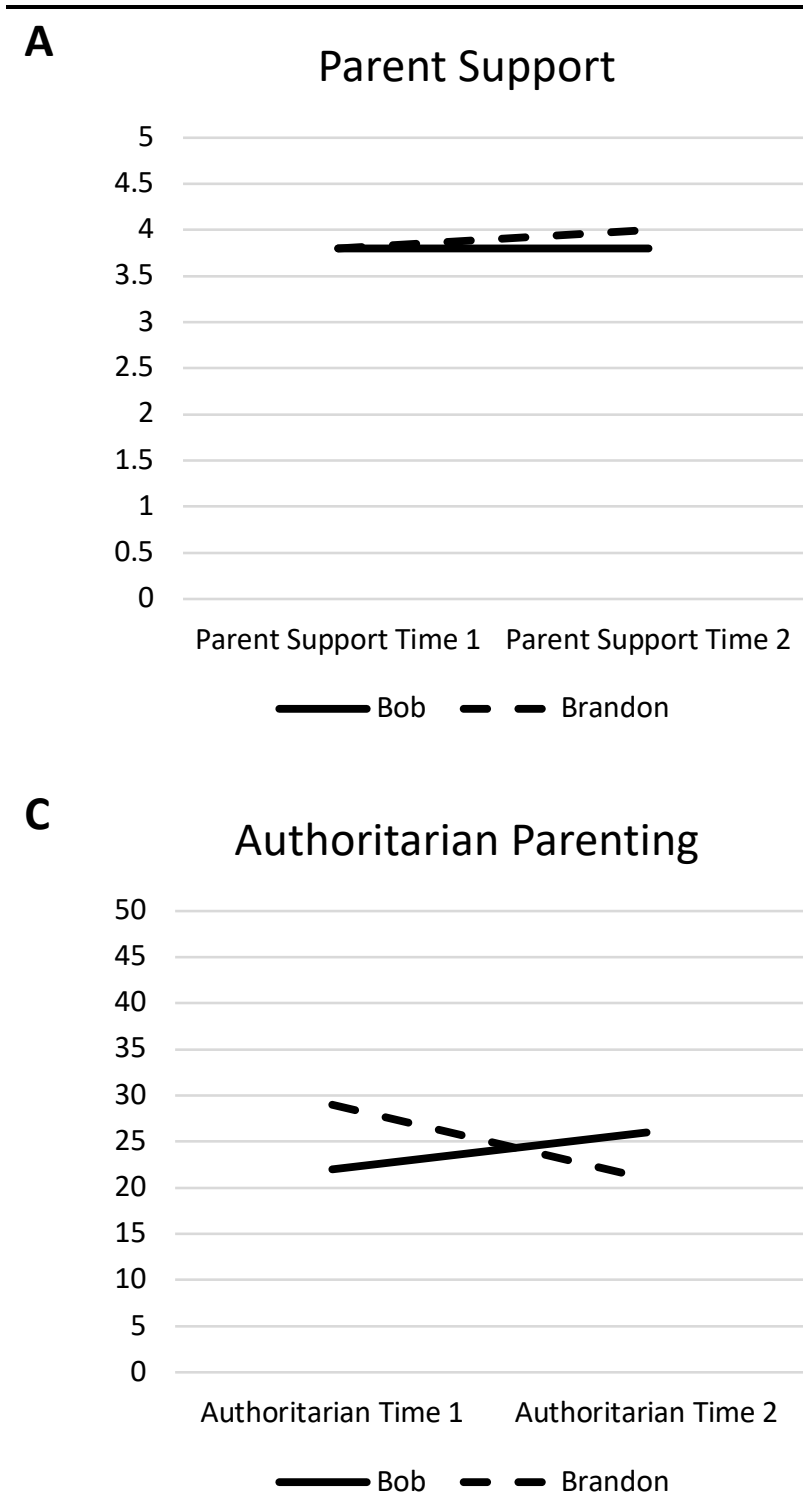

B

Parent Pressure

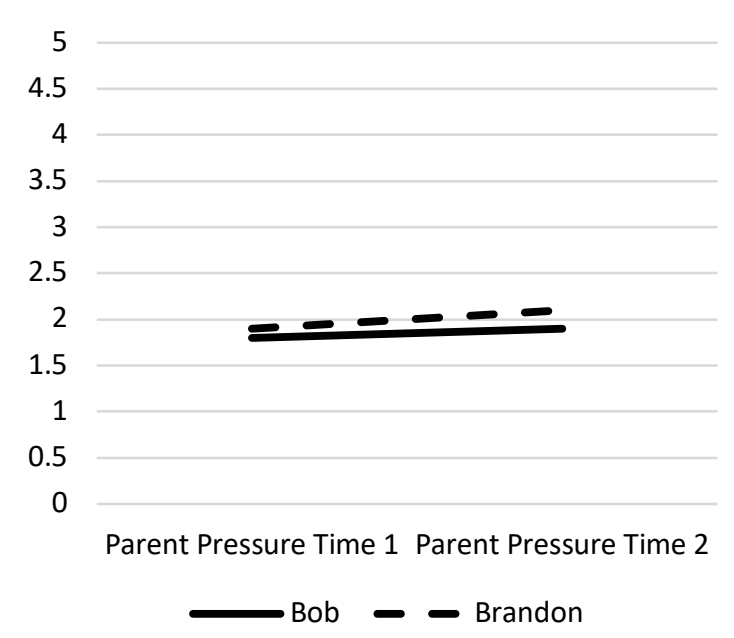

D

\section{Authoritative Parenting}

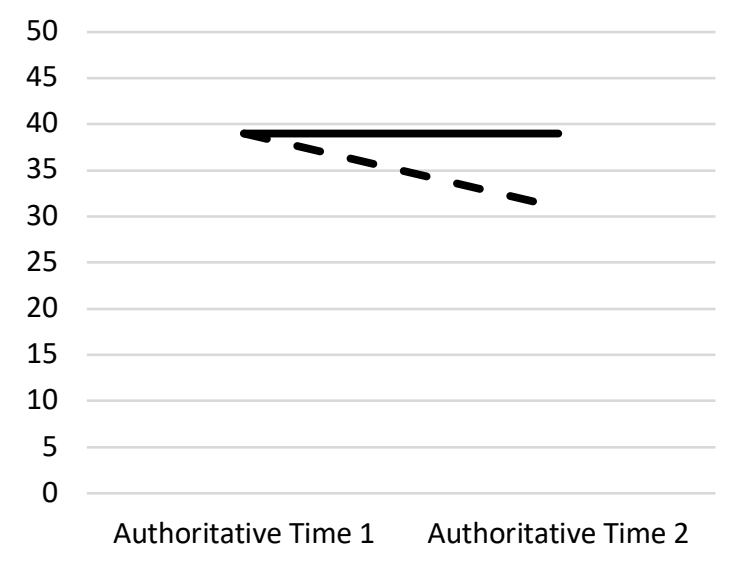

Figure 17. Changes perceived by Bob (parent) and Brandon (child). (A) Perceived changes in parental support, (B) Perceived changes in parental pressure, (C) Perceived changes in authoritarian parenting, and (D) perceived changes in authoritative parenting. 


\section{E}

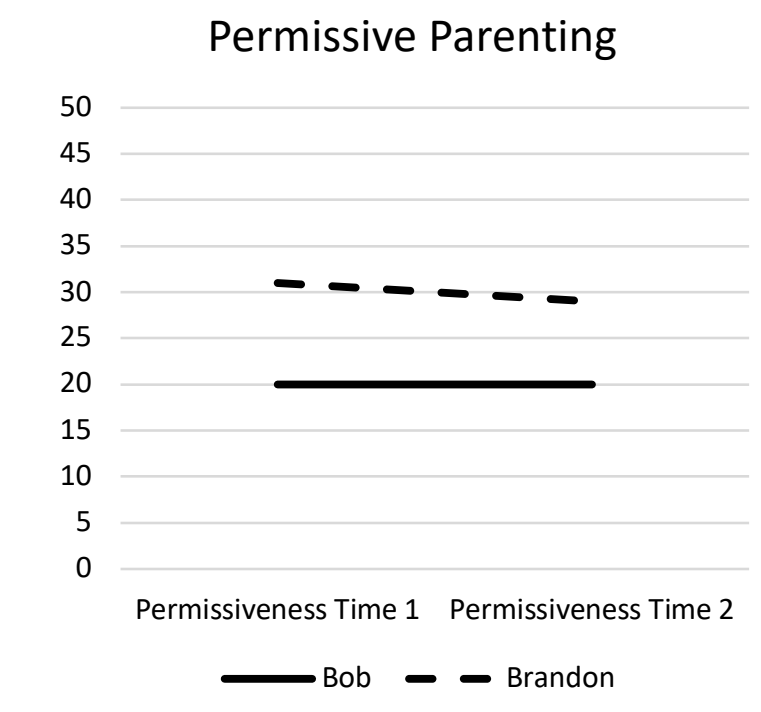

G

\section{Problems in Communication}

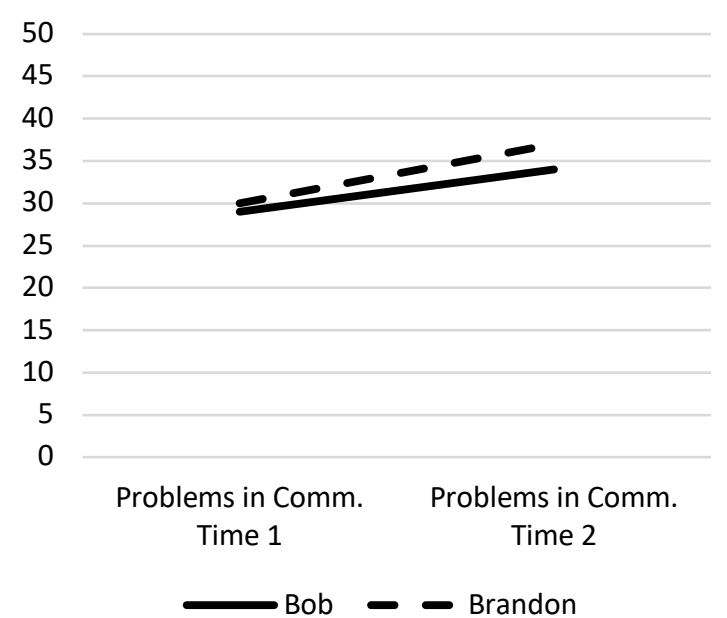

$\mathbf{F}$

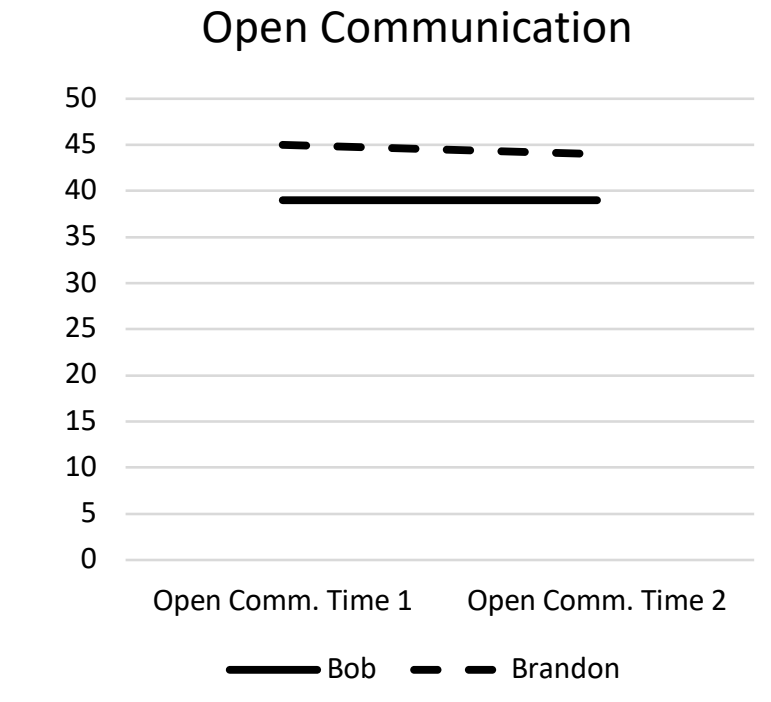

H

\section{Overall Quality of \\ Communication}

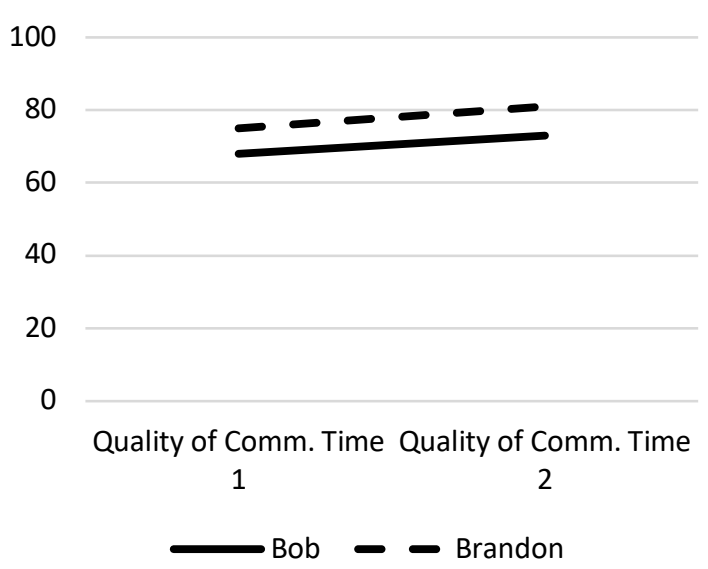

Figure 18. Changes perceived by Bob (parent) and Brandon (child). (E) Perceived changes in permissive parenting, (F) Perceived changes in open communication, (G) Perceived changes in problem in communication, and $(\mathrm{H})$ perceived changes in overall quality of communication. 


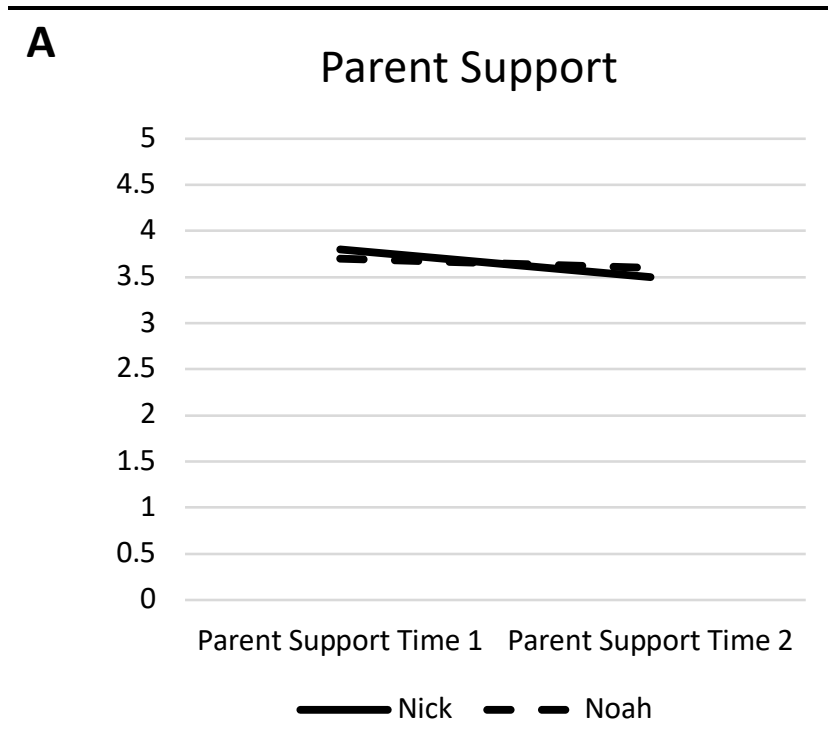

B

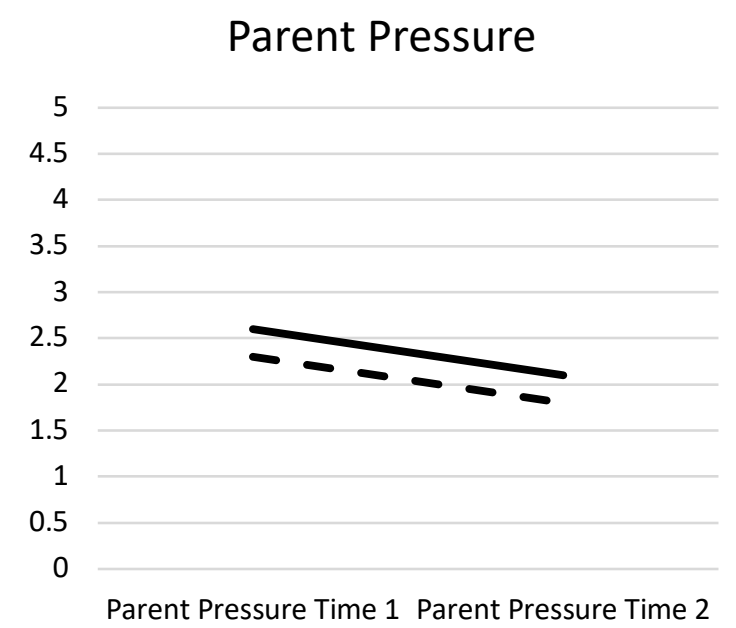

\section{C}

\section{Authoritarian Parenting}

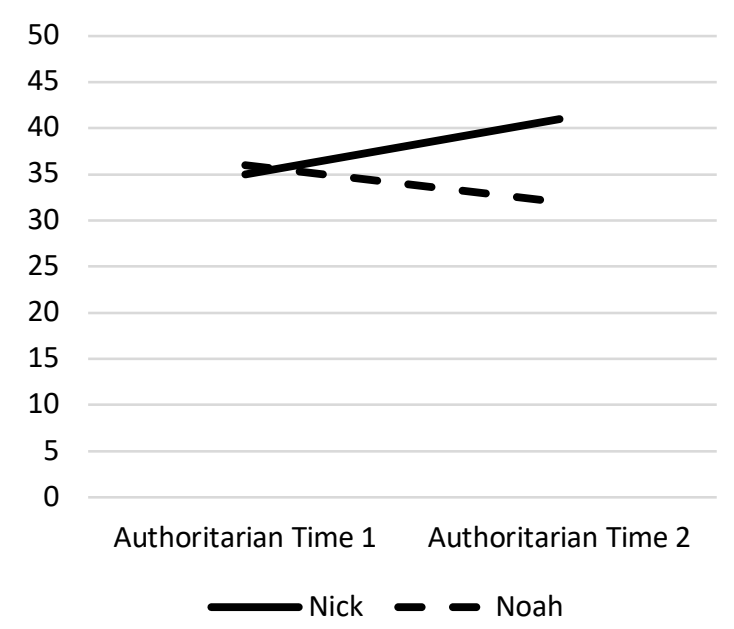

\section{D}

\section{Authoritative Parenting}

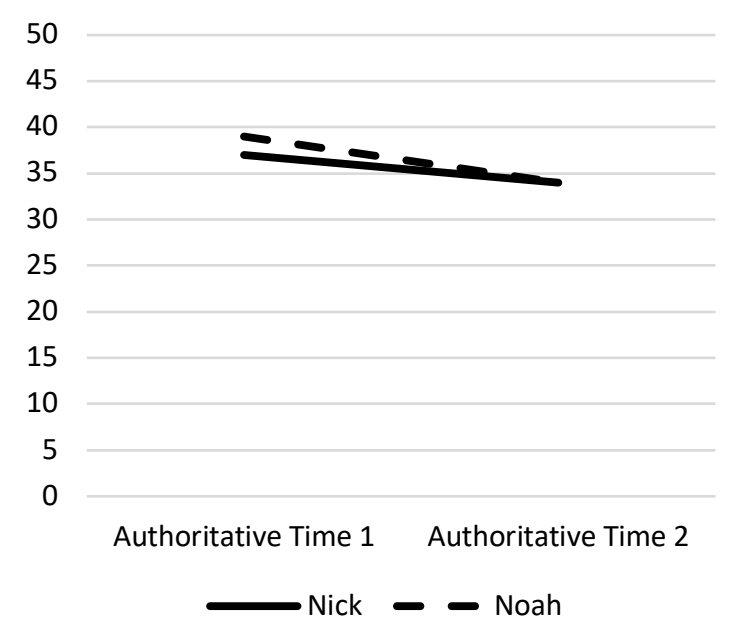

Figure 19. Changes perceived by Nick (parent) and Noah (child). (A) Perceived changes in parental support, (B) Perceived changes in parental pressure, (C) Perceived changes in authoritarian parenting, and (D) perceived changes in authoritative parenting. 


\section{$\mathbf{E}$}

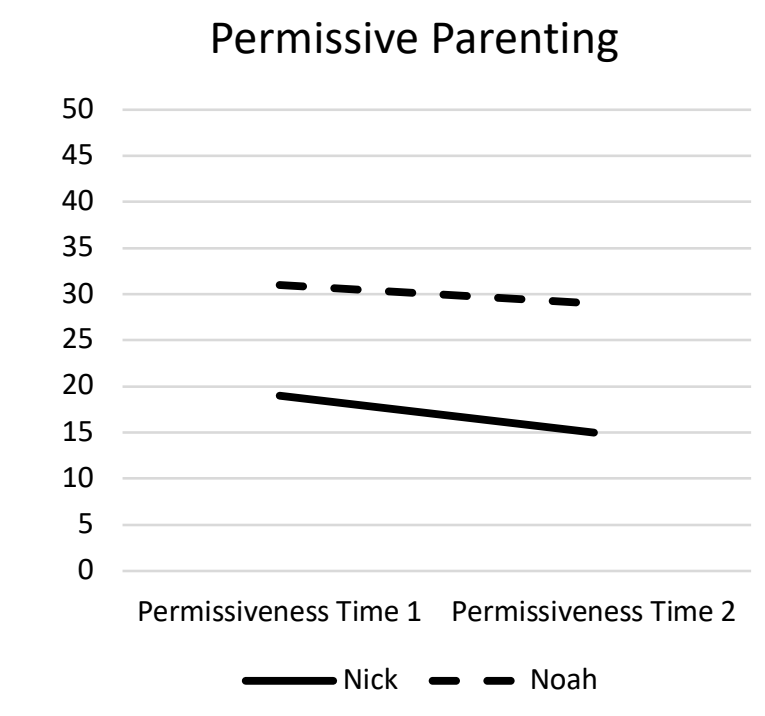

G

\section{Problems in Communication}

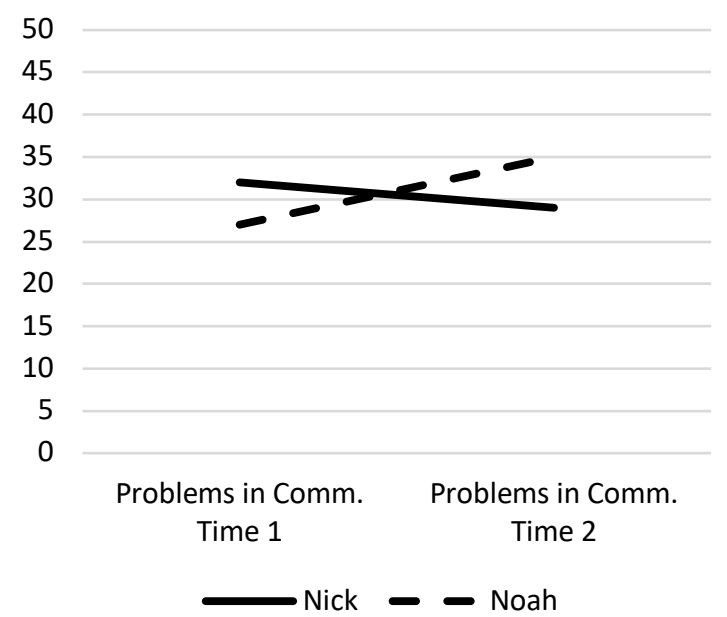

$\mathbf{F}$

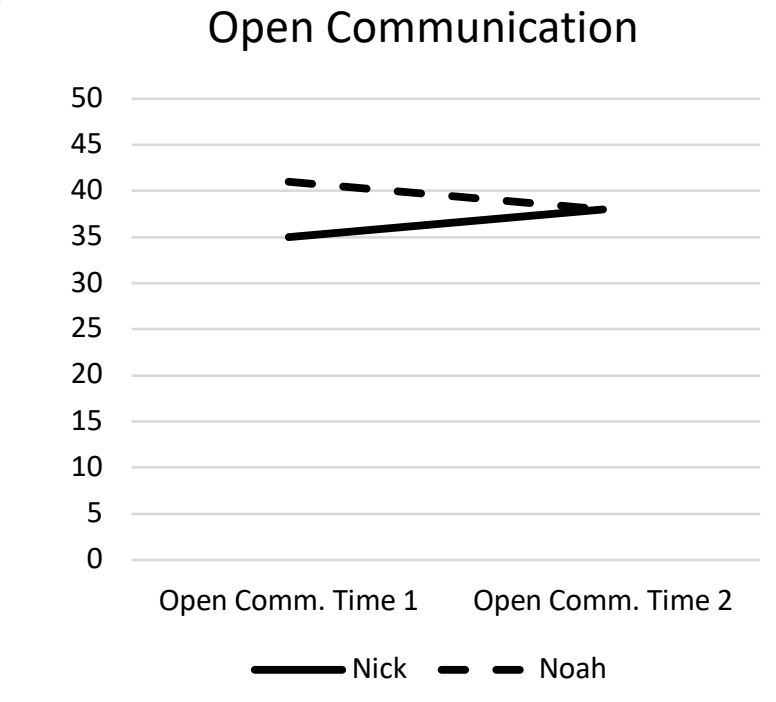

H

\section{Overall Quality of \\ Communication}

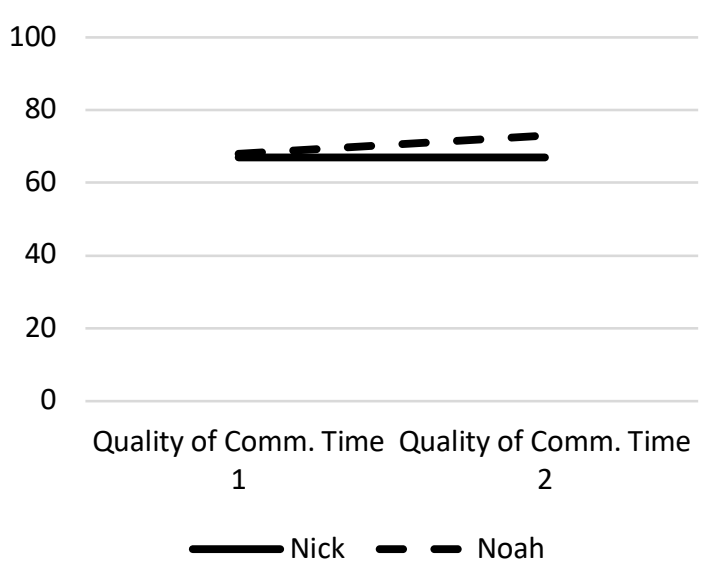

Figure 20. Changes perceived by Nick (parent) and Noah (child). (E) Perceived changes in permissive parenting, (F) Perceived changes in open communication, (G) Perceived changes in problem in communication, and $(\mathrm{H})$ perceived changes in overall quality of communication. 


\section{Appendix E}

\section{Athlete Version: Parental Involvement in Activities Scale (Anderson et al., 2003)}

\begin{tabular}{|c|c|c|c|c|}
\hline $\begin{array}{l}\text { 1. When I tell my mom or dad that I want to } \\
\text { sign up for an activity or lesson, they } \\
\text { think it's a good idea. }\end{array}$ & Strongly Agree & Agree & Disagree & Strongly Disagree \\
\hline $\begin{array}{l}\text { 2. My mom or dad try to make sure that I } \\
\text { get to my games, practices, or lesson, or } \\
\text { performances. }\end{array}$ & Strongly Agree & Agree & Disagree & Strongly Disagree \\
\hline $\begin{array}{l}\text { 3. My mom or dad listen to me when I say I } \\
\text { want to sign up for an activity or lesson. }\end{array}$ & Strongly Agree & Agree & Disagree & Strongly Disagree \\
\hline $\begin{array}{l}\text { 4. My mom or dad let me decide which } \\
\text { activities or lessons to sign up for. }\end{array}$ & Strongly Agree & Agree & Disagree & Strongly Disagree \\
\hline $\begin{array}{l}\text { 5. My mom or dad try to make sure I get } \\
\text { what I need to be in activities or take } \\
\text { lessons, like a uniform or instrument. }\end{array}$ & Strongly Agree & Agree & Disagree & Strongly Disagree \\
\hline $\begin{array}{l}\text { 6. My mom or dad care about all of my } \\
\text { activities. }\end{array}$ & Strongly Agree & Agree & Disagree & Strongly Disagree \\
\hline $\begin{array}{l}\text { 7. My mom or dad push me to sign up for } \\
\text { activities or lesson that I'm not sure I } \\
\text { want to. }\end{array}$ & Strongly Agree & Agree & Disagree & Strongly Disagree \\
\hline $\begin{array}{l}\text { 8. My mom or dad get upset when I don't do } \\
\text { as well as they would like me to in my } \\
\text { activities. }\end{array}$ & Strongly Agree & Agree & Disagree & Strongly Disagree \\
\hline $\begin{array}{l}\text { 9. My mom or dad sign me up for activities } \\
\text { or lessons without asking me if it's okay. }\end{array}$ & Strongly Agree & Agree & Disagree & Strongly Disagree \\
\hline $\begin{array}{l}\text { 10. My mom or dad want me to be in too } \\
\text { many activities. }\end{array}$ & Strongly Agree & Agree & Disagree & Strongly Disagree \\
\hline $\begin{array}{l}\text { 11. My mom or dad might be mad at me if I } \\
\text { don't sign up for certain activities or } \\
\text { lessons. }\end{array}$ & Strongly Agree & Agree & Disagree & Strongly Disagree \\
\hline $\begin{array}{l}\text { 12. My mom or dad only pay attention to } \\
\text { some of my activities. }\end{array}$ & Strongly Agree & Agree & Disagree & Strongly Disagree \\
\hline $\begin{array}{l}\text { 13. My mom or dad would be upset if I } \\
\text { dropped out of an activity. }\end{array}$ & Strongly Agree & Agree & Disagree & Strongly Disagree \\
\hline $\begin{array}{l}\text { 14. When it comes to my activities, my mom } \\
\text { or dad expect too much of me. }\end{array}$ & Strongly Agree & Agree & Disagree & Strongly Disagree \\
\hline $\begin{array}{l}\text { 15. When it comes to my activities, my mom } \\
\text { or dad think that the most important thing } \\
\text { is that I have fun. }\end{array}$ & Strongly Agree & Agree & Disagree & Strongly Disagree \\
\hline $\begin{array}{l}\text { 16. My mom or dad want me to spend too } \\
\text { much time in activities outside of school. }\end{array}$ & Strongly Agree & Agree & Disagree & Strongly Disagree \\
\hline
\end{tabular}




\section{Appendix $\mathrm{F}$}

Parent Version: Parental Involvement in Activities Scale (Anderson et al., 2003)

\begin{tabular}{|c|c|c|c|c|}
\hline $\begin{array}{l}\text { 1. When my child tells me that he/she wants } \\
\text { to sign up for an activity or lesson, I } \\
\text { think it's a good idea. }\end{array}$ & Strongly Agree & Agree & Disagree & Strongly Disagree \\
\hline $\begin{array}{l}\text { 2. I try to make sure that my child gets to } \\
\text { his/her games, practices, or lesson, or } \\
\text { performances. }\end{array}$ & Strongly Agree & Agree & Disagree & Strongly Disagree \\
\hline $\begin{array}{l}\text { 3. I listen to my child when he/she says that } \\
\text { he/she wants to sign up for an activity or } \\
\text { lesson. }\end{array}$ & Strongly Agree & Agree & Disagree & Strongly Disagree \\
\hline $\begin{array}{l}\text { 4. I let my child decided which activities or } \\
\text { lessons he/she wants to sign up for. }\end{array}$ & Strongly Agree & Agree & Disagree & Strongly Disagree \\
\hline $\begin{array}{l}\text { 5. I try to make sure that my child gets what } \\
\text { he/she needs to be in activities or take } \\
\text { lessons, like a uniform or instrument. }\end{array}$ & Strongly Agree & Agree & Disagree & Strongly Disagree \\
\hline 6. I care about all of my child's activities. & Strongly Agree & Agree & Disagree & Strongly Disagree \\
\hline $\begin{array}{l}\text { 7. I push my child to sign up for activities } \\
\text { or lesson that he/she is not sure he/she } \\
\text { wants to do. }\end{array}$ & Strongly Agree & Agree & Disagree & Strongly Disagree \\
\hline $\begin{array}{l}\text { 8. I get upset when my child doesn't do as } \\
\text { well as I would like he/she to in his/her } \\
\text { activities. }\end{array}$ & Strongly Agree & Agree & Disagree & Strongly Disagree \\
\hline $\begin{array}{l}\text { 9. I sign my child up for activities or } \\
\text { lessons without asking him/her if it's } \\
\text { okay. }\end{array}$ & Strongly Agree & Agree & Disagree & Strongly Disagree \\
\hline $\begin{array}{l}\text { 10. I want my child to be in too many } \\
\text { activities. }\end{array}$ & Strongly Agree & Agree & Disagree & Strongly Disagree \\
\hline $\begin{array}{l}\text { 11. I might be mad at my child if he/she } \\
\text { doesn't sign up for certain activities or } \\
\text { lessons. }\end{array}$ & Strongly Agree & Agree & Disagree & Strongly Disagree \\
\hline $\begin{array}{l}\text { 12. I only pay attention to some of my } \\
\text { child's activities. }\end{array}$ & Strongly Agree & Agree & Disagree & Strongly Disagree \\
\hline $\begin{array}{l}\text { 13. I would be upset if my child dropped out } \\
\text { of an activity. }\end{array}$ & Strongly Agree & Agree & Disagree & Strongly Disagree \\
\hline $\begin{array}{l}\text { 14. When it comes to my child's activities, I } \\
\text { expect too much of him/her. }\end{array}$ & Strongly Agree & Agree & Disagree & Strongly Disagree \\
\hline $\begin{array}{l}\text { 15. When it comes to my child's activities, I } \\
\text { think that the most important thing is for } \\
\text { my child to have fun. }\end{array}$ & Strongly Agree & Agree & Disagree & Strongly Disagree \\
\hline $\begin{array}{l}\text { 16. I want my child to spend too much time } \\
\text { in activities outside of school. }\end{array}$ & Strongly Agree & Agree & Disagree & Strongly Disagree \\
\hline
\end{tabular}




\section{Appendix G}

Athlete Version: Parent-Adolescent Communication Scale (Barnes \& Olson, 1985)

Strongly Disagree: (Coded as 1)

Disagree: (Coded as 2)

Neither Agree nor Disagree: (Coded as 3)

Agree: (Coded as 4)

Strongly Agree: (Coded as 5)

\begin{tabular}{|c|c|c|c|c|c|}
\hline $\begin{array}{l}\text { 1. I can discuss my beliefs with my mother/father } \\
\text { without feeling restrained or embarrassed. }\end{array}$ & 1 & 2 & 3 & 4 & 5 \\
\hline $\begin{array}{l}\text { 2. Sometimes I have trouble believing everything my } \\
\text { mother/father tells me. }\end{array}$ & 1 & 2 & 3 & 4 & 5 \\
\hline 3. My mother/father is always a good listener. & 1 & 2 & 3 & 4 & 5 \\
\hline $\begin{array}{l}\text { 4. I am sometimes afraid to ask my mother/father for } \\
\text { what I want. }\end{array}$ & 1 & 2 & 3 & 4 & 5 \\
\hline $\begin{array}{l}\text { 5. My mother/father has a tendency to say things to me } \\
\text { which would be better left unsaid. }\end{array}$ & 1 & 2 & 3 & 4 & 5 \\
\hline $\begin{array}{l}\text { 6. My mother/father can tell how I'm feeling without } \\
\text { asking. }\end{array}$ & 1 & 2 & 3 & 4 & 5 \\
\hline $\begin{array}{l}\text { 7. I am very satisfied with how my mother/ father and I } \\
\text { talk together. }\end{array}$ & 1 & 2 & 3 & 4 & 5 \\
\hline 8. If I were in trouble, I could tell my mother/father. & 1 & 2 & 3 & 4 & 5 \\
\hline 9. I openly show affection to my mother/father. & 1 & 2 & 3 & 4 & 5 \\
\hline $\begin{array}{l}\text { 10. When we are having a problem, I often give my } \\
\text { mother/father the silent treatment. }\end{array}$ & 1 & 2 & 3 & 4 & 5 \\
\hline 11. I am careful about what I say to my mother/father. & 1 & 2 & 3 & 4 & 5 \\
\hline $\begin{array}{l}\text { 12. When talking to my mother/father, I have a tendency } \\
\text { to say things that would be better left unsaid. }\end{array}$ & 1 & 2 & 3 & 4 & 5 \\
\hline $\begin{array}{l}\text { 13. When I ask questions, I get honest answers from my } \\
\text { mother/father. }\end{array}$ & 1 & 2 & 3 & 4 & 5 \\
\hline
\end{tabular}




\begin{tabular}{|l|ccccc|}
\hline $\begin{array}{l}\text { 14. My mother/father tries to understand my point of } \\
\text { view. }\end{array}$ & 1 & 2 & 3 & 4 & 5 \\
\hline $\begin{array}{l}\text { 15. There are topics I avoid discussing with my } \\
\text { mother/father. }\end{array}$ & 1 & 2 & 3 & 4 & 5 \\
\hline $\begin{array}{l}\text { 16. I find it easy to discuss problems with my } \\
\text { mother/father. }\end{array}$ & 1 & 2 & 3 & 4 & 5 \\
\hline $\begin{array}{l}\text { 17. It is very easy for me to express all my true feelings } \\
\text { to my mother/father. }\end{array}$ & 1 & 2 & 3 & 4 & 5 \\
\hline $\begin{array}{l}\text { 18. My mother/father nags/bothers me. } \\
\text { 19. My mother/father sometimes insults me when she/he } \\
\text { is angry with me. }\end{array}$ & 1 & 2 & 3 & 4 & 5 \\
\hline $\begin{array}{l}\text { 20. I don't think I can tell my mother/father how I really } \\
\text { feel about some things. }\end{array}$ & 1 & 2 & 3 & 4 & 5 \\
\hline
\end{tabular}




\section{Appendix $\mathrm{H}$}

\section{Parent Version: Parent-Adolescent Communication Scale (Barnes \& Olson, 1985)}

Strongly Disagree: (Coded as 1)

Disagree: (Coded as 2)

Neither Agree nor Disagree: (Coded as 3)

Agree: (Coded as 4)

Strongly Agree: (Coded as 5)

\begin{tabular}{|c|c|c|c|c|c|}
\hline $\begin{array}{l}\text { 1. My child can discuss his/her beliefs with me without } \\
\text { feeling restrained or embarrassed. }\end{array}$ & 1 & 2 & 3 & 4 & 5 \\
\hline $\begin{array}{l}\text { 2. Sometimes my child has trouble believing everything } \\
\text { that I tell him/her. }\end{array}$ & 1 & 2 & 3 & 4 & 5 \\
\hline 3. I am always a good listener for my child. & 1 & 2 & 3 & 4 & 5 \\
\hline $\begin{array}{l}\text { 4. My child is sometimes afraid to ask me for what } \\
\text { he/she wants. }\end{array}$ & 1 & 2 & 3 & 4 & 5 \\
\hline $\begin{array}{l}\text { 5. I have a tendency to say things to my child which } \\
\text { would be better left unsaid. }\end{array}$ & 1 & 2 & 3 & 4 & 5 \\
\hline 6. I can tell how my child is feeling without asking. & 1 & 2 & 3 & 4 & 5 \\
\hline 7. My child is very satisfied with how I talk to him/her. & 1 & 2 & 3 & 4 & 5 \\
\hline 8. If my child was in trouble, he/she could tell me. & 1 & 2 & 3 & 4 & 5 \\
\hline 9. My child openly shows affection to me. & 1 & 2 & 3 & 4 & 5 \\
\hline $\begin{array}{l}\text { 10. When we are having a problem, my child often gives } \\
\text { me the silent treatment. }\end{array}$ & 1 & 2 & 3 & 4 & 5 \\
\hline 11. My child is careful about what he/she says to me. & 1 & 2 & 3 & 4 & 5 \\
\hline $\begin{array}{l}\text { 12. When my child talks to me, he/she has a tendency to } \\
\text { say things that would be better left unsaid. }\end{array}$ & 1 & 2 & 3 & 4 & 5 \\
\hline $\begin{array}{l}\text { 13. When my child asks questions, I give him/her honest } \\
\text { answers. }\end{array}$ & 1 & 2 & 3 & 4 & 5 \\
\hline
\end{tabular}




\begin{tabular}{|c|c|c|c|c|c|}
\hline 14. I try to understand my child's point of view. & 1 & 2 & 3 & 4 & 5 \\
\hline $\begin{array}{l}\text { 15. There are topics that my child avoids discussing with } \\
\text { me. }\end{array}$ & 1 & 2 & 3 & 4 & 5 \\
\hline 16. My child finds it easy to discuss problems with me. & 1 & 2 & 3 & 4 & 5 \\
\hline $\begin{array}{l}\text { 17. It is very easy for my child to express all of his/her } \\
\text { true feelings to me. }\end{array}$ & 1 & 2 & 3 & 4 & 5 \\
\hline 18. I nag/bother my child. & 1 & 2 & 3 & 4 & 5 \\
\hline 19. I often insult my child when I am angry with him/her. & 1 & 2 & 3 & 4 & 5 \\
\hline $\begin{array}{l}\text { 20. My child doesn't think he/she can tell me how he/she } \\
\text { really feels about some things }\end{array}$ & 1 & 2 & 3 & 4 & 5 \\
\hline
\end{tabular}




\section{Appendix I}

\section{Athlete Version: Parental Authority Questionnaire (Buri, 1991)}

Strongly Disagree: (Coded as 1)

Disagree: (Coded as 2)

Neither Agree nor Disagree: (Coded as 3)

Agree: (Coded as 4)

Strongly Agree: (Coded as 5)

\begin{tabular}{|c|c|c|c|c|c|}
\hline $\begin{array}{l}\text { 1. While I was growing up my mother/father felt that } \\
\text { in a well-run home the children should have their } \\
\text { way in the family as often as the parents do. }\end{array}$ & 1 & 2 & 3 & 4 & 5 \\
\hline $\begin{array}{l}\text { 2. Even if her children didn't agree with her/him, my } \\
\text { mother/father felt that it was for our own good if we } \\
\text { were forced to conform to what he/she thought was } \\
\text { right. }\end{array}$ & 1 & 2 & 3 & 4 & 5 \\
\hline $\begin{array}{l}\text { 3. Whenever my mother/father told me to do } \\
\text { something as I was growing up, she/he expected me } \\
\text { to do it immediately without asking any questions. }\end{array}$ & 1 & 2 & 3 & 4 & 5 \\
\hline $\begin{array}{l}\text { 4. As I was growing up, once family policy had been } \\
\text { established, my mother/father discussed the } \\
\text { reasoning behind the policy with the children in the } \\
\text { family. }\end{array}$ & 1 & 2 & 3 & 4 & 5 \\
\hline $\begin{array}{l}\text { 5. My mother/father has always encouraged verbal } \\
\text { give-and-take whenever I have felt that family rules } \\
\text { and restrictions were unreasonable. }\end{array}$ & 1 & 2 & 3 & 4 & 5 \\
\hline $\begin{array}{l}\text { 6. My mother/father has always felt that what her/his } \\
\text { children need is to be free to make up their own } \\
\text { minds and to do what they want to do, even if this } \\
\text { does not agree with what their parents might want. }\end{array}$ & 1 & 2 & 3 & 4 & 5 \\
\hline $\begin{array}{l}\text { 7. As I was growing up my mother/father did not allow } \\
\text { me to question any decision she/he had made. }\end{array}$ & 1 & 2 & 3 & 4 & 5 \\
\hline $\begin{array}{l}\text { 8. As I was growing up my mother/father directed the } \\
\text { activities and decisions of the children in the family } \\
\text { through reasoning and discipline. }\end{array}$ & 1 & 2 & 3 & 4 & 5 \\
\hline $\begin{array}{l}\text { 9. My mother/father has always felt that more force } \\
\text { should be used by parents in order to get their } \\
\text { children to behave the way they are supposed to. }\end{array}$ & 1 & 2 & 3 & 4 & 5 \\
\hline $\begin{array}{l}\text { 10. As I was growing up my mother/father did not feel } \\
\text { that I needed to obey rules and regulations of }\end{array}$ & 1 & 2 & 3 & 4 & 5 \\
\hline
\end{tabular}




\begin{tabular}{|c|c|c|c|c|c|}
\hline $\begin{array}{l}\text { behavior simply because someone in authority had } \\
\text { established them. }\end{array}$ & & & & & \\
\hline $\begin{array}{l}\text { 11. As I was growing up I knew what my mother/father } \\
\text { expected of me in my family, but I also felt free to } \\
\text { discuss those expectations with my mother/father } \\
\text { when I felt that they were unreasonable. }\end{array}$ & 1 & 2 & 3 & 4 & 5 \\
\hline $\begin{array}{l}\text { 12. My mother/father felt that wise parents should teach } \\
\text { their children early just who is boss in the family. }\end{array}$ & 1 & 2 & 3 & 4 & 5 \\
\hline $\begin{array}{l}\text { 13. As I was growing up, my mother/father seldom gave } \\
\text { me expectations and guidelines for my behavior. }\end{array}$ & 1 & 2 & 3 & 4 & 5 \\
\hline $\begin{array}{l}\text { 14. Most of the time as I was growing up my } \\
\text { mother/father did what the children in the family } \\
\text { wanted when making family decisions. }\end{array}$ & 1 & 2 & 3 & 4 & 5 \\
\hline $\begin{array}{l}\text { 15. As the children in my family were growing up, my } \\
\text { mother/father consistently gave us direction and } \\
\text { guidance in rational and objective ways. }\end{array}$ & 1 & 2 & 3 & 4 & 5 \\
\hline $\begin{array}{l}\text { 16. As I was growing up my mother/father would get } \\
\text { very upset if I tried to disagree with her/him. }\end{array}$ & 1 & 2 & 3 & 4 & 5 \\
\hline $\begin{array}{l}\text { 17. My mother/father feels that most problems in } \\
\text { society would be solved if parents would not restrict } \\
\text { their children's activities, decisions, and desires as } \\
\text { they are growing up. }\end{array}$ & 1 & 2 & 3 & 4 & 5 \\
\hline $\begin{array}{l}\text { 18. As I was growing up my mother/father let me know } \\
\text { what behavior she/he expected of me, and if I didn't } \\
\text { meet those expectations, she/he punished me. }\end{array}$ & 1 & 2 & 3 & 4 & 5 \\
\hline $\begin{array}{l}\text { 19. As I was growing up my mother/father allowed me } \\
\text { to decide most things for myself without a lot of } \\
\text { direction from her/him. }\end{array}$ & 1 & 2 & 3 & 4 & 5 \\
\hline $\begin{array}{l}\text { 20. As I was growing up my mother/father took my } \\
\text { opinions into consideration when making family } \\
\text { decisions, but she/he would not decide for } \\
\text { something simply because I wanted it. }\end{array}$ & 1 & 2 & 3 & 4 & 5 \\
\hline $\begin{array}{l}\text { 21. My mother/father did not view her/himself as } \\
\text { responsible for directing and guiding my behavior as } \\
\text { I was growing up. }\end{array}$ & 1 & 2 & 3 & 4 & 5 \\
\hline $\begin{array}{l}\text { 22. My mother/father had clear standards of behavior } \\
\text { for the children in our home as I was growing up, } \\
\text { but she/he was willing to adjust those standards to } \\
\text { the needs of each of the individual children in the } \\
\text { family. }\end{array}$ & 1 & 2 & 3 & 4 & 5 \\
\hline
\end{tabular}




\begin{tabular}{|c|c|c|c|c|c|}
\hline $\begin{array}{l}\text { 23. My mother/father gave me direction for my behavior } \\
\text { and activities as I was growing up and she/he } \\
\text { expected me to follow her/his direction, but she/he } \\
\text { was always willing to listen to my concerns and to } \\
\text { discuss that direction with me. }\end{array}$ & 1 & 2 & 3 & 4 & 5 \\
\hline $\begin{array}{l}\text { 24. As I was growing up my mother/father allowed me } \\
\text { to form my own point of view on family matters and } \\
\text { she/he generally allowed me to decide for myself } \\
\text { what I was going to do. }\end{array}$ & 1 & 2 & 3 & 4 & 5 \\
\hline $\begin{array}{l}\text { 25. My mother/father has always felt that most problems } \\
\text { in society would be solved if we could get parents to } \\
\text { strictly and forcibly deal with their children when } \\
\text { they don't do what they are supposed to as they are } \\
\text { growing up. }\end{array}$ & 1 & 2 & 3 & 4 & 5 \\
\hline $\begin{array}{l}\text { 26. As I was growing up my mother/father often told me } \\
\text { exactly what she/he wanted me to do and how } \\
\text { she/he expected me to do it. }\end{array}$ & 1 & 2 & 3 & 4 & 5 \\
\hline $\begin{array}{l}\text { 27. As I was growing up my mother/father gave me } \\
\text { clear direction for my behaviors and activities, but } \\
\text { she/he was also understanding when I disagreed } \\
\text { with her/him. }\end{array}$ & 1 & 2 & 3 & 4 & 5 \\
\hline $\begin{array}{l}\text { 28. As I was growing up my mother/father did not direct } \\
\text { the behaviors, activities, and desires of the children } \\
\text { in the family. }\end{array}$ & 1 & 2 & 3 & 4 & 5 \\
\hline $\begin{array}{l}\text { 29. As I was growing up I knew what my mother/father } \\
\text { expected of me in the family and she/he insisted that } \\
\text { I conform to those expectations simply out of } \\
\text { respect for her/his authority. }\end{array}$ & 1 & 2 & 3 & 4 & 5 \\
\hline $\begin{array}{l}\text { 30. As I was growing up, if my mother/father made a } \\
\text { decision in the family that hurt me, she/he was } \\
\text { willing to discuss that decision with me and to admit } \\
\text { it if she/he had made a mistake. }\end{array}$ & 1 & 2 & 3 & 4 & 5 \\
\hline
\end{tabular}




\section{Appendix $\mathrm{J}$}

\section{Parent Version: Parental Authority Questionnaire (Buri, 1991)}

Strongly Disagree: (Coded as 1)

Disagree: (Coded as 2)

Neither Agree nor Disagree: (Coded as 3)

Agree: (Coded as 4)

Strongly Agree: (Coded as 5)

\begin{tabular}{|c|c|c|c|c|c|}
\hline $\begin{array}{l}\text { 1. While my child was growing up I felt that in a well- } \\
\text { run home the children should have their way in the } \\
\text { family as often as the parents do. }\end{array}$ & 1 & 2 & 3 & 4 & 5 \\
\hline $\begin{array}{l}\text { 2. Even if my children didn't agree with me, I felt that } \\
\text { it was for their own good if I forced them to } \\
\text { conform to what I thought was right. }\end{array}$ & 1 & 2 & 3 & 4 & 5 \\
\hline $\begin{array}{l}\text { 3. Whenever I told my children to do something as } \\
\text { they were growing up, I expected them to do it } \\
\text { immediately without asking any questions. }\end{array}$ & 1 & 2 & 3 & 4 & 5 \\
\hline $\begin{array}{l}\text { 4. As my children were growing up, once family policy } \\
\text { had been established, I discussed the reasoning } \\
\text { behind the policy with the children in the family. }\end{array}$ & 1 & 2 & 3 & 4 & 5 \\
\hline $\begin{array}{l}\text { 5. I have always encouraged verbal give-and-take } \\
\text { whenever I have felt that family rules and } \\
\text { restrictions were unreasonable. }\end{array}$ & 1 & 2 & 3 & 4 & 5 \\
\hline $\begin{array}{l}\text { 6. I have always felt that what my children need is to } \\
\text { be free to make up their own minds and do what } \\
\text { they want to do, even if this does not agree with } \\
\text { what I might want. }\end{array}$ & 1 & 2 & 3 & 4 & 5 \\
\hline $\begin{array}{l}\text { 7. As my children were growing up I did not allow } \\
\text { them to question any decision I had made. }\end{array}$ & 1 & 2 & 3 & 4 & 5 \\
\hline $\begin{array}{l}\text { 8. As my children were growing up, I directed the } \\
\text { activities and decisions of the children in the family } \\
\text { through reasoning and discipline. }\end{array}$ & 1 & 2 & 3 & 4 & 5 \\
\hline $\begin{array}{l}\text { 9. I have always felt that more force should be used by } \\
\text { parents in order to get their children to behave the } \\
\text { way they are supposed to. }\end{array}$ & 1 & 2 & 3 & 4 & 5 \\
\hline $\begin{array}{l}\text { 10. As my children were growing up I did not feel that } \\
\text { they needed to obey rules and regulations of } \\
\text { behavior simply because someone in authority had } \\
\text { established them. }\end{array}$ & 1 & 2 & 3 & 4 & 5 \\
\hline
\end{tabular}




\begin{tabular}{|c|c|c|c|c|c|}
\hline $\begin{array}{l}\text { 11. As my children were growing up they knew what I } \\
\text { expected of them in my family, but they were also } \\
\text { free to discuss those expectations with me when } \\
\text { they felt that they were unreasonable. }\end{array}$ & 1 & 2 & 3 & 4 & 5 \\
\hline $\begin{array}{l}\text { 12. I feel that wise parents should teach their children } \\
\text { early just who is boss in the family. }\end{array}$ & 1 & 2 & 3 & 4 & 5 \\
\hline $\begin{array}{l}\text { 13. As my children were growing up, I seldom gave } \\
\text { them expectations and guidelines for their behavior. }\end{array}$ & 1 & 2 & 3 & 4 & 5 \\
\hline $\begin{array}{l}\text { 14. Most of the time as my children were growing up I } \\
\text { did what the children in the family wanted when } \\
\text { making family decisions. }\end{array}$ & 1 & 2 & 3 & 4 & 5 \\
\hline $\begin{array}{l}\text { 15. As the children in my family were growing up, I } \\
\text { consistently gave them direction and guidance in } \\
\text { rational and objective ways. }\end{array}$ & 1 & 2 & 3 & 4 & 5 \\
\hline $\begin{array}{l}\text { 16. As my children were growing up I would get very } \\
\text { upset if they tried to disagree with me. }\end{array}$ & 1 & 2 & 3 & 4 & 5 \\
\hline $\begin{array}{l}\text { 17. I feel that most problems in society would be solved } \\
\text { if parents don't restrict their children's activities, } \\
\text { decisions, and desires as they are growing up. }\end{array}$ & 1 & 2 & 3 & 4 & 5 \\
\hline $\begin{array}{l}\text { 18. As my children were growing up I let them know } \\
\text { what behavior I expected of them, and if they didn't } \\
\text { meet those expectations, I punished them. }\end{array}$ & 1 & 2 & 3 & 4 & 5 \\
\hline $\begin{array}{l}\text { 19. As my children were growing up I allowed them to } \\
\text { decide most things for themselves without a lot of } \\
\text { direction from me. }\end{array}$ & 1 & 2 & 3 & 4 & 5 \\
\hline $\begin{array}{l}\text { 20. As my children were growing up I took their } \\
\text { opinions into consideration when making family } \\
\text { decisions, but I would not decide for something } \\
\text { simply because they wanted it. }\end{array}$ & 1 & 2 & 3 & 4 & 5 \\
\hline $\begin{array}{l}\text { 21. I did not view myself as responsible for directing } \\
\text { and guiding my children's behavior as they were } \\
\text { growing up. }\end{array}$ & 1 & 2 & 3 & 4 & 5 \\
\hline $\begin{array}{l}\text { 22. I had clear standards of behavior for the children in } \\
\text { our home as they were growing up, but I was willing } \\
\text { to adjust those standards to the needs of each of the } \\
\text { individual children in the family. }\end{array}$ & 1 & 2 & 3 & 4 & 5 \\
\hline $\begin{array}{l}\text { 23. I gave my children direction for their behavior and } \\
\text { activities as they were growing up and I expected } \\
\text { them to follow my direction, but I was always } \\
\text { willing to listen to their concerns and to discuss that } \\
\text { direction with them. }\end{array}$ & 1 & 2 & 3 & 4 & 5 \\
\hline
\end{tabular}




\begin{tabular}{|l|llllll|}
\hline $\begin{array}{l}\text { 24. As my children were growing up I allowed them to } \\
\text { form their own point of view on family matters and I } \\
\text { generally allowed them to decide for themselves } \\
\text { what they were going to do. }\end{array}$ & 1 & 2 & 3 & 4 & 5 \\
\hline $\begin{array}{l}\text { 25. I have always felt that most problems in society } \\
\text { would be solved if we could get parents to strictly } \\
\text { and forcibly deal with their children when they don't } \\
\text { do what they are supposed to as they are growing } \\
\text { up. }\end{array}$ & 1 & 2 & 3 & 4 & 5 \\
\hline $\begin{array}{l}\text { 26. As my children were growing up I often told them } \\
\text { exactly what I wanted them to do and how I } \\
\text { expected them to do it. }\end{array}$ & 1 & 2 & 3 & 4 & 5 \\
\hline $\begin{array}{l}\text { 27. As my children were growing up I gave them clear } \\
\text { direction for their behaviors and activities, but I was } \\
\text { also understanding when they disagreed with me. }\end{array}$ & 1 & 2 & 3 & 4 & 5 \\
\hline $\begin{array}{l}\text { 28. As my children were growing up I did not direct the } \\
\text { behaviors, activities, and desires of the children in } \\
\text { the family. }\end{array}$ & 1 & 2 & 3 & 4 & 5 \\
\hline $\begin{array}{l}\text { 29. As my children were growing up they knew what I } \\
\text { expected of them in the family and I insisted that } \\
\text { they conform to those expectations simply out of } \\
\text { respect for my authority. }\end{array}$ & 1 & 2 & 3 & 4 & 5 \\
\hline $\begin{array}{l}\text { 30. As my children were growing up, if I made a } \\
\text { decision in the family that hurt them, I was willing } \\
\text { to discuss that decision with them and to admit it if I } \\
\text { had made a mistake. }\end{array}$ & 1 & 2 & 3 & 4 & 5 \\
\hline
\end{tabular}




\section{Appendix K}

\section{Parent Interview Guide}

\section{Icebreaker:}

1) Please tell me a little bit about yourself and your family.

2) In your family, how many of your kids participate in competitive sports? And for how long have they been playing competitively?

3) Did you or your spouse ever play sports? (Probe: competitive or recreational?)

4) How would you describe a day in which you prepare your son/daughter to his/her game and/or practice?

a. What are some of the positive and negative things associated with practices/games? (both in general and specific to your son/daughter).

\section{Transition Questions: Parents at Practices and Games}

5) When you have been watching your son/daughter train or compete in their respective sport, have you ever seen any example of really good parents? Can you describe what you have seen?

6) Have you ever seen examples of parental behaviour that you feel is inappropriate at sporting events? Can you describe what you saw?

7) How would you describe a good sport parent?

8) How do you feel about going to your son/daughter's practices and games and watching them play?

\section{Parent-Athlete Interaction:}

9) There are various types of parenting styles. How would you describe your style of parenting?

10) Can you provide an example of a situation during which you and your son/daughter experienced a conflict in opinion?

a. How did you arrive at a conclusion?

b. How do you think your son/daughter felt at the end?

11) Parent(s) engage in their child's sporting experience to various extents. How would you describe your involvement?

a. Can you provide an example?

12) How would you say you prepare your son/daughter for his/her training/competition?

13) Do you and your child discuss topics related to his/her sporting experiences?

a. How would you describe these interactions?

14) Has there been a time in your sport parenting experience where you have witnessed your child failing to accomplish a task? How did you react? What did you say? And how do you think your child felt?

15) Has there been a time in your sport parenting experience where you have witnessed your child being successful in accomplishing a task? How did you react? What did you say? And how do you think your child felt? 


\section{Parent-Athlete Communication:}

Parent's Communication Behaviour Before Training/Competition

16) How would you describe your interaction with your child before arriving at his/her training or competition? (Probe for communication during the car ride).

17) How do you communicate with your child before his/her training/competition? (Probe: Reflect on your body language, the tone of your voice, and the words that you use in your interaction).

\section{Parent's Communication Behaviour During Training/Competition}

18) How do you react when your child makes a mistake during practices/games?

19) Does your behaviour change during games? (Probe: When your child's team is winning, when they are losing, and when it is close).

a. If yes, how do think your behaviour changes affect your child?

b. If no, please explain why.

20) Can you provide an example that best describes your verbal and nonverbal communication with your child during his/her training/competition?

\section{Parent's Communication Behaviour After Training/Competition}

21) How would you describe your verbal and nonverbal communication with your child after his/her training or competition?

a. Does your behaviour change based on the outcome of his/her game or his/her performance during practice? And how?

22) What things do you say or do to convey a message to your child after his/her training/games?

a. Would your communication with your child after his games alter based on his performance or the outcome of the game?

23) Provide an example of a post-game interaction with your child after he/she performed well.

24) Provide an example of a post-game interaction with your child after he/she performed poorly.

\section{Ending Questions}

25) If you had a chance to explain to your child the reason behind the way you communicate with him or her before, during and after his/her training/competition, what would you say? 


\section{Appendix L}

\section{Athlete Interview Guide}

\section{Icebreaker:}

1) Tell me a little bit about yourself and the sports you play.

2) What sports do you play competitively and how long have you been playing them?

3) How often do you train and compete for your sport?

4) Which of your parents is most involved in your sport? And how would you describe their involvement?

\section{Transition Questions: Parents at Practices and Games}

5) When you have been competing or training (in said sport) have you ever seen any example of really good parents? Can you describe what you have seen?

6) Have you ever seen examples of parental behaviour that you feel is inappropriate at sporting events? This does not have to refer to your own parents, but anything you have seen? Can you describe what you saw?

\section{Parent-Athlete Interaction:}

7) How do you feel about your parents coming to watch you practice or play? And why?

8) Parents engage in various parenting styles and practices. How would you describe your parent's parenting style?

a. Can you provide an example of a specific situation?

9) Can you provide an example of a situation during which you and your parent experienced a conflict in opinion?

a. How did you arrive at a conclusion?

b. How do you think your parent felt at the end?

10) Parent(s) engage in their child's sporting experience to various extents. How would you describe your parent's involvement in your sporting career?

11) How would you say your parents prepare you for your competition and/or training?

12) Do you and your parents discuss topics related to your sporting experiences?

a. How would you describe these interactions?

13) Has there been a time in your sporting experience where you have failed to accomplish a task? How did your parents react? What did they say? And how did that make you feel?

14) Has there been a time in your sporting experience where you were successful in accomplishing a task? How did your parents react? What did they say? And how did that make you feel?

\section{Parent-Athlete Communication:}

\section{Parent's Communication Behaviour Before Training/Competition}

15) How would you describe your interaction with your parent(s) before arriving at your training or competition? (Probe for communication during the car ride).

16) How do your parents communicate with you before your training/competition? (Probe: Their body language, the tone of their voice, and the words that they use to communicate with you). 


\section{Parent's Communication Behaviour During Training/Competition}

17) Think about a time that you made a mistake during practices or games. How would you describe your parent's reaction at that moment?

18) Do you ever notice your parent's behaviour changing during games? (Probe: When you are winning, when you are losing, and when it is close).

a. If yes, how do those behaviour changes make you feel?

b. If no, please explain whether you would like their behaviour to change (and how) or remain the same.

19) Can you provide an example that best describes your parent's verbal and nonverbal communication with you during your training/competition? (Probe: Their body language, the tone of their voice, and the words they use).

\section{Parent's Communication Behaviour After Training/Competition}

20) How would you describe your parent(s)' communication with you after your training or competition?

a. Do their behaviour change based on the outcome of your game or your performance during practice?

21) What things do your parents do or say that you like after your games/trainings?

22) What things do your parents do or say that you don't like after your games/trainings?

\section{Ending Questions}

23) If you had a chance to tell your parents how you would like them to communicate with you when you are training or competing, what would you say? (Probe: Before, during, and after a training/competition). 
Appendix M

Workshop Slides 


\section{Parent-Athlete Communication Workshop}

\author{
Sina Azimi - MSc Student \\ Supervisor: Dr. Katherine Tamminen \\ University of Toronto
Faculty of Kinesiology and Physical Education
}

Introduction

- Participation in sport has been linked to higher physical activity level and better overall health.

- 1.1 Million Canadian kids and youth are currently involved in swimming lessons, instruction or competition.

- Top team sport in Canada: Soccer with 767,000 kids (3-17 years old).

- $70 \%$ of kids who participate in competitive sports quit by the age of 13 .

(National Alliance for Youth Sports)

- Why? Increase in family and interpersonal pressure, Low perceived competence \& Lack of enjoyment.
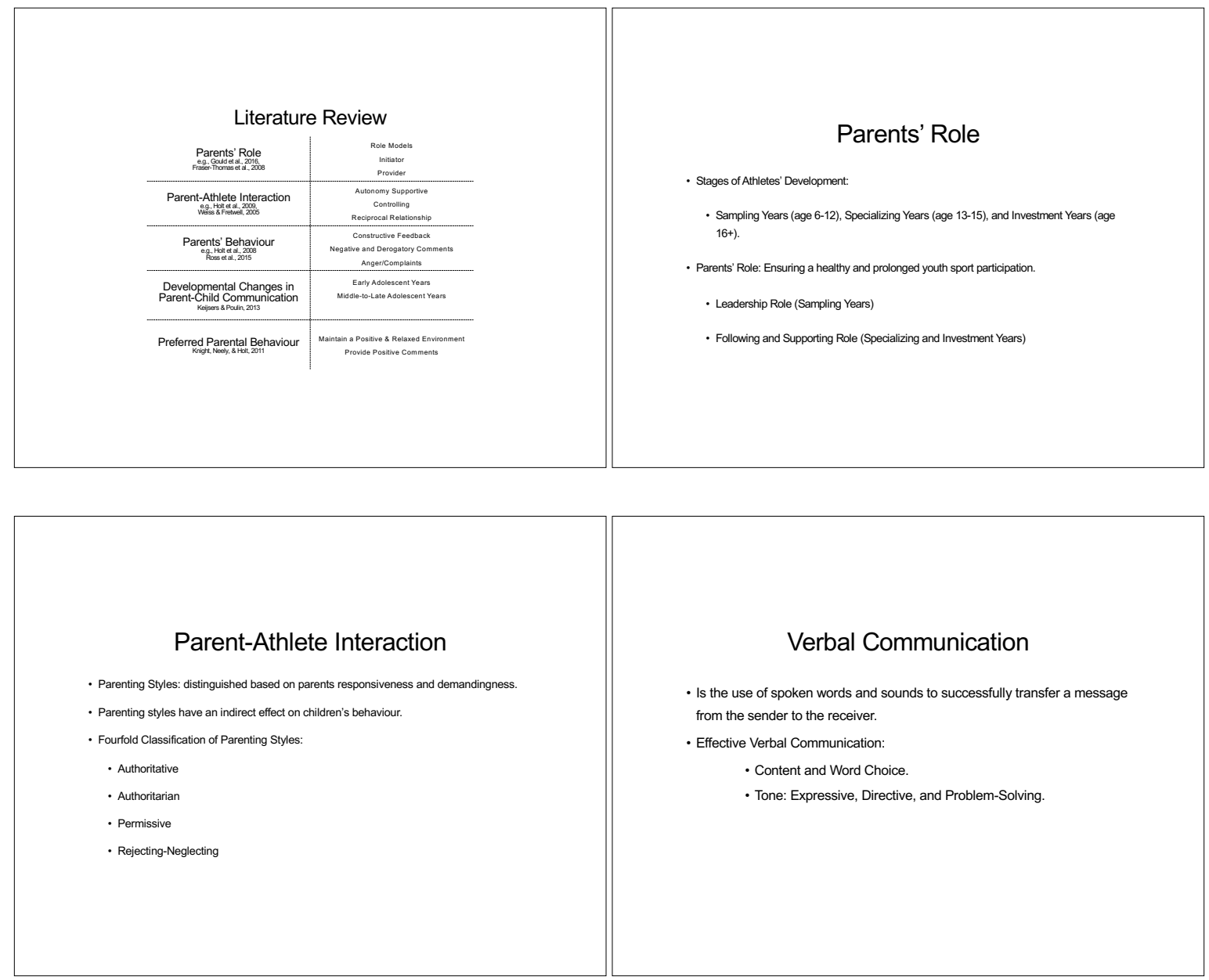


\section{Nonverbal Communication}

- Is all aspects of communication other than words.

- It consists of gestures, body language, personal objects, physical appearance, and facial expressions

- Nonverbal behaviours account for $65 \%$ to $93 \%$ of the total meaning of communication

- Types of nonverbal communication: Kinesics, Haptics, Paralanguage, and Silence.

\section{Developmental Changes in Parent-Child} Communication

- Early adolescence is predominantly characterized by a strive for greater autonomy and independence.

- As children become more independent, they may no longer allow their parents to know everything about their lives.

- Parents can support the development of adolescents' autonomy by allowing privacy and by increasingly granting adolescents a right to make decisions.
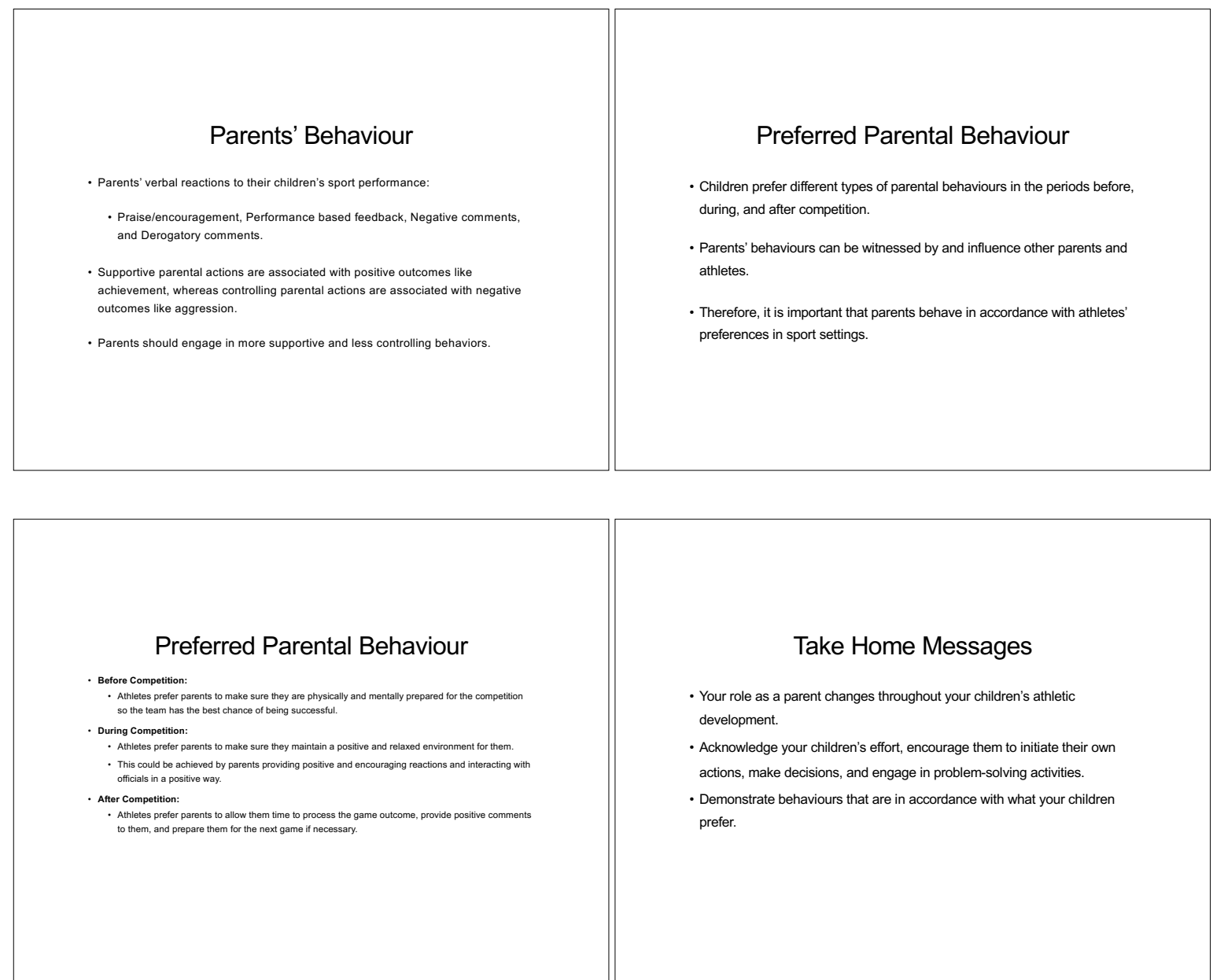

\section{Take Home Messages}

- Your role as a parent changes throughout your children's athletic development.

- Acknowledge your children's effort, encourage them to initiate their own actions, make decisions, and engage in problem-solving activities. - Demonstrate behaviours that are in accordance with what your children prefer. 


\section{Appendix N}

\section{Parent Audio Diary Guide}

Consider your interactions with your child before, during and/or after his/her training or competition. Please choose one context (e.g., after practice) to complete your entries for the next six weeks. Start the audio recorder and answer the following questions:

\section{Description:}

1. What happened? Do not make judgements yet or try to draw conclusions; simply describe.

\section{Feelings:}

2. What were your reactions and feelings? Again, do not move on to analysing these yet.

\section{Evaluation:}

3. What was good or bad about the experience? Make value judgements.

\section{Analysis:}

4. What sense can you make of the situation? Bring in ideas from outside the experience to help you. What was really going on? Were different people's experience similar or different in important ways?

\section{Conclusion:}

5. What can be concluded? In a general sense, from these experiences and the analysis you have undertaken?

6. What can be concluded about your own specific, unique, and personal situation or way of thinking/interacting?

\section{Personal Action Plan:}

7. What are you going to do differently in this type of situation next time? What steps are you going to take on the basis of what you have learnt? 


\section{Appendix $\mathrm{O}$}

\section{Information Page}

SUPPORTING ORGANIZATION

CHILDREN'S AID SOCIETY

CENTRE FOR ADDICTION AND

MENTAL HEALTH

KIDS HELP PHONE

PARENT HELPLINE
CONTACT INFORMATION

416-924-4640
http://www.torontocas.ca
1-866-797-0000
http://www.camh.ca/en/hospital/Pages/home.aspx
1-800-668-6868
https://kidshelpphone.ca
778-782-3548
http://www.informationchildren.com/parent-
support/parent-helpline/




\section{Appendix $\mathrm{P}$}

Recruitment Brochure

\section{Researchers in the Faculty of Kinesiology and Physical Education at}

\section{the University of Toronto are seeking volunteers to participate in a}

\section{research study about parents in youth sports.}

- Participation is open to:

- Male and Female athletes between 13-15 years of age who currently participate in OPDL soccer / AAA hockey.

- Athletes' parent or guardian who travels to and from games and practices with their son/daughter, and attends and watches their son/daughter's games and practices.

- Our research study consists of surveys, interviews, and audio diaries.

- Each athlete will receive $\$ \mathbf{1 0 . 0 0}$ for their participation in the study.

- Each parent will receive $\mathbf{\$ 3 0 . 0 0}$ for their participation in the study.

For more detailed information about the study and its methods contact Sina Azimi. 